\title{
WestVirginiaUniversity
}

THE RESEARCH REPOSITORY @ WVU

Graduate Theses, Dissertations, and Problem Reports

2020

\section{Modeling of Rotary Packed Beds for Reactive and Non-Reactive Systems}

\author{
Chinyere Evangeline Ezeobinwune \\ West Virginia University, cee0004@mix.wvu.edu
}

Follow this and additional works at: https://researchrepository.wvu.edu/etd

Part of the Other Chemical Engineering Commons, Process Control and Systems Commons, and the Transport Phenomena Commons

\section{Recommended Citation}

Ezeobinwune, Chinyere Evangeline, "Modeling of Rotary Packed Beds for Reactive and Non-Reactive Systems" (2020). Graduate Theses, Dissertations, and Problem Reports. 7508.

https://researchrepository.wvu.edu/etd/7508

This Thesis is protected by copyright and/or related rights. It has been brought to you by the The Research Repository @ WVU with permission from the rights-holder(s). You are free to use this Thesis in any way that is permitted by the copyright and related rights legislation that applies to your use. For other uses you must obtain permission from the rights-holder(s) directly, unless additional rights are indicated by a Creative Commons license in the record and/ or on the work itself. This Thesis has been accepted for inclusion in WVU Graduate Theses, Dissertations, and Problem Reports collection by an authorized administrator of The Research Repository @ WVU. For more information, please contact researchrepository@mail.wvu.edu. 
Graduate Theses, Dissertations, and Problem Reports

2020

Modeling of Rotary Packed Beds for Reactive and Non-Reactive Systems

Chinyere Evangeline Ezeobinwune

Follow this and additional works at: https://researchrepository.wvu.edu/etd

Part of the Other Chemical Engineering Commons, Process Control and Systems Commons, and the Transport Phenomena Commons 


\title{
Modeling of Rotary Packed Beds for Reactive and Non- Reactive Systems
}

\author{
Chinyere Evangeline Ezeobinwune
}

\author{
Thesis submitted to the \\ Benjamin M. Statler College of Engineering and Mineral Resources \\ at West Virginia University \\ in partial fulfillment of the requirements for the degree of \\ Masters of Science in Chemical Engineering \\ Debangsu Bhattacharyya, Ph.D., Chair \\ Nagasree Garapati, Ph.D., P.E. \\ Stephen Zitney, Ph.D. \\ Department of Chemical and Biomedical Engineering \\ Morgantown, West Virginia
}

2020

Keywords: Modeling, Rotary Air Preheater, Reactive Systems, Metal Organic Frameworks, Circumferential Direction, Carbon Capture.

Copyright 2020 Chinyere Ezeobinwune 


\section{ABSTRACT \\ Modeling of Rotary Packed Beds for Reactive and Non-Reactive Systems Chinyere Ezeobinwune}

Rotary packed beds (RPBs) are used in a wide range of reactive and non-reactive applications. In this research, a 2-d, first-principles, dynamic model of a non-reactive RPB that is used for heat exchange between the outgoing flue gas from a power plant and the incoming air to the boiler/pulverizer of the power plant is developed. A 2-d, first-principles model of a reactive RPB is developed where a functionalized metal-organic framework (MOF) is used for $\mathrm{CO}_{2}$ capture.

For the non-reactive system, a Ljungstrom-type air preheater (APH) is considered. Existing models for these rotating heat exchangers are typically 1 -d. There are very few works in the existing literature where 2-d models are developed and validated with the experimental data. With this motivation, a 2$\mathrm{d}$ dynamic model of an industrial-scale APH that considers variability of the transport variables in the axial and circumferential (i.e. direction of rotation) direction is developed and validated with the industrial data. Sensitivity studies to a number of key operating conditions such as the rotational speed and inlet flow rate and temperature of air/flue gas are performed.

For the reactive system, a MOF-based RPB for $\mathrm{CO}_{2}$ capture is considered. In the capture section, $\mathrm{CO}_{2}$ from the flue gas reacts with the impregnated diamine while, $\mathrm{CO}_{2}$ is released by temperature swing in the regeneration section. As rapid rejection/addition of heat is required in the capture/desorption section to achieve large swing in the $\mathrm{CO}_{2}$-loading of the sorbent, an embedded static cooler is used in the capture section, while an embedded static heater is used in the desorption section where steam is considered as the heating utility. In the desorption section, steam is also directly injected for reducing the partial pressure of $\mathrm{CO}_{2}$. Mass and heat transfer models along with a model for the reaction kinetics are included. Finally, a techno-economic analysis is performed. Key operating variables such as the rotation speed of the bed and temperature of the bed are optimized for minimizing the equivalent annual operating cost of the reactive capture system. 


\section{DEDICATION}

To my husband and son,

Paul and Jayden Akula. 


\section{Acknowledgement}

I would like to express my deepest gratitude to my research advisor Dr. Debangsu Bhattacharyya, for his expertise, patience and support during the duration of my program at WVU. I'm immensely grateful to him for accepting me into his research team. Also, I will like to thank my Advisory and Examining Committee members, Dr. Steve Zitney and Dr. Nagasree Garapati for their guidance, assistance and editing of this research work.

I extend my gratitude to all the members of the Advanced Process and Energy Systems Engineering Groupfor their support and direction throughout my research program. Special thanks to Ryan Hughes and Goutham Kotamreddy for their contribution towards this research project.

I would also like to acknowledge the support and unending encouragement of my family. To my mother and siblings, thank you for your unconditional love and support these past years. To my husband, you were my inspiration throughout the duration of this thesis. Thank you for being there for me. Your love is what has gotten me this far. To my son, Jayden Akula, whose ever smiling face always made me happy and inspired me. Having him halfway during my program. was not easy but he has made my life wonderful.

I would like to acknowledge financial support through the Carbon Capture Simulation for Industry Impact (CCSI2), funded through the U.S. DOE Office of Fossil Energy by the Los Alamos National Laboratory through contract\# 379419.

Finally, I will like to thank God Almighty, for his protection and guidance over my life. 


\section{Table of Contents}

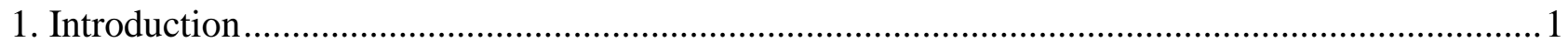

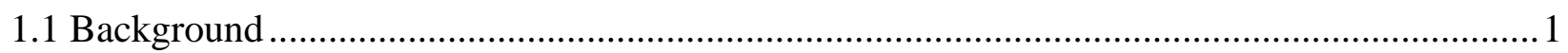

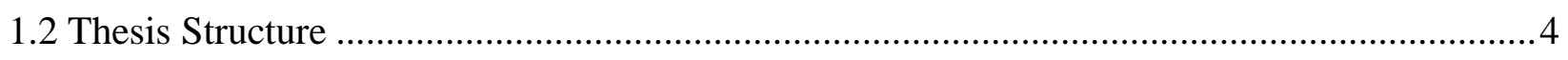

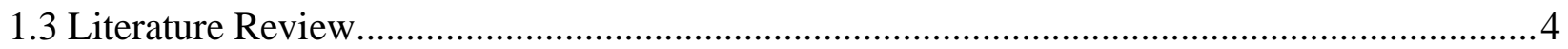

2. MODEL DEVELOPMENT FOR NON-REACTIVE AND REACTIVE RPBS ........................... 10

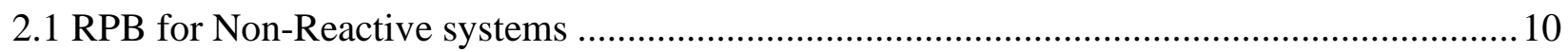

2.2 Boundary Conditions (Non-Reactive Systems) ..................................................................... 13

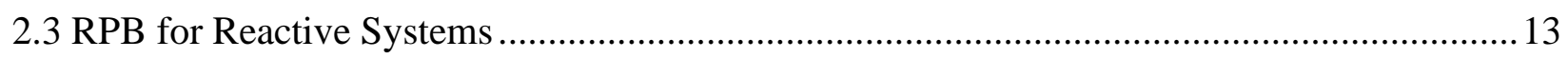

2.4 Boundary Conditions of RPB (Non-Reactive Systems) …................................................. 17

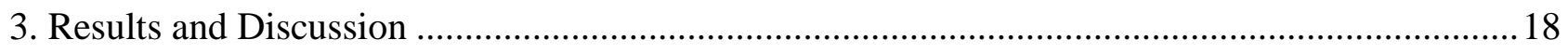

3.1 RPB for Non-Reactive Systems (Ljungstrom APH) ........................................................... 18

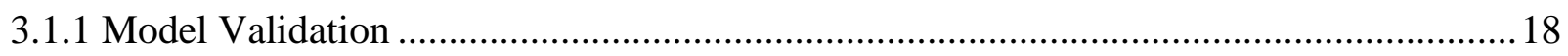

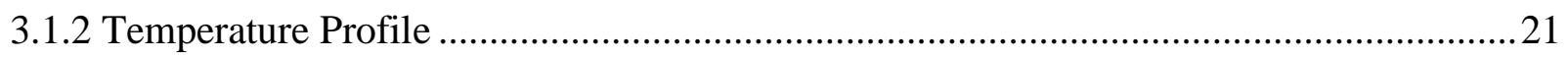

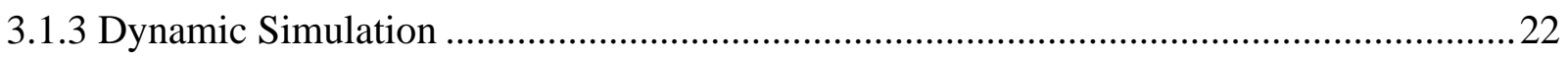

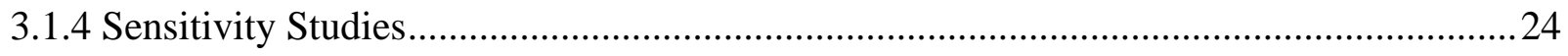

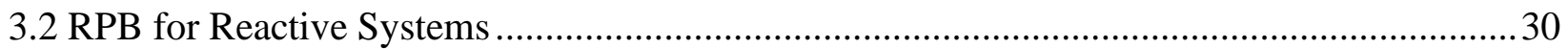

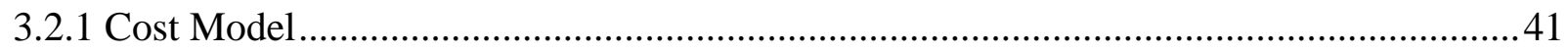

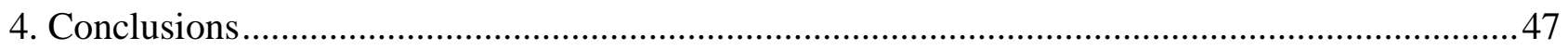

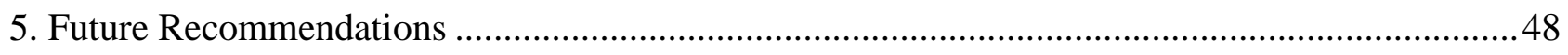

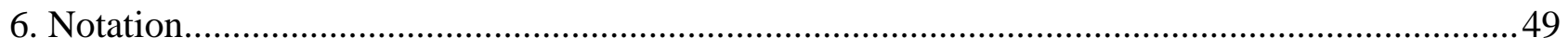

6.1. RPB for Non-Reactive Systems(Ljungstrom APH) ……………………………............49

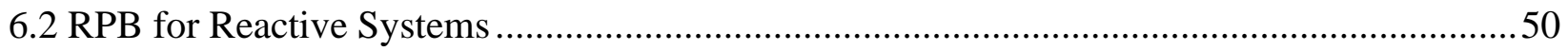

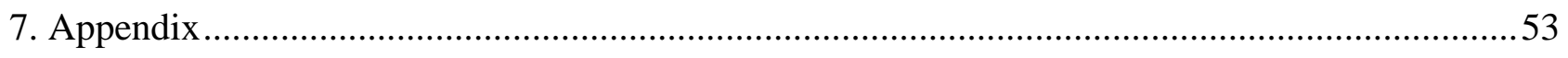

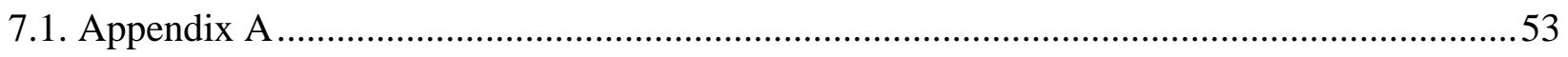

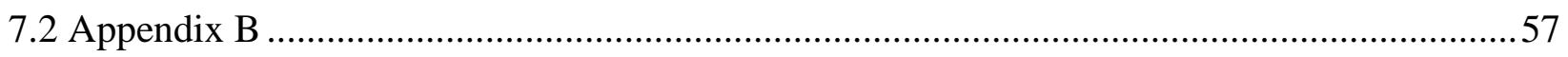

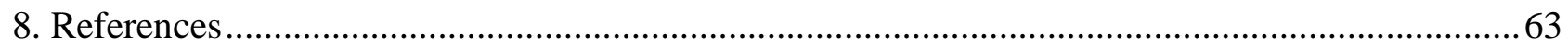




\section{List of Figures}

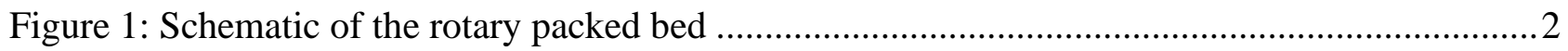

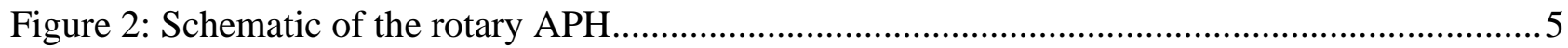

Figure 3: dmpn-Mg2(dobpdc) Isotherm (Milner et al., 2017) ........................................................ 8

Figure 4: A Differential control volume schematic (three heat fluxes: Red - Heat carried by gas;

Blue - Heat carried by matrix; Black - Heat conducted through matrix) ……………......................11

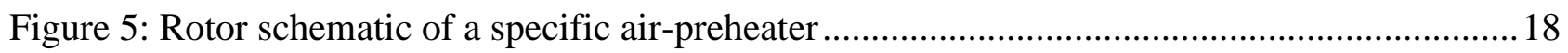

Figure 6: Comparison of the Experiment data of Skiepko and Shah (2004) with model predicted results for the outlet flue gas temperature across the circumferential direction. ................................20

Figure 7: Comparison of the Experiment data of Skiepko and Shah (2004) with model predicted results for the outlet air temperature across the circumferential direction.........................................2 20 Figure 8: Temperature distance along the angular distance of the matrix in the flue gas sector(Exit of Bed)

Figure 9: Temperature distance along the angular distance of the matrix in the Air sector(Exit of Bed). 21

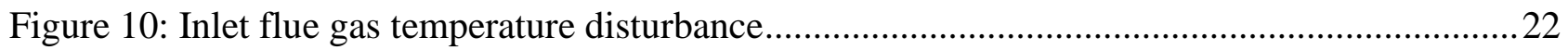

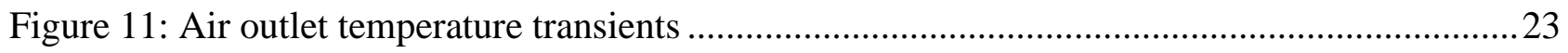

Figure 12: Flue gas outlet temperature transients ……………………………………………....23

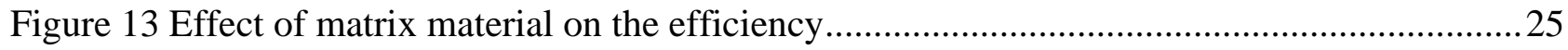

Figure 14: Effect of rotational speed on the outlet temperatures......................................................26

Figure 15: Temperature profile of the matrix at various rotational speed .........................................2

Figure 16: Effect of matrix length on thermal efficiency ................................................................2 28

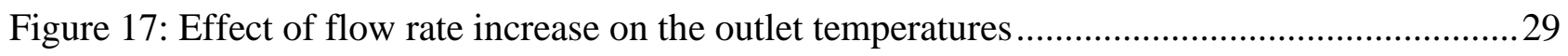

Figure 18: Effect of carryover losses on thermal efficiency of APH ................................................30

Figure 19: Schematic of the RPB for $\mathrm{CO}_{2}$ capture ............................. Error! Bookmark not defined.

Figure 20: Temperature profile along the circumferential direction (axial location: gas exit from the capture section)

Figure 21: Gas-phase composition profile along circumferential direction (axial location: gas exit from the capture section) 
Figure 22: Gas phase composition profile along the axial direction (circumferential location: solid entrance to the capture section).

Figure 23: Solid phase loading along circumferential direction (axial location: gas exit from the capture section)

Figure 24: Solid phase loading along the axial direction (circumferential location: solid entrance to the capture section.. 35

Figure 25: Solids loading profile along circumferential direction at various axial locations ..... 36

Figure 26: Temperature profile along circumferential direction at various axial positions 36 Figure 27 : Gas phase composition profile in the circumferential location for changes in rpm (Axial location: gas exit from the capture section). 37

Figure 28: Solid loading profile in the circumferential location for changes in rpm (Axial location: gas exit from the capture section))

Figure 29: Temperature profile along circumferential direction (axial location: exit of bed)..... 38

Figure 30: Gas phase composition profile along circumferential direction (axial location:exit of bed)

Figure 31: Solid phase loading along circumferential direction (axial location: $\mathrm{CO}_{2}$-rich stream exit of bed) 39

Figure 32: Gas-phase composition profile (bottom of bed) for changes in solids flow 40

Figure 33: Solid loading profile (Bottom of bed) for changes in solid flow ..... 40

Figure 34: RPB EAOC (\$Million/year) versus rotational speed for no heat recovery 42

Figure 35: Lean Loading versus rotational speed for no heat recovery.... .43

Figure 36: RPB EAOC (\$Million/year) versus rotational speed for $85 \%$ heat recovery..................44

Figure 37: RPB EAOC (\$Million/year) for various MOF cost estimates ....................................45

Figure 38: Capital cost uncertainty effect on RPB EAOC(\$Million/year) ..................................46

Figure 39: Conservation of adsorbate flowing through an increment dz of a rotary packed bed......57

Figure 40: Conservation of adsorbent across an increment of a rotary packed bed .59 


\section{List of Tables}

Table 1: Heat Transfer/Pressure drop Correlations of the APH model. ....................................... 12

Table 2: Boundary/Initial Conditions of the APH model. ......................................................... 13

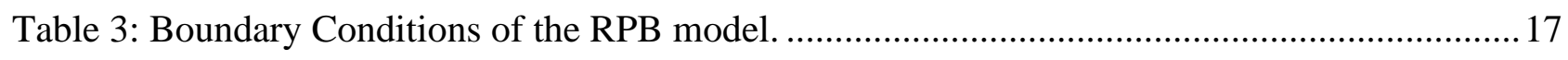

Table 4: Design parameters and operating conditions(L. Wang et al., 2019) ................................ 19

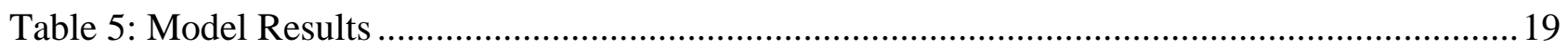

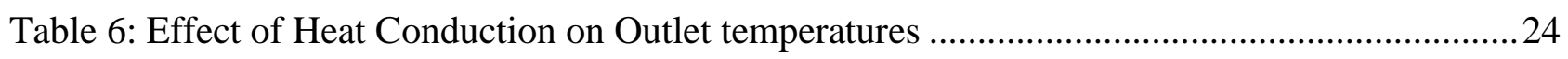

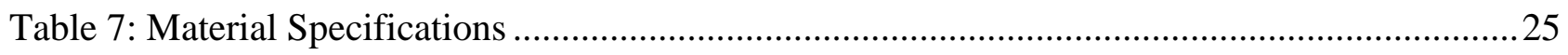

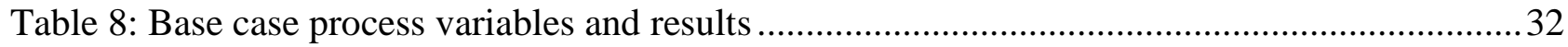

Table 9: Optimal EAOC (\$Million/year) case with different heat recoveries ................................44

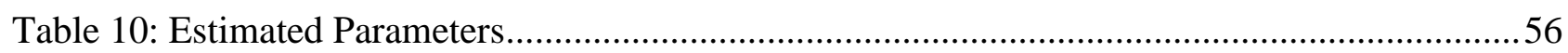




\section{Introduction}

\subsection{Background}

Process intensification can lead to remarkable reduction in equipment size, consumption of energy, or production of waste (Ramshaw,1995). Process intensification can lead to improved equipment design by improving the driving force or by overcoming limitations in the 'conventional' processes (Lutze et al., 2010). A rotary packed bed (RPB) is a typical process intensification device, which is compact, typically of low cost and high efficiency. RPBs can be used in a wide range of industrial applications, from energy recovery to gas separations /reactions, to list a few. A schematic of a typical RPB is shown in Figure 1. RPBs can be applied to both reactive and non-reactive systems. In this research, a 2-d, first-principles, dynamic model of a non-reactive system that is used for heat exchange between the outgoing flue gas from a power plant and the incoming air to the boiler/pulverizer of the power plant is developed. A 2-d, first-principles model of a reactive system is developed where a functionalized metal-organic framework (MOF) is used for $\mathrm{CO}_{2}$ capture.

One notable example of the RPBs used in the industrial application for non-reactive systems is the Ljungstrom-type air preheater (APH). Due to its lighter weight, compact volume, and enhanced heat transfer than many other types of APHs, the Ljungstrom-type APHs are widely used in coal-fired power plants for heat recovery (Bu et al., 2018). The heat transfer surface of these APHs is a nonsorbing solid matrix with a high heat capacity. Heat exchange in these APHs is achieved through convective heat transfer between the solid matrix and the hot or the cold stream in different sections as the bed rotates. In the countercurrent arrangement as shown in Figure 1, cold air enters from the bottom in the heating section while the hot flue gas enters from the top in the cooling section.

Existing models for these rotating heat exchangers are typically 1-d considering variation only in the axial direction (Büyükalaca \& Y1lmaz, 2002; Mioralli \& Ganzarolli, 2013; Sanaye \& Hajabdollahi, 2009). However, as the bed rotates, its temperature also changes in the circumferential (angular) direction. There are very few works in the existing literature on the rotating APH where 2-d models were developed and validated (Heidari-Kaydan \& Hajidavalloo, 2014; Skiepko \& Shah, 2004). However, neglecting the variability in the circumferential direction can lead to inaccuracies in the thermal and mechanical design of the APHs. Furthermore, results from a 1-d model can be inaccurate 
under off-design conditions. A 2-d model is also desired for optimizing the bed design and operating conditions. In this research, a 2-d dynamic model of an industrial-scale APH will be developed, validated and used for transient studies.

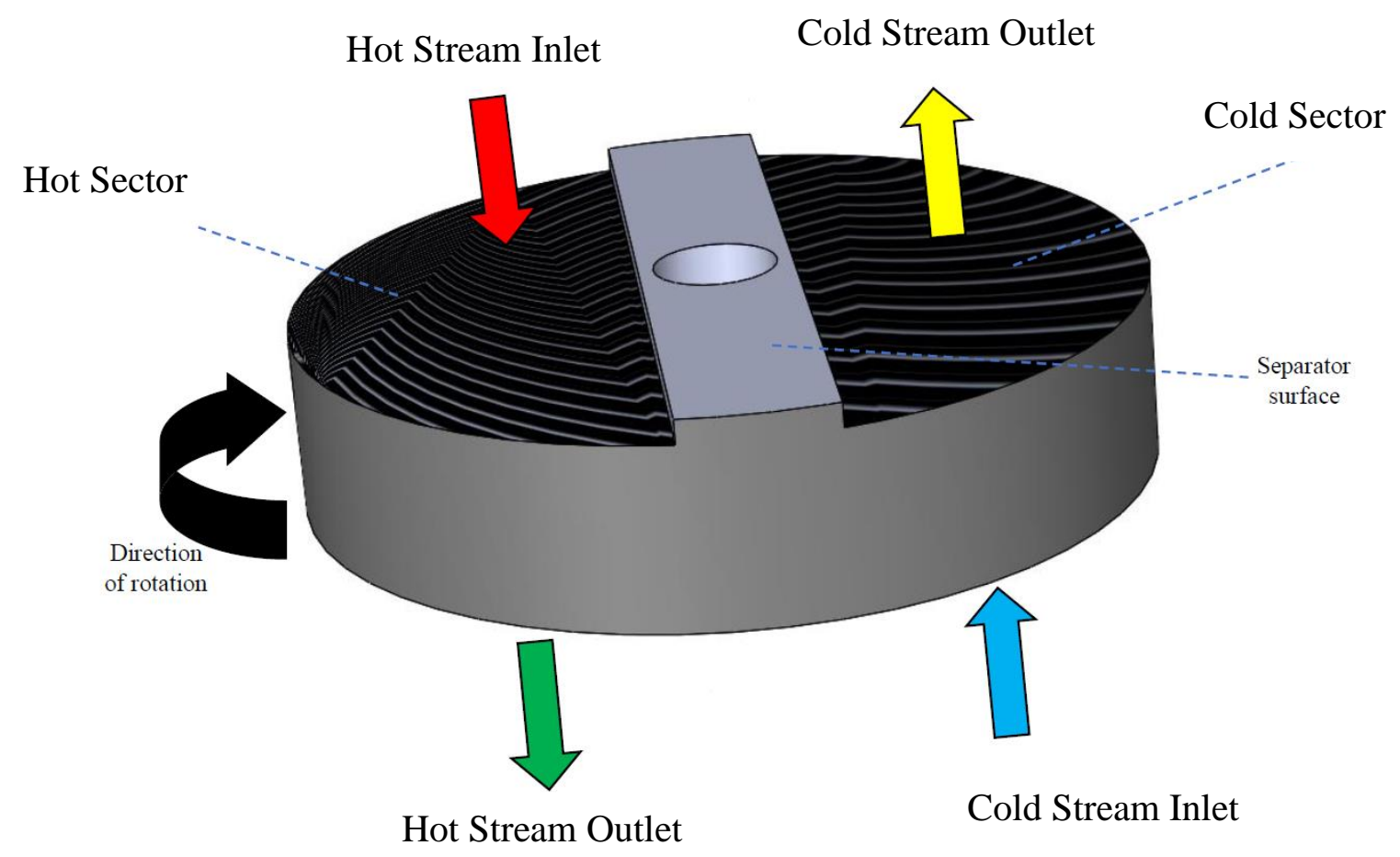

Figure 1: Schematic of the rotary packed bed

RPBs have been widely investigated for possible use in many separation applications including absorption, stripping, extraction, etc. RPBs are used for enhancing mass transfer where the gravity effect present in typical towers is replaced by the centrifugal force present in the RPB (Ramshaw and Mallinson, 1981). The RPB considered in this work is a rotating cylindrical wheel which is divided into two equal sections: the adsorbing section and the regeneration section (desorption of $\mathrm{CO}_{2}$ ). The regeneration and adsorption streams are in a counter-current flow arrangement. The rotary bed reactor unites the features of a rotary desiccant wheel and a Ljungstrom-type APH. It is assumed that the functionalized MOF is placed on the spinning wheel matrix in a way similar to that in the desiccant wheel. As the reactor rotates, $\mathrm{CO}_{2}$ is adsorbed while the matrix passes through the flue gas section; 
while at the regeneration section, steam or any hot utility can be used directly or indirectly to regenerate the bed.

There are several fundamental differences between the RPB for $\mathrm{CO}_{2}$ capture and the typical RPBs investigated in the literature. First, typical RPBs have been investigated for gas-liquid and solid-liquid systems while the system of interest in this research is a solid-gas system. Secondly, typical gas-liquid RPBs when used for $\mathrm{CO}_{2}$ capture applications have been designed for mainly absorption that is mass transfer limited. In the proposed RPB, both adsorption and desorption take place on the same RPB in different sectors. Thus, the temperature and loading profile of the bed as it exits the capture section affect the energy penalty in the desorption section. Similarly, the temperature and loading profile of the bed as it exits the desorption section affect the performance of the desorption section. Thirdly, in the typical RPBs for solvent-based capture, the liquid-gas contact takes place on the surface of the rotating packing thus motivating development of 1-d models. However, as the bed itself rotates in the proposed RPB configuration, the extent of $\mathrm{CO}_{2}$ loading in the sorbent keeps changing in the circumferential direction. The extent of $\mathrm{CO}_{2}$ loading affects the mass transfer rate. Since the adsorption is exothermic and desorption is endothermic, the thermal profile of the bed also changes in the circumferential direction, which in turn affects the mass transfer/reaction rates. To capture these phenomena, a 2-d model that captures the variation of gas and solid composition in the axial and angular directions is desired. Furthermore, in the RPBs for solvent-based $\mathrm{CO}_{2}$ capture, the gas-liquid contact takes place on the surface since the packing itself is not reactive. In the proposed RPB of interest here, the gas also diffuses into the reactive packing. In this research, a 2-d model of a rotary packed bed for functionalized-MOF based $\mathrm{CO}_{2}$ capture (both adsorption and desorption) application is developed.

In summary, the research objectives are as follows:

Objective \#1: Develop and validate a 2-d dynamic model of a rotating APH

Objective \#2: Develop a 2-d model of a RPB for $\mathrm{CO}_{2}$ capture using the functionalized MOF followed by techno-economic analysis 


\subsection{Thesis Structure}

The thesis is divided into five chapters, Chapter one provides the background and a review of the existing literature on RPBs. The literature review is divided into two main sections. The first section focuses on RPBs for non - reactive systems and the second section reviews RPBs for reactive systems. Chapter 2 focuses on the development, assumptions, boundary conditions of the reactive and non-reactive system models. Only heat transfer is modeled for the non-reactive system while, mass transfer, heat transfer, and reaction kinetics are modeled for the reactive system consists of. Results from the modeling are presented in Chapter 3. Model validation for the non-reactive RPB, sensitivity studies and techno-economic analysis are presented. Chapter 4 concludes the thesis with a summary of findings from this work. Chapter 5 suggests future work for both the reactive and nonreactive systems.The notations used in this work and the supplementary information including derivation of model equations can be found in Sections 6 and 7, respectively.

\subsection{Literature Review}

\section{RPBs for APH Application (non-reactive system):}

A typical Ljungstrom-type APH is shown in Figure 2. It consists of a central rotor that keeps rotating at a constant speed, the solid matrix is attached to the central rotor. The APH is divided into two sectors- the hot flue gas enters from the top in one sector, while the ambient air enters from the bottom in the other sector. 


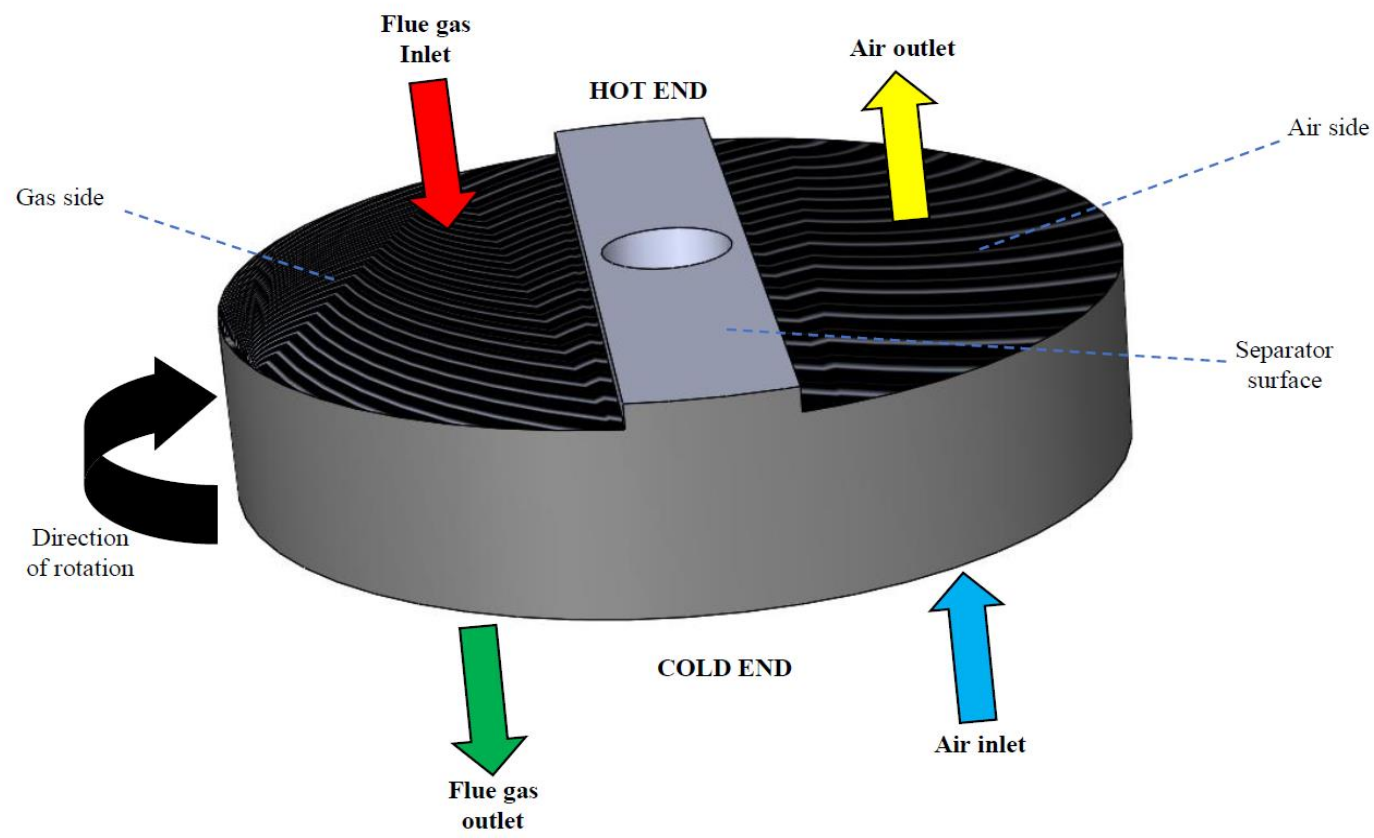

Figure 2: Schematic of the rotary APH

Several numerical models of the heat transfer occurring in APH has been developed in the open literature. (Skiepko \& Shah, 2004) formulated a steady-state model of APH, including longitudinal heat conduction in the matrix. The computed temperature distributions were found to compare well with the experimental data. (Nielsen et al., 2013) developed a numerical model that takes the regenerator housing into account. The impact of the housing on the performance is quantified by comparing the regenerator effectiveness for cases where the housing is ignored vs. the instances where it is included. Although rotary APHs are used in power plants because of their numerous advantages, challenges like ammonium bisulfate deposition and corrosion are still one of the biggest hurdles to be overcome because of the porous nature and appropriate temperature window. To prevent the corrosion at the cold end, the accurate temperature distribution in the APH must be estimated for reliability. Because of the complexity in the geometry of the APH and low sensitivity of some parameters to the heat transfer calculation, some major assumptions are made to calculate the temperature distribution. ( $\mathrm{Li}, 1983)$ developed a transient one-dimensional numerical model that calculates the fluid and metal temperature distributions for the APH by proposing a numerical finite difference method, while accounting for axial heat conduction. (Ghodsipour \& Sadrameli, 2003) developed a mathematical model of the APH and the model parameters are optimized using the experimental data. Model results were compared with the experimental data and the results were 
found to be consistent with the experiment. One major concern of the experiment is that no consideration was given to the circumferential temperature gradient, which is a critical aspect of the APH. (Wang et al., 2009) investigated the effect of thermal stress deformation in a rotary APH, a simplified 1-d model was established and the temperature distribution of this model as a function of length and time is calculated, the thermal stress distribution in the axial direction and at two transitional interfaces: one where the matrix rotates from the cold air to the hot gas and the other where the matrix rotates from the hot gas to the cold air was evaluated. (Mioralli \& Ganzarolli, 2013) developed a 1-d transient model of a rotary regenerator with a constant pressure drop or pumping power, a scale analysis was conducted to determine the minimum level of porosity that maximizes the heat transfer rate. (Kanaś et al., 2019) analyzed heat and mass transfer in a rotary heat exchanger operating under high speed rotor conditions, like the previous studies, no considerations were given into variation in the circumferential direction, the influence of number of transfer units on the temperature effectiveness is determined for the rotary regenerator.

However, as the bed rotates, its temperature also changes in the circumferential (angular) direction. There are very few works in the existing literature on the rotating APH, where 2-d models were developed and validated. (Skiepko \& Shah, 2004) compared results obtained from a 2-d steady-state model with the experimental data from an industrial-scale APH. The error between the computed and experimental heat transfer effectiveness was found to be within 3\%. (Heidari-Kaydan \& Hajidavalloo, 2014) investigated the thermal behavior of an industrial-scale APH, temperatures profile at different conditions were presented, and the impact of critical parameters such as rotational speed, separator plate and fluid flow rate were presented. A more recent study by (Wang et al., 2019) studied the effect of ammonium bisulfate deposition on the safe operation of the APH. The authors performed a multiobjective optimization to maximize the effectiveness and to minimize the pressure drop. The design parameters included rotor radius, fluid sector angle, and matrix layer height. In general, there is a lack of 2-d dynamic models of industrial-scale APHs in the open literature including validation of these models using the industrial data. A 2-d mathematical model capturing the variability of key state and performance variables in the circumferential direction in addition to the axial direction would be desired for improving the accuracy of the APH models. 


\section{Functionalized MOF-based $\mathrm{CO}_{2}$ Capture Application (reactive system):}

The amount of carbon dioxide in the atmosphere is currently rising globally by around six billion tons per year ( Zhao et al., 2007). Thus, it is essential to separate and recover carbon dioxide from the flue gases released by power plants to avoid surplus $\mathrm{CO}_{2}$ emissions. Carbon capture and sequestration (CCS) technologies will continue to play a vital role in $\mathrm{CO}_{2}$ capture until substantial changes are made to the energy infrastructure (Sumida et al., 2012). Presently, carbon capture by amine absorption is the most widely used technology (Wang et al., 2011; Wu et al., 2020). Still, this process is energyintensive in solvent regeneration (Liang et al., 2016); other significant drawbacks include solvent degradation and corrosion. Therefore, alternative technologies are also being investigated. The use of solid sorbents is considered as one of the potential options.

Various type of MOFs are being investigated. The MOFs facilitate pressure/temperature-dependent molecular sieving (Li et al., 2011; Wang \& Cohen, 2009). MOFs have very desirable properties for $\mathrm{CO}_{2}$ capture such as high pore volume, surface area, and remarkable turnability (D'Alessandro et al., 2010; Li et al., 2011). The diamine-appended MOF being developed by Lawrence Berkeley National $\mathrm{Lab}$ (LBNL)/UC, Berkeley has strong potential in reducing the cost for carbon capture (McDonald et al., 2015; Milner et al., 2017; Siegelman et al., 2017). As shown in Figure 3, these isotherms are stepshaped, which increases the sorbents potential for carbon capture and offer the prospect to achieve a large working capacity under smaller temperature and pressure ranges than most traditional sorbents. The step-shaped isotherms are obtained due to unique cooroperative reaction meahcnaisms exhbited by these MOFs leading to formation of carbamate chains and carbamte-carbamic acid pairs. These diamine-appended MOFs also show outstanding long-term stability and perform adequately under humid conditions (McDonald et al., 2015). 


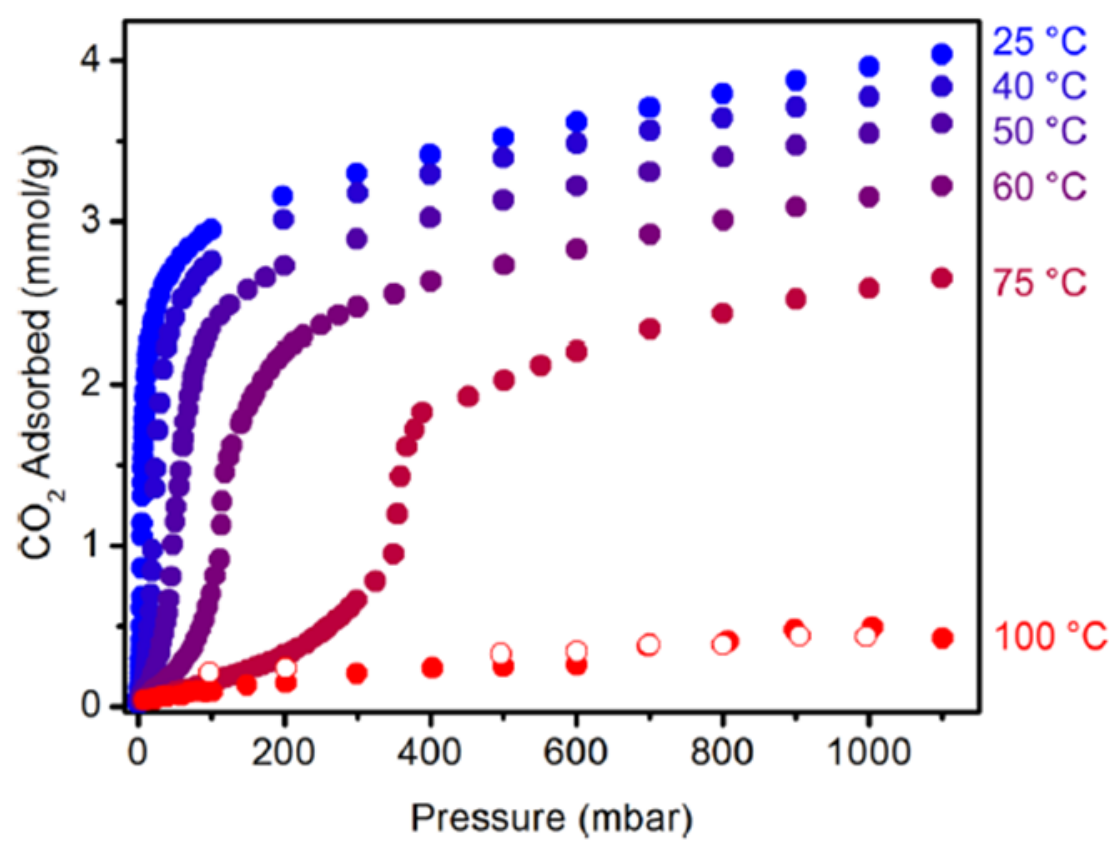

Figure 3: dmpn-Mg2(dobpdc) Isotherm (Milner et al., 2017)

The design of a suitable adsorption process involves the development of a model that can describe adsorption dynamics efficiently with the MOFs. However, the vast amount of exhaust gas from fossilfired power plants entering the post-combustion capture process is difficult to process in conventional contactor designs such as packed bed columns (Thiels et al., 2016). For taking advantage of the high working capacity of this functionalized MOF, the type and design of the contactor would play a critical role. A large quantity of $\mathrm{CO}_{2}$ capture during adsorption releases a large amount of heat since the heat of adsorption is about $-65 \mathrm{~kJ} / \mathrm{mol}$ of $\mathrm{CO}_{2}$ capture. The resulting temperature rise will cause a considerable shift in the isotherm; thus the high potential of this MOF cannot be realized unless the heat is rejected efficiently. Similarly, a large amount of heat must be provided for efficient regeneration. For solid-gas systems, different type of reactors has been investigated in the open literature including fixed bed reactors (Dantas et al., 2009; Dantas et al., 2011), moving bed reactors (Jung et al., 2018; Kim et al., 2013; Son et al., 2014), fluidized bed reactors (Kim et al., 2014; Modekurti et al., 2013) and rotating bed reactors (Lin et al., 2004).

One of the current limitations of the diamine-appended MOF is that it has weak attrition resistance; therefore, moving or fluidized beds may not be feasible. To the best of our knowledge, there has been no investigation in the open literature on the modeling and simulation of a reactive RPB for solidsorbent based $\mathrm{CO}_{2}$ capture. A similar idea of the rotary technology concept for reactive systems has 
been used for chemical looping combustion and desiccant dehumidification. (De Antonellis et al., 2010) successfully extended the rotary idea to investigate and optimize desiccant wheels performance, the optimal rotational speed, and best process air angular sector was determined using several performance criteria. (Zhao et al., 2013) have also used this idea to propose a rotary bed reactor for chemical looping combustion (CLC) with carbon capture. The solid wheel rotates between the fuel and air streams. Two purging sectors are used to avoid mixing between the fuel and the air stream. A simple 1-d transient model has been developed by the authors without considering any embedded heat exchanger.

RPBs can help to overcome the limitations of traditional fixed packed beds that suffer from significant pressure drop, low separation efficiencies, and small adsorption capacities. RPBs can help to obtain high loading capacities in a very compact design (Agarwal et al., 2010; Chen et al., 2006). Furthermore, the rotational speed presents an additional degree of freedom that increases the flexibility of the RPBs (Sudhoff et al., 2015). The presence of centrifugal force increases mass transfer rates, including diffusion in bulk fluid, interphase mass transfer, and possibly intraparticle diffusion (Lin \& Liu, 2000). Along with these advantages, RPBs could be used as a building block in modular plants, since they are compact, offer high capacity at low volume, and are flexible in operation. 


\section{MODEL DEVELOPMENT FOR NON-REACTIVE AND REACTIVE RPBS}

The first part of this chapter focuses on the development of a mathematical model of a Ljungstrom APH used in power plants for waste heat recovery, while the second part focuses on model development of a rotary packed bed for reactive systems. The system is represented via a cylindrical coordinate system. The model is two dimensional, the variable $x$ represents the axial direction ( the direction of fluid flow) and the variable $\theta$ represents the circumferential direction (the direction of matrix rotation).

\subsection{RPB for Non-Reactive systems}

\section{Objective \#1: Develop and validate a 2-d Dynamic model of a rotating APH.}

The objective of this task is to develop a dynamic model of a rotating Ljungstrom-type APH. The matrix rotates with a fixed angular velocity and acts as a medium of heat storage and heat transfer from the hot fluid to the cold fluid. Heat is transferred from the fluid to the matrix through convection, the heat stored in the matrix is transported to the cold side via rotation of the matrix. In this section, the model equations are presented briefly, with further details in Appendix A. Figure 4 shows the modeling domain. The main assumptions used in the derivation of the transient 2-D Ljungstrom-type APH model are listed as follows:

- The temperature varies is as a function of $t, x$ and $\theta$, only.

- The matrix duct wall is insulated at the boundaries.

- The properties of the fluid and matrix are constant with respect to pressure and temperature.

- No chemical reactions occur in the matrix.

- Temperature change in the radial direction is neglected.

- There is no heat exchange between the fluids at the entry or exit cross-section.

- Rotating speed is slow enough to neglect wheel mechanical work production 


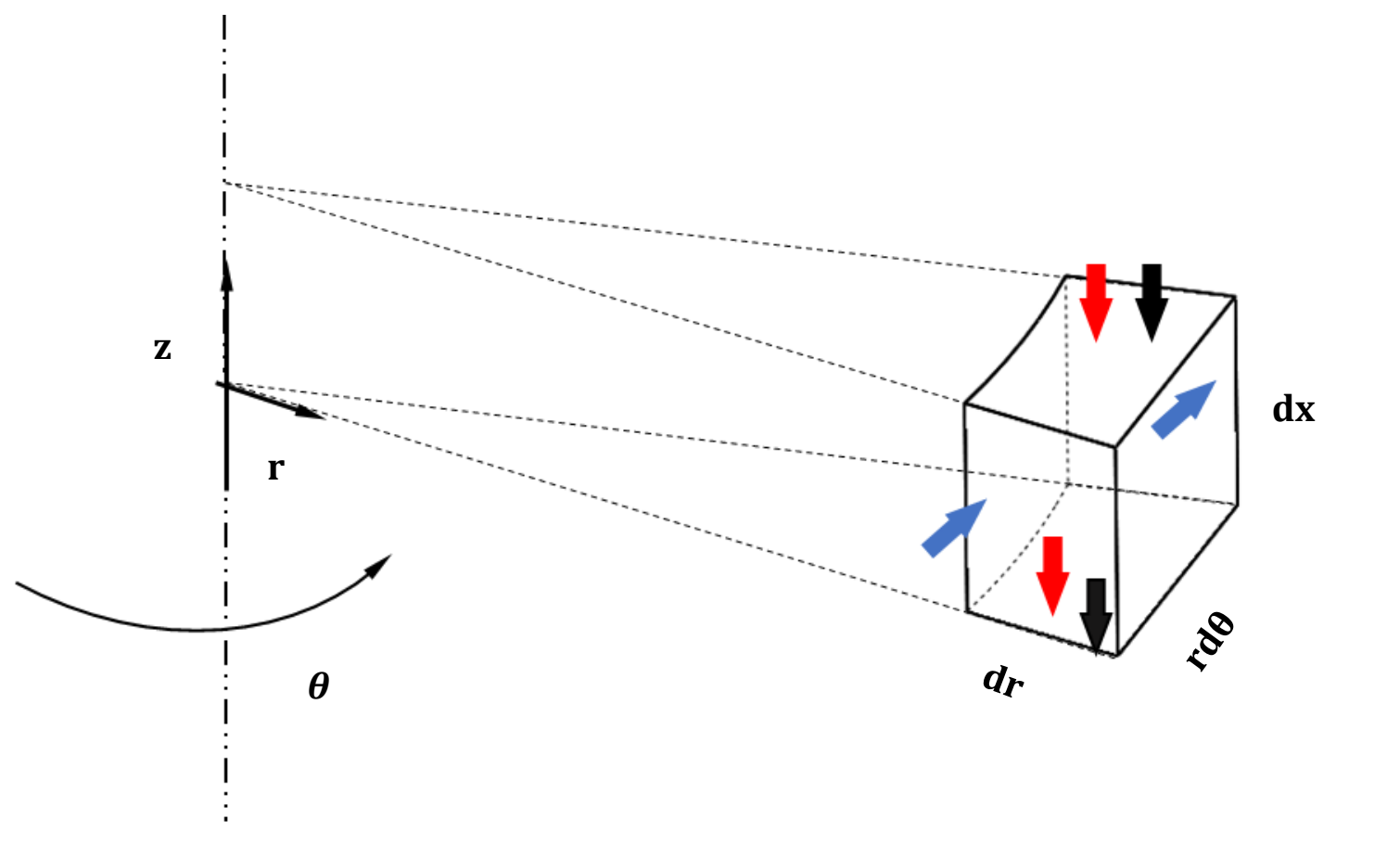

Figure 4: A Differential control volume schematic (three heat fluxes: Red - Heat carried by gas; Blue - Heat carried by matrix; Black - Heat conducted through matrix)

Assuming 2-d temperature distribution for the matrix and the gas flow along the channel of length L, the energy balance applied to a control volume leads to a set of coupled differential equations, one for the gas and the other for the matrix wall. The dimensionless energy equation for the fluid that considers the accumulation term, heat transfer due to convection and the fluid-matrix heat transfer term can be expressed as follows:

$$
\begin{gathered}
m_{c} c_{p, c} \frac{L}{v_{z}} \frac{\partial T_{c}}{d t}+m_{c} c_{p, c} \frac{\partial T_{c}}{d z}=h A\left(T_{c}-T_{m c}\right) \\
m_{h} c_{p, h} \frac{L}{v_{z}} \frac{\partial T_{h}}{d t}+m_{h} c_{p, h} \frac{\partial T_{h}}{d z}=h A\left(T_{m h}-T_{h}\right)
\end{gathered}
$$

, where $z$ is the non-dimensional axial distance and is defined as

$$
z=\frac{\bar{Z}}{L}
$$


The energy equation for the matrix that considers the accumulation term (first term on the LHS), heat transfer due to rotation of the matrix (second term on the LHS), the fluid-matrix heat transfer term (first term on the RHS) and heat transfer due to axial conduction (last term on the RHS) can be written as:

$$
M_{m} c_{p, m} \frac{\partial T_{m}}{\partial t}+M_{m} c_{p, m} \omega \frac{\partial T_{m}}{\partial \theta}=h A\left(T_{f}-T_{m}\right)+\frac{k_{m} A_{k}}{L} \frac{\partial^{2} T_{m}}{\partial z^{2}}
$$

The APH efficiency is defined as the ratio of actual rate of heat transfer to the maximum possible heat transfer in the air preheater:

$$
\varepsilon=\frac{m_{h, \text { in }} c_{p, h}\left(T_{h, \text { in }}-T_{h, o u t}\right)}{m_{h, \text { in }} c_{p, h} T_{h, \text { in }}-m_{c, \text { in }} c_{p, c} T_{c, i n}}
$$

Physical properties of the fluid (density, viscosity, thermal conductivity and specific heat capacity) used in the above equations are obtained through procedure calls from Aspen Properties. The PDAEs are solved in Aspen Custom Modeler by using the method of lines. The codes are written to simulate the APH from an initial condition until a steady state. The geometry-dependent flow properties are evaluated using the equations in Table 1. Heat transfer and friction factor data for the matrix surfaces in rotary APHs are presented as experimental correlations in terms of Reynolds number.

Table 1: Heat Transfer/Pressure drop Correlations of the APH model.

$N u=0.042 R e^{0.69} \operatorname{Pr}^{0.4}$
$R e=\frac{\rho_{f} v_{z} d_{h}}{\mu_{f}}$
$\Delta p=\frac{\rho_{f} f L v_{x}^{2}}{2 d_{h}}$
$f=2.96 R e^{-0.3}$
$\dot{\mathrm{m}}=\rho_{f} v_{z} A_{c r}$
$T_{f, \text { avg }}=\int_{\theta_{0}}^{\theta_{n}} \frac{m c_{p, f} T_{f} \partial \theta}{m c_{p, f}}$




\subsection{Boundary Conditions (Non-Reactive Systems)}

The boundary condition of the fluid is at the inlet of the flow, i.e. the flue gas inlet and the air inlet, the other arises from the continuous character of the matrix at the interface. The initial condition of the system assumes the matrix and fluid are initially at the temperature of the cold air.

Table 2: Boundary/Initial Conditions of the APH model.

$\mathrm{IC} T_{h}(0, z, \theta)=T_{c}(0, z, \theta)=T_{m}(0, z, \theta)=T_{c, i n}$
$\mathrm{BC} 1 T_{h, z=0}=T_{h, i n}=1$
$\mathrm{BC} 2 T_{c, z=1}=T_{c, i n}=0$
$\mathrm{BC} 3 \frac{\partial T_{m}\left(t, z^{*}=0, \theta\right)}{\partial z}=0=\frac{\partial T_{m}\left(t, z^{*}=1, \theta\right)}{\partial x}$
$\mathrm{BC} 4 T_{m c_{1}}\left(t, z, \frac{2 \pi}{3}\right)=T_{m c_{2}}\left(t, z, \frac{2 \pi}{3}\right)$
$\mathrm{BC} 5 T_{m c_{2}}(t, z, \pi)=T_{m h}(t, z, \pi)$

\subsection{RPB for Reactive Systems}

\section{Objective \#2: Develop a 2-d model of a RPB for $\mathrm{CO}_{2}$ capture using the functionalized MOF}

In the proposed RPB configuration, the RPB is divided into adsorption and desorption sections. A static embedded cooler is considered in the capture section where cooling water is used as the cold utility. In the desorption section, a static embedded heater is used where steam is used as the heating utility.

Model assumptions are as follows:

- External and Internal mass-transfer resistances are combined in an overall mass transfer coefficient.

- Radial variation of transport variables is neglected. 
- Each particle has a uniform temperature and concentration (i.e., there is no temperature and concentration profile within particles).

- The flow pattern is described by the axially dispersed plug flow model.

The model equations are presented briefly below, additional information can be found in Appendix B

\section{Bulk Gas Phase Species Balance:}

$$
\frac{\partial v_{g} C_{g, i}}{L \partial z}=\varepsilon_{b} \frac{\partial}{L \partial z}\left(D_{z} \frac{\partial C_{g, i}}{L \partial z}\right)-\left(1-\varepsilon_{b}\right) \rho_{s} \frac{d q_{i}}{d t}
$$

Where $C_{g, i}$ represents the adsorbate concentration in the bulk phase, $D_{z}$ denotes the axial dispersion coefficient which combines the effect of all mechanisms that contributes to axial mixing; $q_{i}$ denotes the loading of species $\mathrm{i}$, this forms a link between the gas phase and Solid-phase species balance equations.

The rate of adsorption/desorption into the MOF particle is calculated assuming a linear driving force:

$$
\frac{6 k_{f, i}}{d_{p}}\left(C_{g, i}-\left.C_{p, i}\right|_{r=r_{p}}\right)=\rho_{s} \frac{\partial q_{i}}{\partial t}
$$

where $k_{f, i}$ is the external mass transfer coefficient and $\left.C_{p, i}\right|_{r=r_{p}}$ is the concentration at the particle surface which determines the concentration gradient that drives the mass transfer.

\section{Solid Phase Species Balance:}

A mass balance of adsorbent in the fluid flowing through an increment $\mathrm{d} \theta$ of the bed gives:

$$
\omega \frac{\partial C_{s, i}}{\partial \theta}+\left(1-\varepsilon_{b}\right) \rho_{s} \frac{d q_{i}}{d t}=0
$$




\section{Bulk Gas-Phase Energy Balance}

The energy balance for the bulk gas phase which considers the heat exchange between the bulk gas and adsorbent may be represented as follows;

$$
c_{p, g} v_{g} \rho_{g} \frac{\partial T_{g}}{L \partial z}=\left(1-\varepsilon_{b}\right) h_{g s} a_{s}\left(T_{s}-T_{g}\right)+h_{t} a_{t}\left(T_{w}-T_{g}\right)
$$

Where, $h_{t}$ denotes the heat transfer coefficient between the tube-side wall and solid, $a_{t}$ is the specific surface area of the embedded heat exchanger and $T_{w}$ denotes the temperature of the tube wall.

\section{Bulk Solid-phase energy balance}

For the solid phase, the solid particles are treated as a bulk and an energy balance equation can be written that considers the energy transfer by convection through the bed by the rotation of the solid, the film heat transfer term, and the heat generated by the adsorption of the adsorbate, as shown by the following equation:

$$
\rho_{s} c_{p, s} \omega \frac{\partial T_{s}}{\partial \theta}=\left(1-\varepsilon_{b}\right) h_{g s} a_{s}\left(T_{g}-T_{s}\right)+\rho_{s}\left(\Delta H_{r x n}\right) \frac{d q_{i}}{d t}
$$

The above equation is used to find the distribution of the solid temperature across the bed, where $\Delta H_{r x n}$ is the enthalpy of $\mathrm{CO}_{2}$ adsorption, $h_{t}$ denotes the heat transfer coefficient between the tubeside wall and solid, $a_{t}$ is the specific surface area of the embedded heat exchanger and $T_{w}$ denotes the temperature of the tube wall.

\section{Tube wall Energy Balance}

Heat transfer across the tube is given by the following equation:

$$
h_{w g t} a_{w g t}\left(T_{w}-T_{\text {tube }}\right)-h_{t} a_{t}\left(T_{w}-T_{g}\right)=0
$$

$h_{w g t}$ denotes the tube-side internal heat transfer coefficient. 


\section{Reaction Kinetics:}

The rate of $\mathrm{CO}_{2}$ adsorption/desorption is assumed to be the sum of the rates for the chemisorbed $\left(x_{\text {chem }}\right)$ and physisorbed $\left(x_{\text {phys }}\right)$ species as shown below:

$$
\begin{aligned}
\frac{d q_{C O 2}}{d t}=\frac{d q_{\text {chem }}}{d t} & +\frac{d q_{\text {phys }}}{d t} \\
& =k_{O C}\left[C_{s, i_{\text {chem }}}\left(P_{C O 2}, T\right)-C_{s, i_{\text {chem }}}\right]+k_{O P}\left[C_{s, i_{\text {phys }}}^{*}\left(P_{C O 2}, T\right)-C_{s, i_{\text {phys }}}\right]
\end{aligned}
$$

The adsorption equilibrium, $C_{\mathrm{S}^{i}}{ }_{\mathrm{CO} 2}^{*}\left(P_{\mathrm{CO} 2}, T\right)$ is described using a set of equations for a dual-site Sips Isotherm, as shown below.

$$
\begin{aligned}
C_{S, i}{ }^{*}{ }_{C O 2}\left(P_{\mathrm{CO} 2}, T\right) & =C_{s, i_{\text {chem }}^{*}}\left(P_{\mathrm{CO} 2}, T\right)+C_{s, i_{\text {phys }}^{*}}\left(P_{\mathrm{CO} 2}, T\right) \\
= & n_{\max , \mathrm{c}}\left[\frac{\left(b_{a} P\right)^{1 / n_{a}}}{1+\left(b_{a} P\right)^{1 / n_{a}}}\right]+n_{\max , p}\left[\frac{\left(b_{b} P\right)^{1 / n_{b}}}{1+\left(b_{b} P\right)^{1 / n_{b}}}\right]
\end{aligned}
$$

, where $b_{a}, n_{a}, n_{b}$ are parameters. The isotherm and reaction kinetic models have been developed by Ryan Hughes. See Appendix B for additional descriptions for these relations. 


\subsection{Boundary Conditions of RPB (Non-Reactive Systems)}

Table 3: Boundary Conditions of the RPB model.

$\left.\mathrm{BC} 1 C_{g, i}\right|_{z=0}=C_{g, i n}$
$\mathrm{BC} 2 \operatorname{To}_{g} C_{g, i(z=0)}-\left.\varepsilon_{b} D_{z} \frac{d C_{g, i}}{d z}\right|_{z=0}=v_{g} C_{g, i n}, z=1$
$\left.\mathrm{BC} 3 \frac{d C_{g, i}}{d z}\right|_{z=L}=0$
$\mathrm{BC} 4 C_{s, i_{i}(\theta=0, z)}=C_{s, i_{i, i n}}$
$\mathrm{BC} 5 T_{g}(t, z=0)=T_{o}$
$\mathrm{BC} 6 T_{s}(t, \theta=0)=T_{s, i n}$




\section{Results and Discussion}

\subsection{RPB for Non-Reactive Systems (Ljungstrom APH)}

\subsubsection{Model Validation}

In this study, the model was validated using data from a typical tri-sector APH with three kinds of heat transfer elements along the matrix length as shown in Figure 5. Design parameters and operating conditions of the industrial APH are obtained from (Wang et al., 2019) and presented in

$$
T_{f, a v g}=\int_{\theta_{0}}^{\theta_{n}} \frac{m c_{p, f} T_{f} \partial \theta}{m c_{p, f}}
$$

Table 4. The numerical model in this study gives a temperature profile in each cross-section of the matrix; therefore, for comparison with the model developed here, the temperature profile is integrated in the circumferential direction at the channel exit to obtain the average value as shown in Eqn 31.

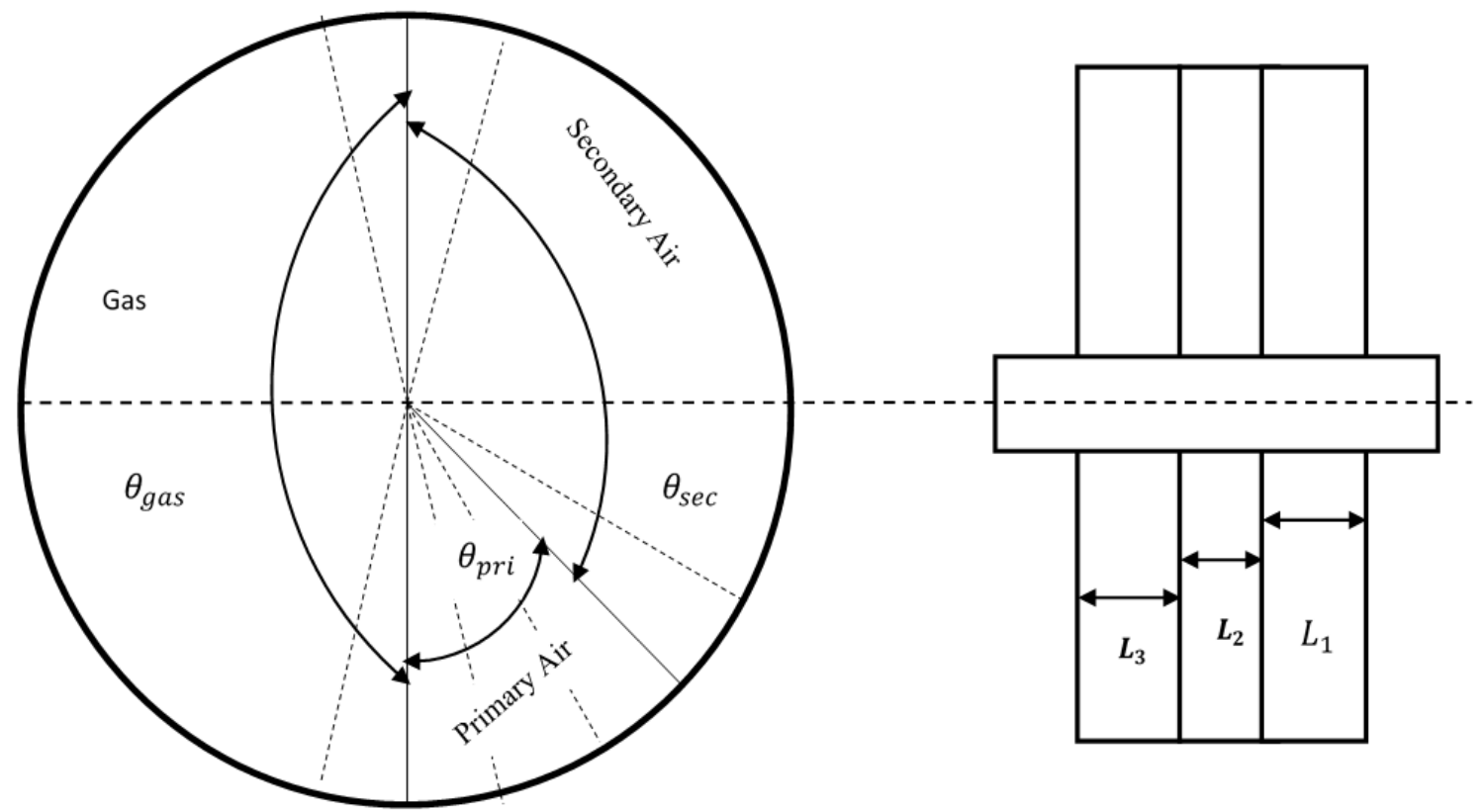

Figure 5: Rotor schematic of a specific air-preheater 


$$
T_{f, a v g}=\int_{\theta_{0}}^{\theta_{n}} \frac{m c_{p, f} T_{f} \partial \theta}{m c_{p, f}}
$$

Table 4: Design parameters and operating conditions( Wang et al., 2019)

\begin{tabular}{|l|l|l|l|}
\hline Parameter & $\begin{array}{l}\text { Value } \\
(\mathrm{HE} 1)\end{array}$ & $\begin{array}{l}\text { Value } \\
(\mathrm{HE} 2)\end{array}$ & $\begin{array}{l}\text { Value } \\
(\mathrm{HE})\end{array}$ \\
\hline Density $\left(\mathrm{kg} / \mathrm{m}^{3}\right)$ & 753.35 & 771.45 & 656.12 \\
\hline Thermal Conductivity $(\mathrm{kW} / \mathrm{m} . \mathrm{K})$ & 52.92 & 52.92 & 52.92 \\
\hline Specific heat of matrix $(\mathrm{kJ} / \mathrm{kg})$. & 456 & 456 & 456 \\
\hline Heat transfer surface area per unit volume $\left(\mathrm{m}^{2} / \mathrm{m}^{3}\right)$ & 420.21 & 430.32 & 365.98 \\
\hline Hydraulic Diameter $\left(D_{h}\right)$ & 0.0086 & 0.0084 & 0.0100 \\
\hline Porosity $(\varepsilon)$ & 0.904 & 0.813 & 0.843 \\
\hline $\mathrm{T}_{\text {gas, in }}\left({ }^{\circ} \mathrm{C}\right)$ & 400 & & \\
\hline $\mathrm{T}_{\text {pri, in }}\left({ }^{\circ} \mathrm{C}\right)$ & 32 & \\
\hline $\mathrm{T}_{\text {sec, in }}\left({ }^{\circ} \mathrm{C}\right)$ & 33 & \\
\hline$\theta_{\text {gas }}\left({ }^{\circ}\right)$ & 180 & \\
\hline$\theta_{\text {pri }}\left({ }^{\circ}\right)$ & 70 & \\
\hline$\theta_{\text {sec }}\left({ }^{\circ}\right)$ & 110 & \\
\hline$\Omega(\mathrm{r} / \mathrm{min})$ & 0.92 & \\
\hline Total height of APH $(\mathrm{m})$ & 2.05 & \\
\hline Radius of the rotor $(\mathrm{m})$ & 8.21 & \\
\hline Radius of the cylinder $(\mathrm{m})$ & 1.63 & \\
\hline$\dot{m}_{\text {gas }}$ & 770.66 & \\
\hline$\dot{m}_{\text {pri }}$ & 268.12 & \\
\hline$\dot{m}_{\text {sec }}$ & 452.532 & \\
\hline
\end{tabular}

Numerical results for the outlet temperature of fluid are compared with the measured data in Table 5. The percentage error is less than $2 \%$. Model results agree fairly well with the measured data.

Table 5: Model Results

\begin{tabular}{|c|c|c|c|}
\hline Outlet Temperature & $\begin{array}{c}\text { Measured (Wang et } \\
\text { al., 2019) }\end{array}$ & Model & Error (\%) \\
\hline $\mathrm{T}_{\text {gas, out }}\left({ }^{\circ} \mathrm{C}\right)$ & 118.3 & 116.93 & 1.17 \\
\hline $\mathrm{T}_{\text {sec,out }}\left({ }^{\circ} \mathrm{C}\right)$ & 340.6 & 337.77 & 0.83 \\
\hline
\end{tabular}




\begin{tabular}{|c|c|c|c|}
\hline $\mathrm{T}_{\text {pri,out }}\left({ }^{\circ} \mathrm{C}\right)$ & 360.2 & 364.198 & 1.09 \\
\hline
\end{tabular}

Model results were compared with the numerical model developed by (Skiepko \& Shah, 2004), where the temperature variations in the angular direction of the outlet flue gas were provided. As shown in Figure 6 and 7, model results compare well for the flue gas and air with those from (Skiepko \& Shah, 2004).

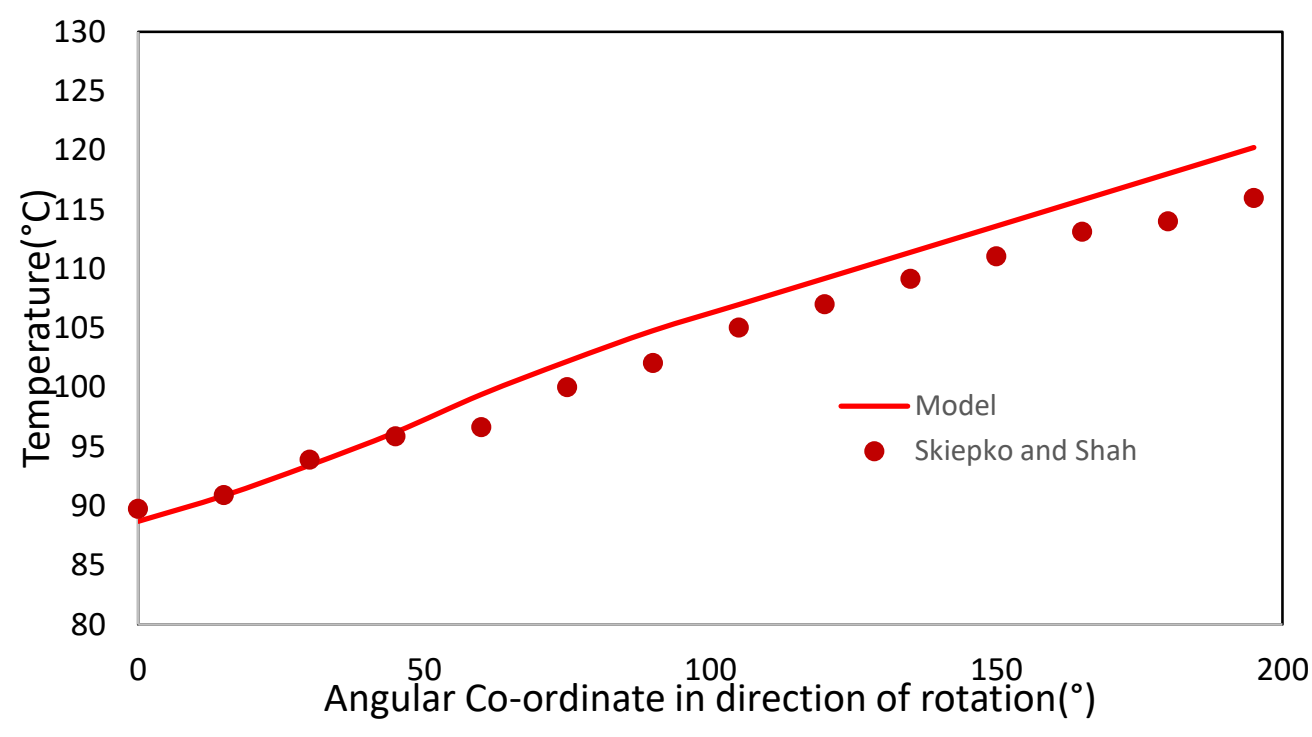

Figure 6: Comparison of the Experiment data of Skiepko and Shah (2004) with model predicted results for the outlet flue gas temperature across the circumferential direction.

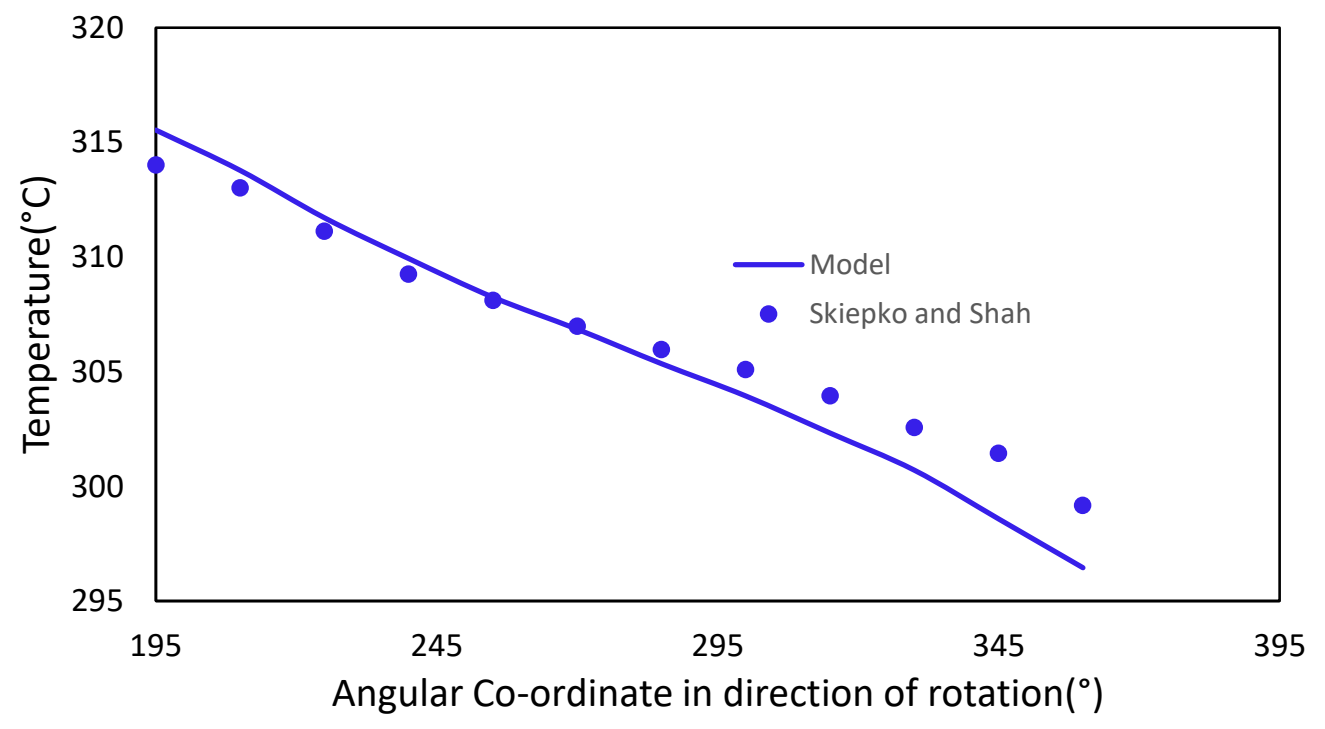


Figure 7: Comparison of the Experiment data of Skiepko and Shah (2004) with model predicted results for the outlet air temperature across the circumferential direction.

\subsubsection{Temperature Profile}

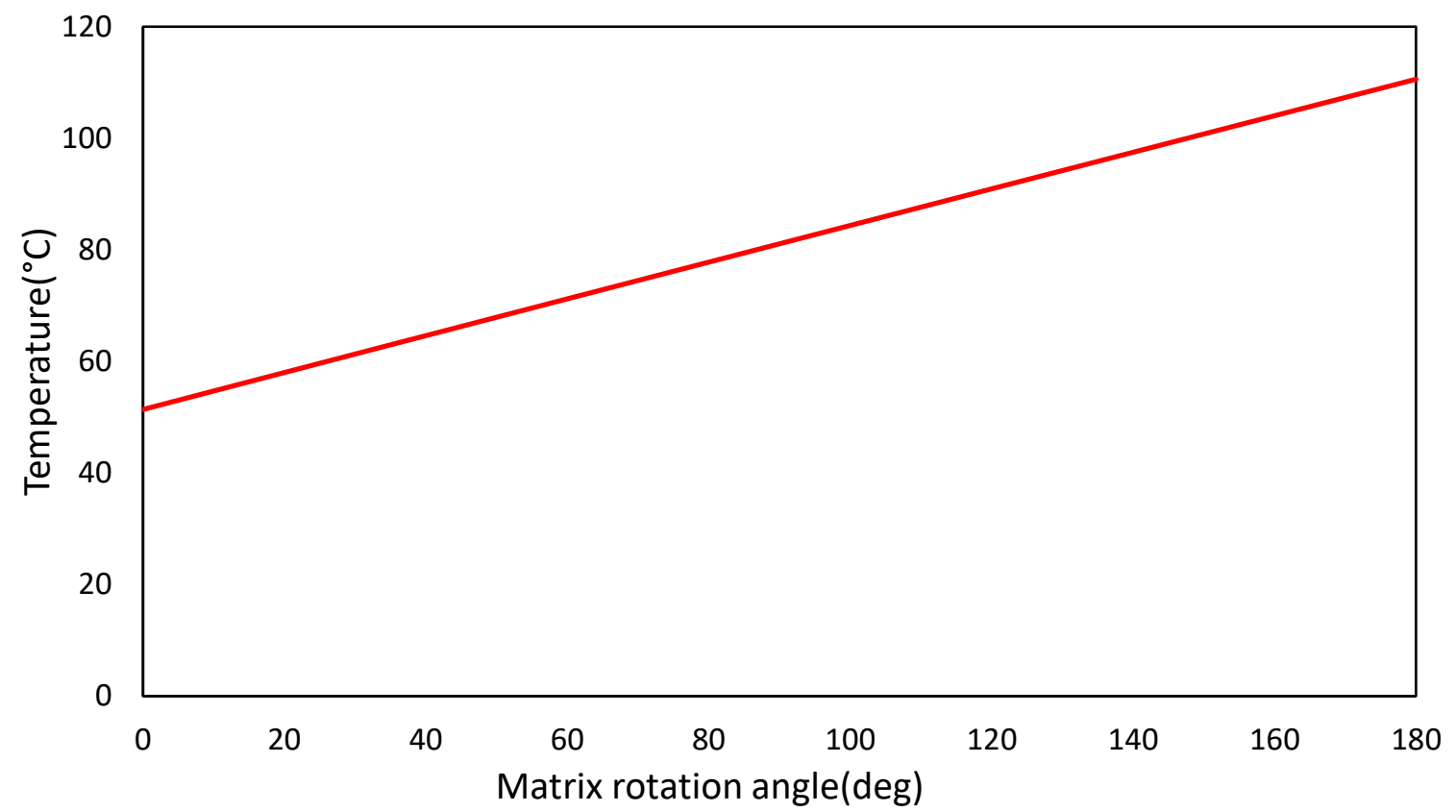

Figure 8: Temperature along the angular distance of the matrix in the flue gas sector (Exit of Bed)

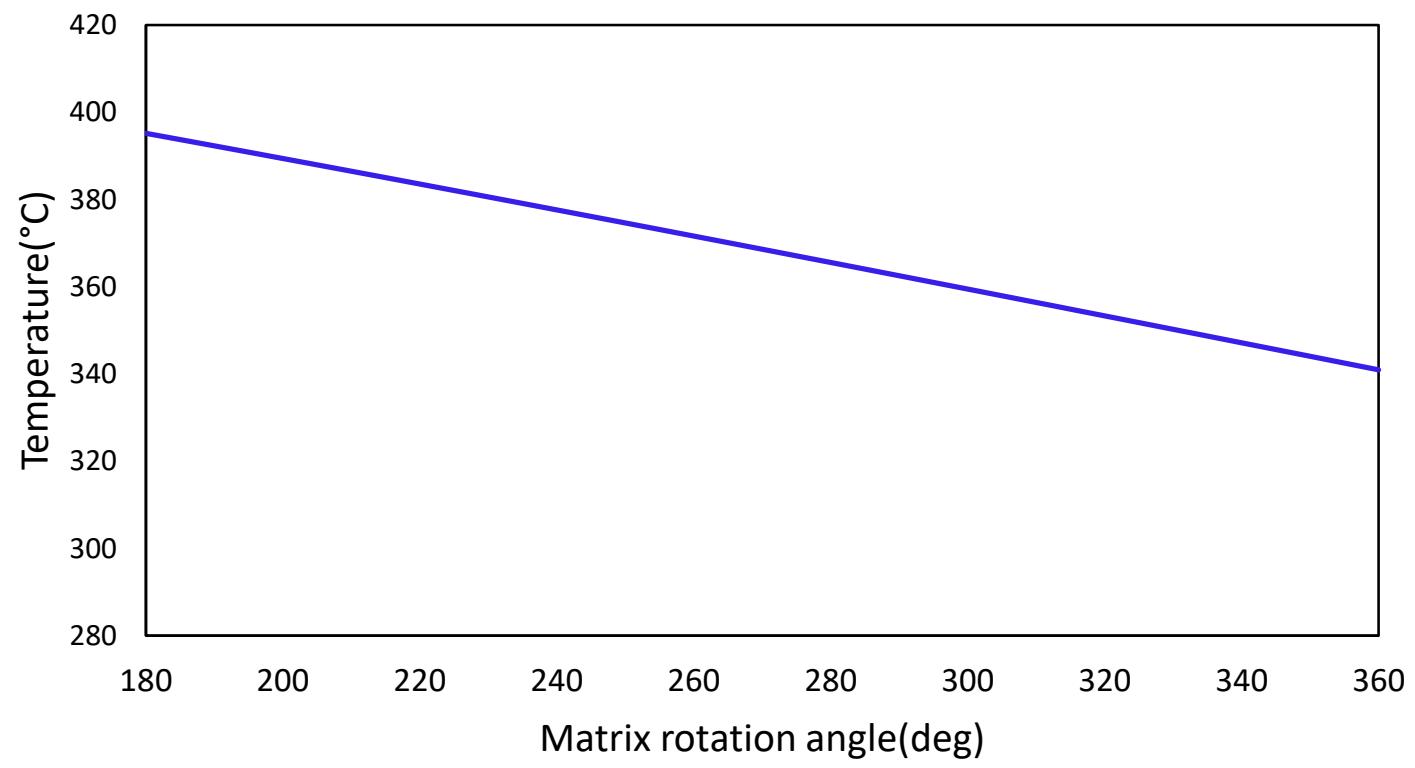


Figure 9: Temperature along the angular distance of the matrix in the Air sector (Exit of Bed)

Figure 8 and 9 show the temperature distributions in the matrix in the air and flue gas sections, respectively. As the matrix rotates from the hot flue gas section to the cold air side, heat is absorbed and hence the gradual rise of the matrix temperature across the cross-section of the flue gas channel. Likewise, as the matrix rotates into the air section, there is a decrease in the matrix temperature as it exchanges thermal energy with the air. The temperature profile across the matrix can be helpful in the selection of materials for the APH.

\subsubsection{Dynamic Simulation}

The thermal efficiency of the APH may vary with the fluctuations in boiler load or the ambient temperature. This section shows the dynamic responses of the outlet temperature to an input disturbance in the flue gas inlet temperature. The model was solved for steady-state conditions and an input disturbance was introduced as a ramp increase in the inlet flue gas temperature by $40^{\circ} \mathrm{C}$ over 5 minutes.

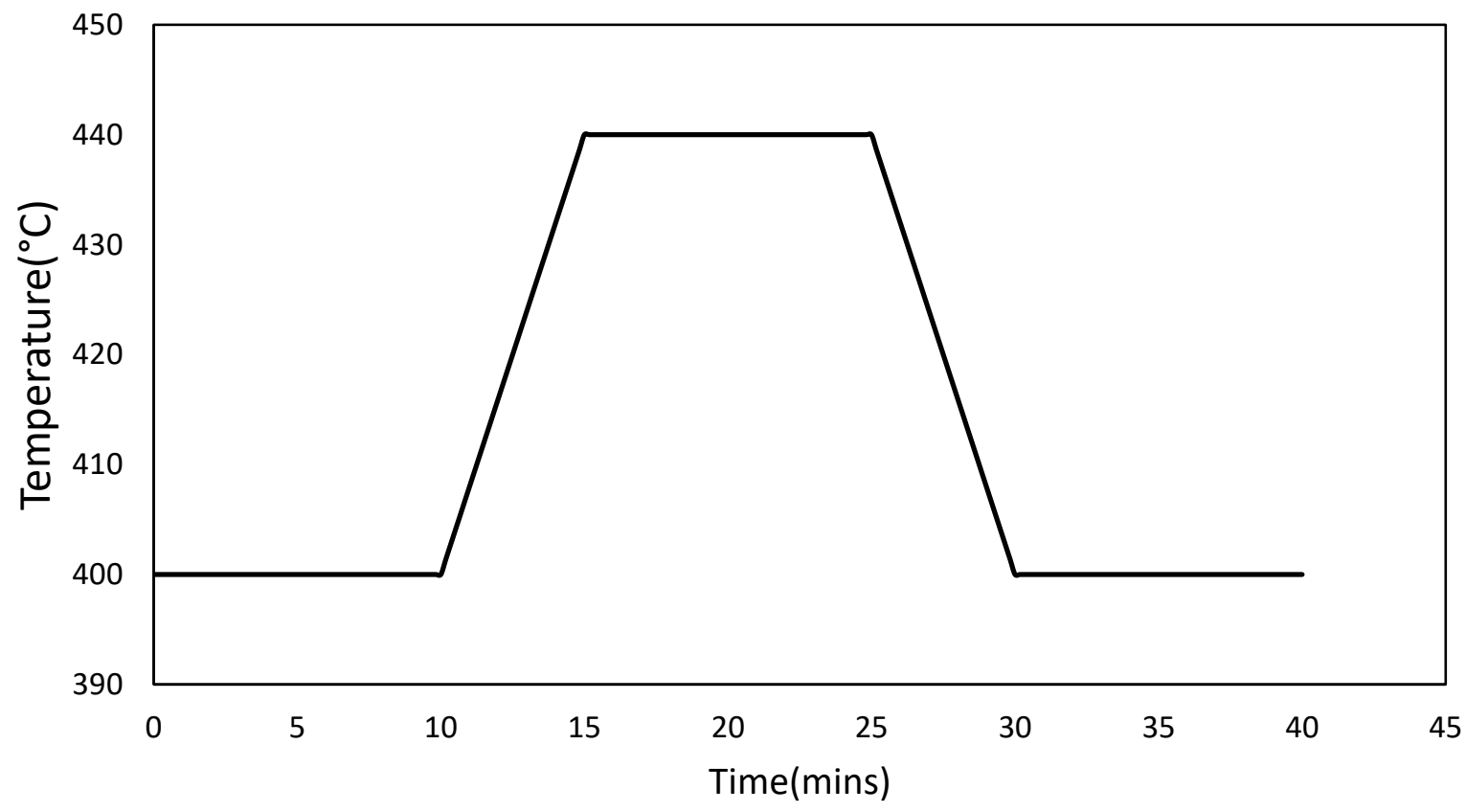

Figure 10: Inlet flue gas temperature disturbance 


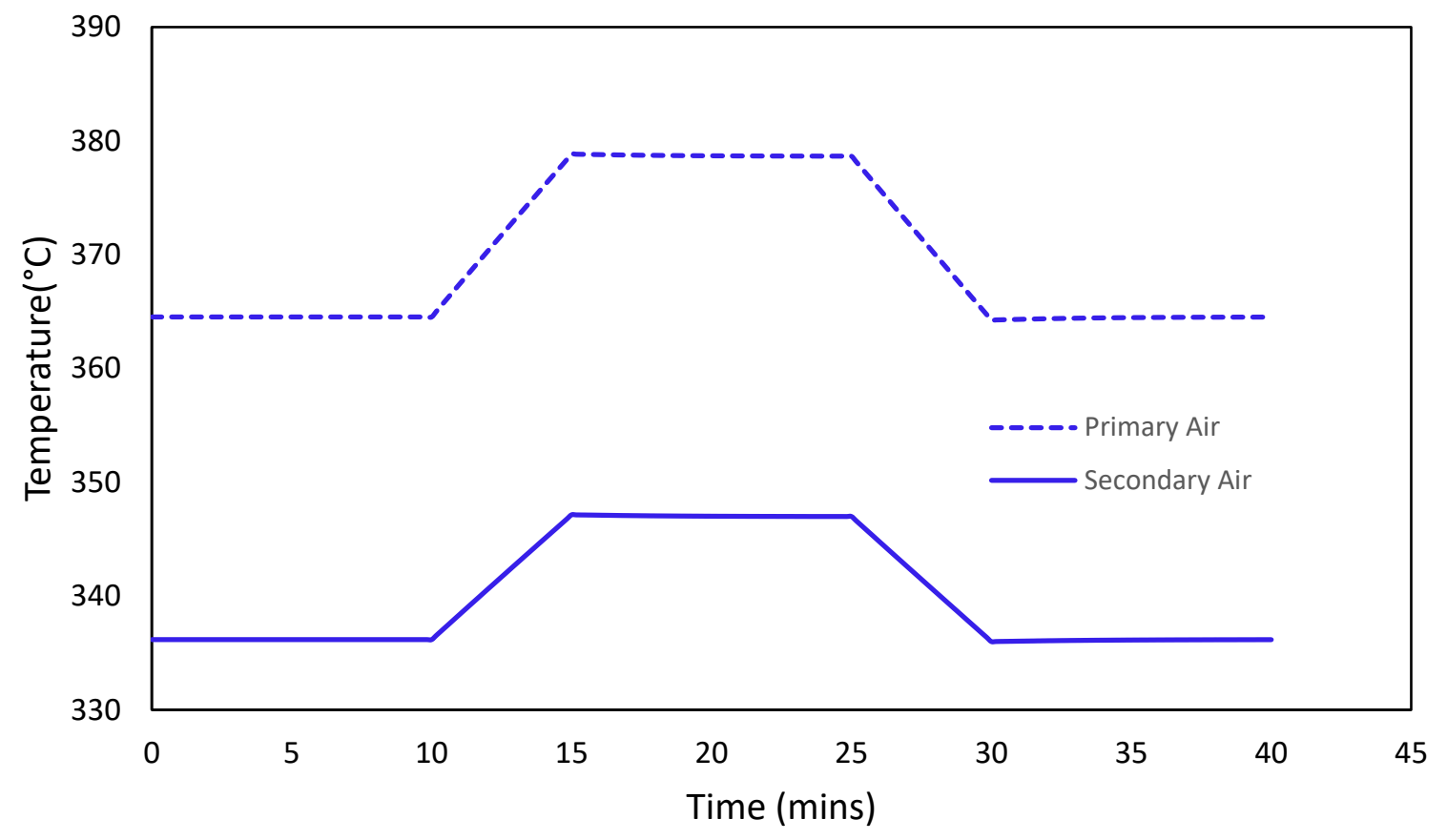

Figure 11: Air outlet temperature transients

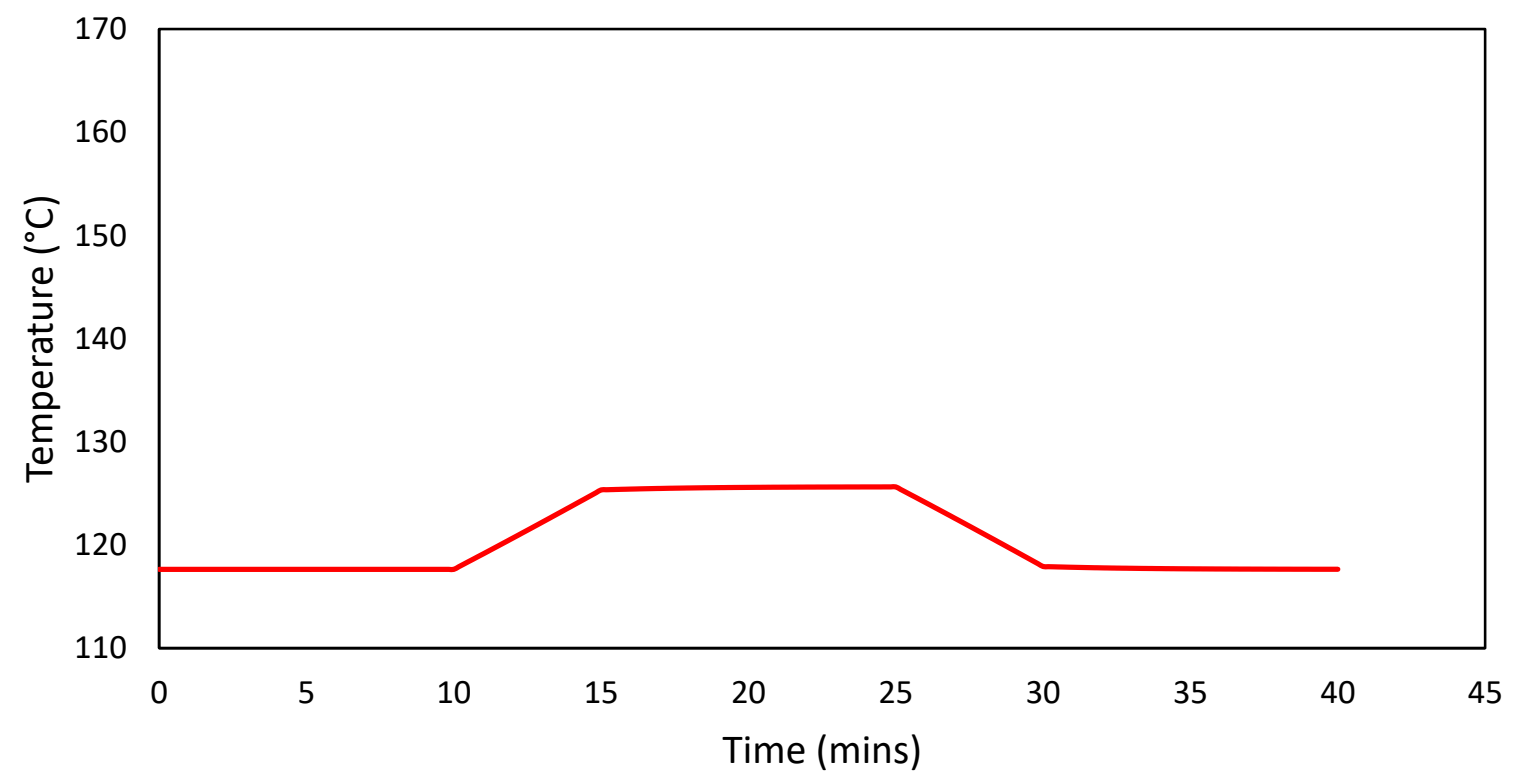

Figure 12: Flue gas outlet temperature transients

As seen in Figure 11 and Figure 12, the outlet temperature of the flue gas and air increases with the increase in inlet temperature as expected. By increasing the flue gas inlet temperature, the matrix 
leaves the hot sector at a higher temperature and more energy is exchanged between the fluids due to higher temperature gradients compared to the base case.

\subsubsection{Sensitivity Studies}

The validated model is used to perform several sensitivity studies. A few key studies are presented below.

\section{Effect of heat conduction}

Longitudinal heat conduction in the wall may not be negligible, particularly for a high effectiveness APH having a short flow length. Results showing the effect of axial heat conduction on the outlet temperature of the flue gas and air are presented in Table 6. It can be seen that there is a slight decrease in the air exit temperature if the effect of longitudinal conduction is considered. The result shows that this effect is negligible for this case primarily because of the low value of the thermal conductivity (which is $52.92 \mathrm{~W} / \mathrm{m} . \mathrm{K}$ for the case considered). However, this may not be the case for matrices made up of metals, thick walls, or short APH flow lengths.

Table 6: Effect of Heat Conduction on Outlet temperatures

\begin{tabular}{crc}
\hline Outlet Temperature & \multicolumn{1}{l}{ Without } & With Conduction $\left({ }^{\circ} \mathbf{C}\right)$ \\
& Conduction $\left({ }^{\circ} \mathbf{C}\right)$ & \\
\hline $\mathrm{T}_{\text {gas, out }}$ & 116.965 & 116.933 \\
$\mathrm{~T}_{\text {pri,out }}$ & 364.250 & 364.198 \\
$\mathrm{~T}_{\text {sec,out }}$ & 337.859 & 337.77 \\
\hline
\end{tabular}

\section{Effect of material type}

Different materials exhibit different thermal and mechanical properties, and this can affect the efficiency of the APH, hence, the material for construction plays an important role. The effect of different matrix materials is studied, properties of the four metals used in the computation are shown in Table 7. Results from the simulation are shown in Figure 13. The efficiency for different materials was computed using Equation 4. It can be observed from the figure that copper has the least efficiency 
while stainless steel has the highest efficiency, although the difference in efficiency is not very significant, such studies can help in matrix material selection for matrix APHs.

Table 7: Material Specifications

\begin{tabular}{|l|l|l|l|l|}
\hline Metals Materials & $\begin{array}{l}\text { Thermal } \\
\text { diffusivity } \\
\left(\mathbf{m m}^{2} / \mathbf{s}\right)\end{array}$ & $\begin{array}{l}\text { Thermal } \\
\text { Conductivity } \\
(\mathbf{W} / \mathbf{m} . K)\end{array}$ & $\begin{array}{l}\text { Specific Heat } \\
\text { Capacity } \\
(\mathbf{J} / \mathbf{k g . K})\end{array}$ & $\begin{array}{l}\text { Density } \\
\mathbf{( k g} / \mathbf{m 3})\end{array}$ \\
\hline Copper & 116 & 397.48 & 385 & 8940 \\
\hline Aluminium & 91 & 225.94 & 921 & 2698 \\
\hline Stainless Steel & 3.68 & 14.644 & 502 & 7920 \\
\hline Carbon Steel & 19.7 & 71.128 & 460 & 7860 \\
\hline
\end{tabular}

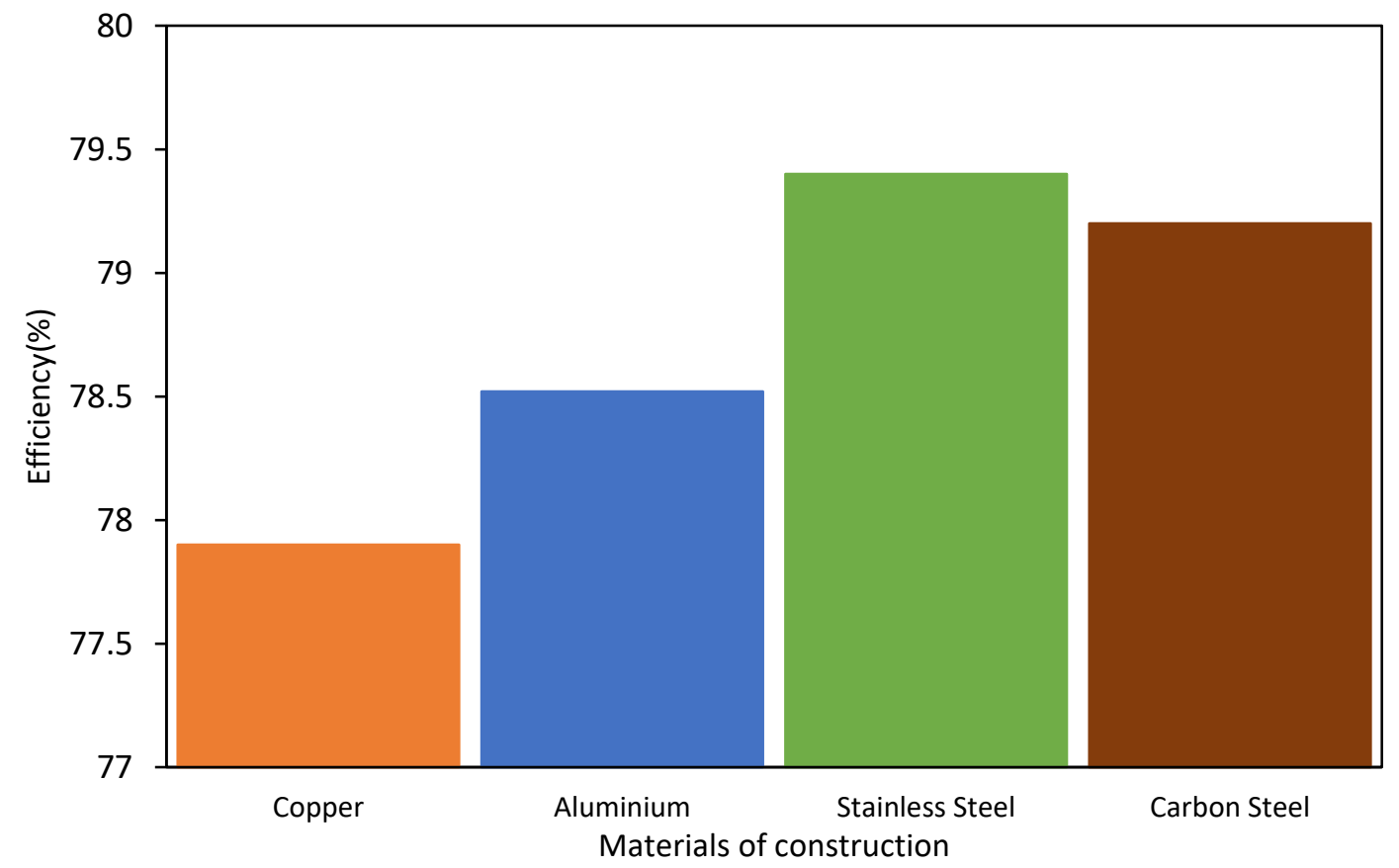

Figure 13 Effect of matrix material on the efficiency

\section{Effect of rotational speed}

The flue gas and air outlet temperatures as a function of the rotor speed are presented in Figure 14. At very low speed, air exits at lower temperature, while the flue gas leaves the preheater at a higher 
temperature because both, air and gas are in contact with the pre-heater walls for an extended period, therefore, they reach heat transfer pinch. As the rotational spped is increased, heat transfer improves. Beyond about $3 \mathrm{rpm}$, heat transfer does not vary much as seen in Figure 14. However, it should be noted that as the rotational speed increases, higher power is consumed and higher internal leakage is induced both of which will reduce the APH efficiency. It can be noted that industrial APH typically rotates around 1-3 rpm.

Figure 15 shows the impact of rotational speed on temperature distribution of the APH along the ciucumferential direction when the axia location is the cold end (i.e., at the ends where air enters and flue gas exits). It is observed that as rotational speed increases, the temperature variability in the circumferential direction decreas as expected. These results can be useful in obtaining optimum operating conditions and in identifying location in the APH that may be susceptible to ABS deposition and corrosion.

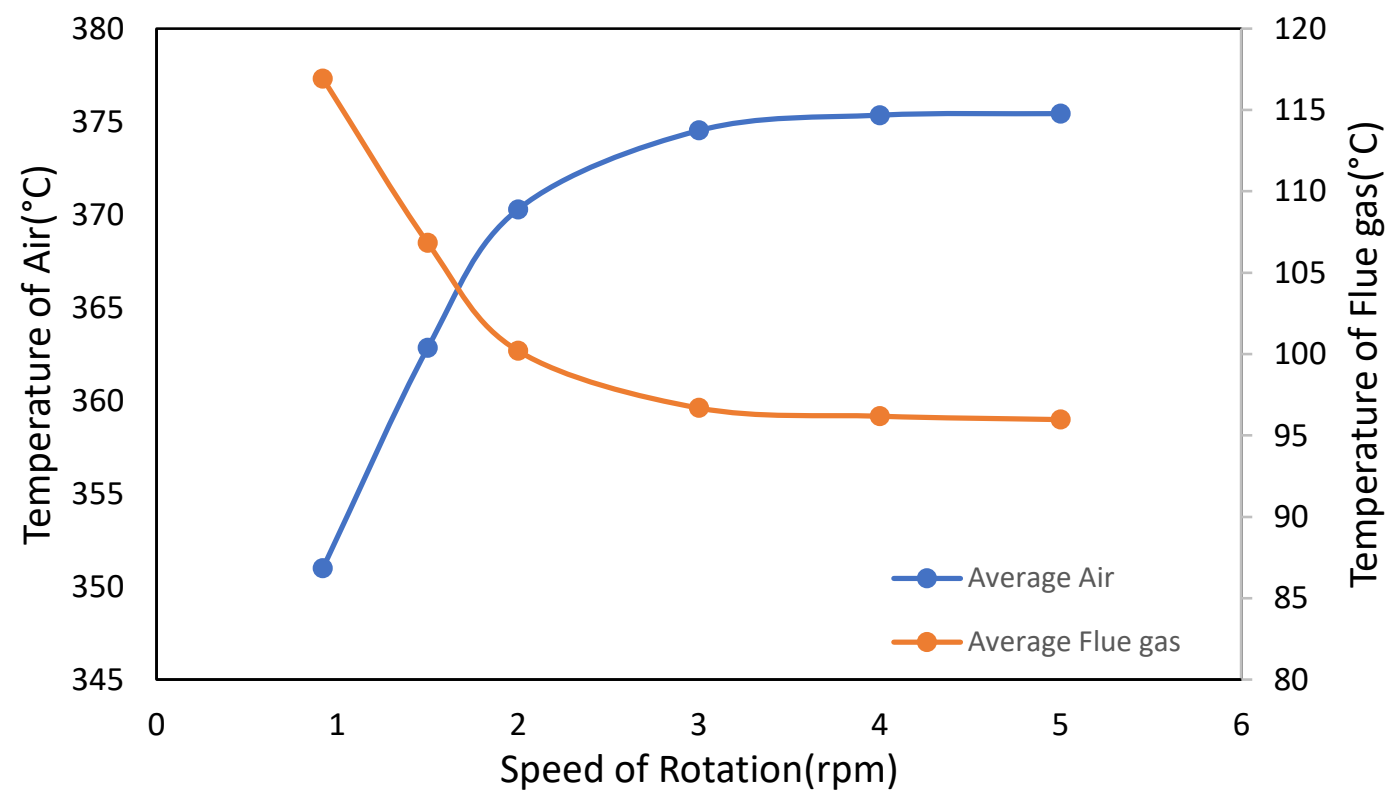

Figure 14: Effect of rotational speed on the outlet temperatures 


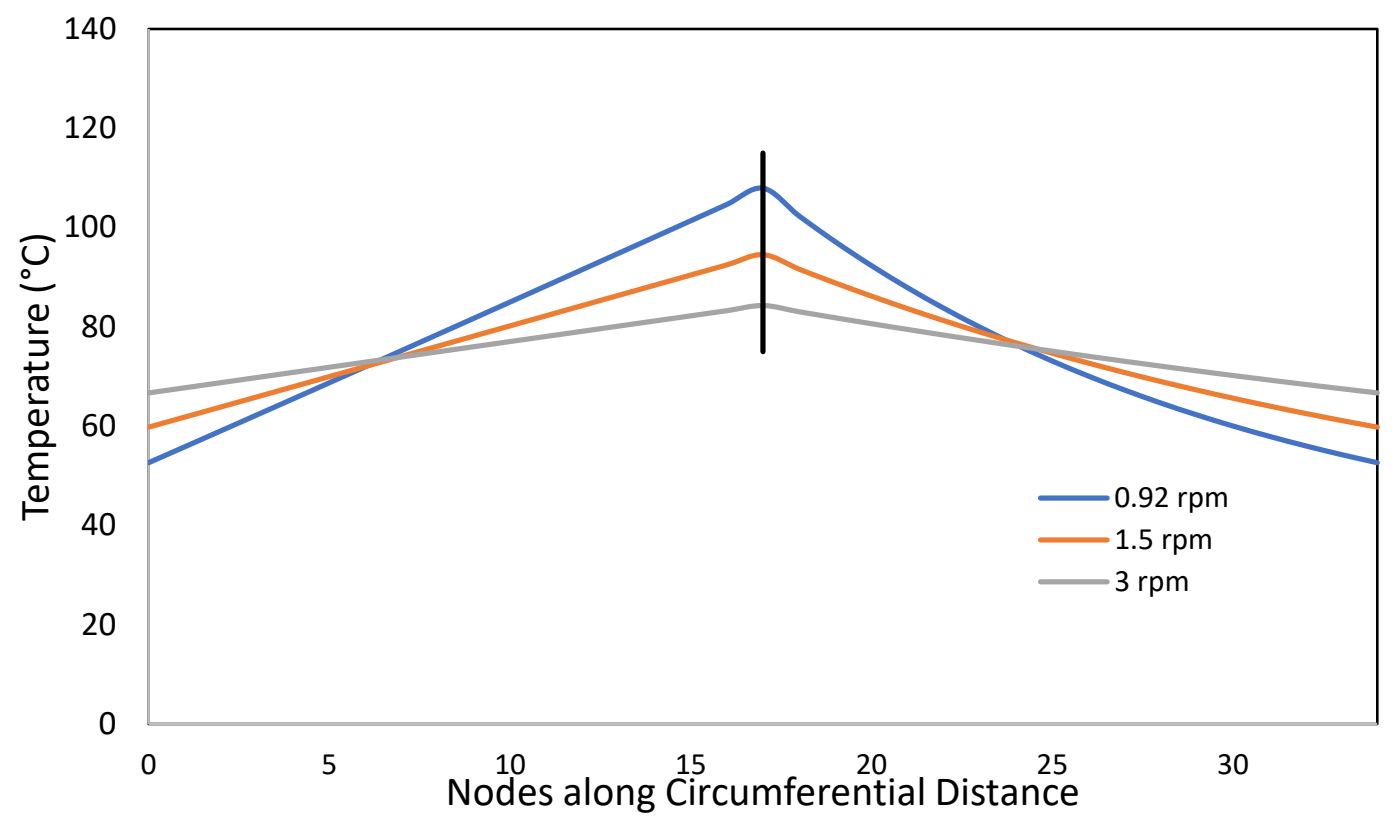

Figure 15: Temperature profile of the matrix at various rotational speed

\section{Effect of Rotor length on thermal efficiency}

Other than the rpm, another important parameter that influences the overall performance of a rotary APH is the rotor length. The efficiency of the APH increases with an increase in the rotor length as seen in Figure 16. A longer rotor length leads to reduced axial temperature gradient in the solid matrix due to decreased effect of axial heat conduction, hence, increasing the overall heat transfer rate. The efficiency increases rapidly until a certain length, at which it slows and approaches an asymptotic value. 


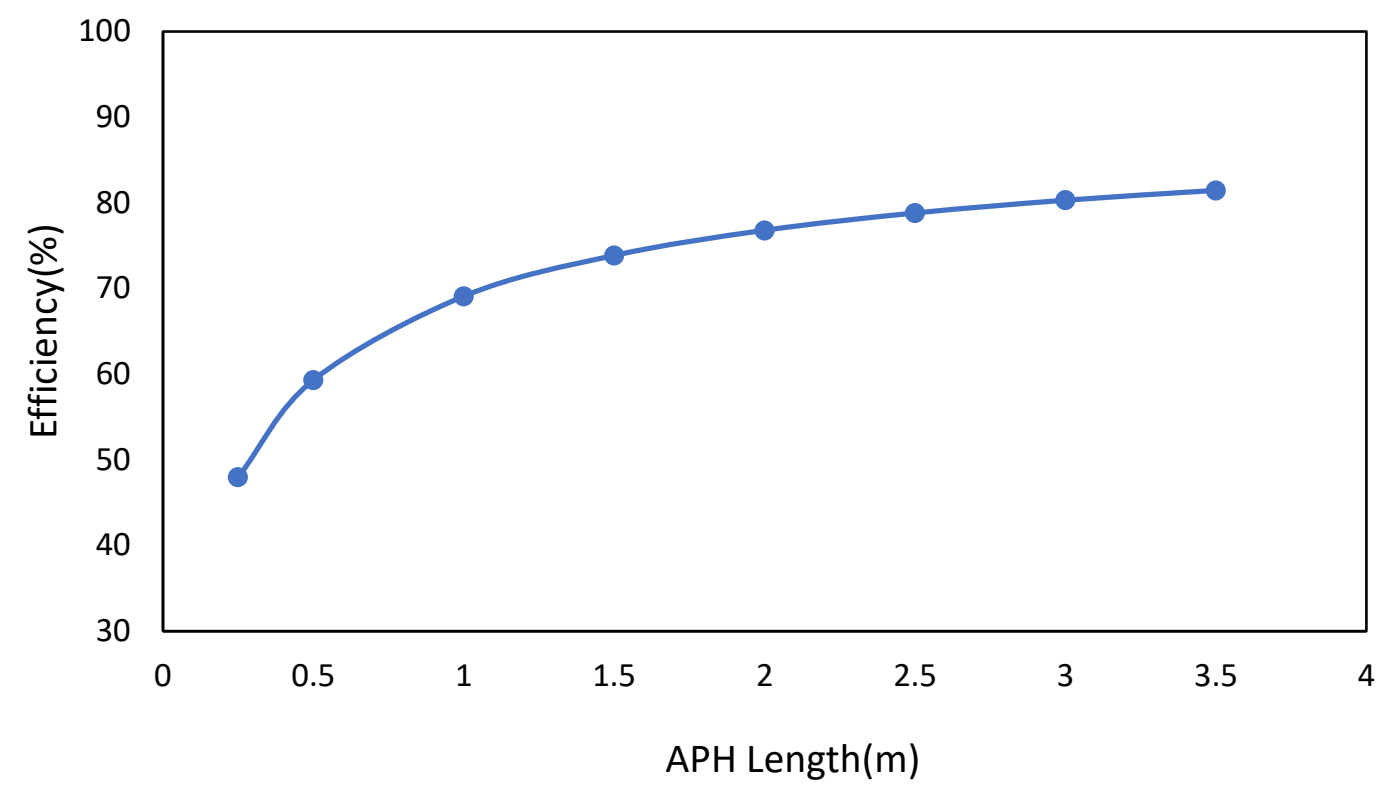

Figure 16: Effect of matrix length on thermal efficiency

\section{Effect of inlet flow rates on exit temperatures}

For simplicity, in this study, the same mass flow rate for both the gas and air is assumed. The response of the air and gas exit temperature due to the reduction in the flow rate is shown in Figure 17. By increasing the flow rate, the average air temperature decreases while the average outlet gas temperature increases. Therefore, the thermal efficiency of the APH is higher at a lower mass flow rate compared to high flow rates. It should be noted that the mass flowrate and corresponding temperature profile can also affect the leakage and that aspect needs to be taken inot consideration as well. 


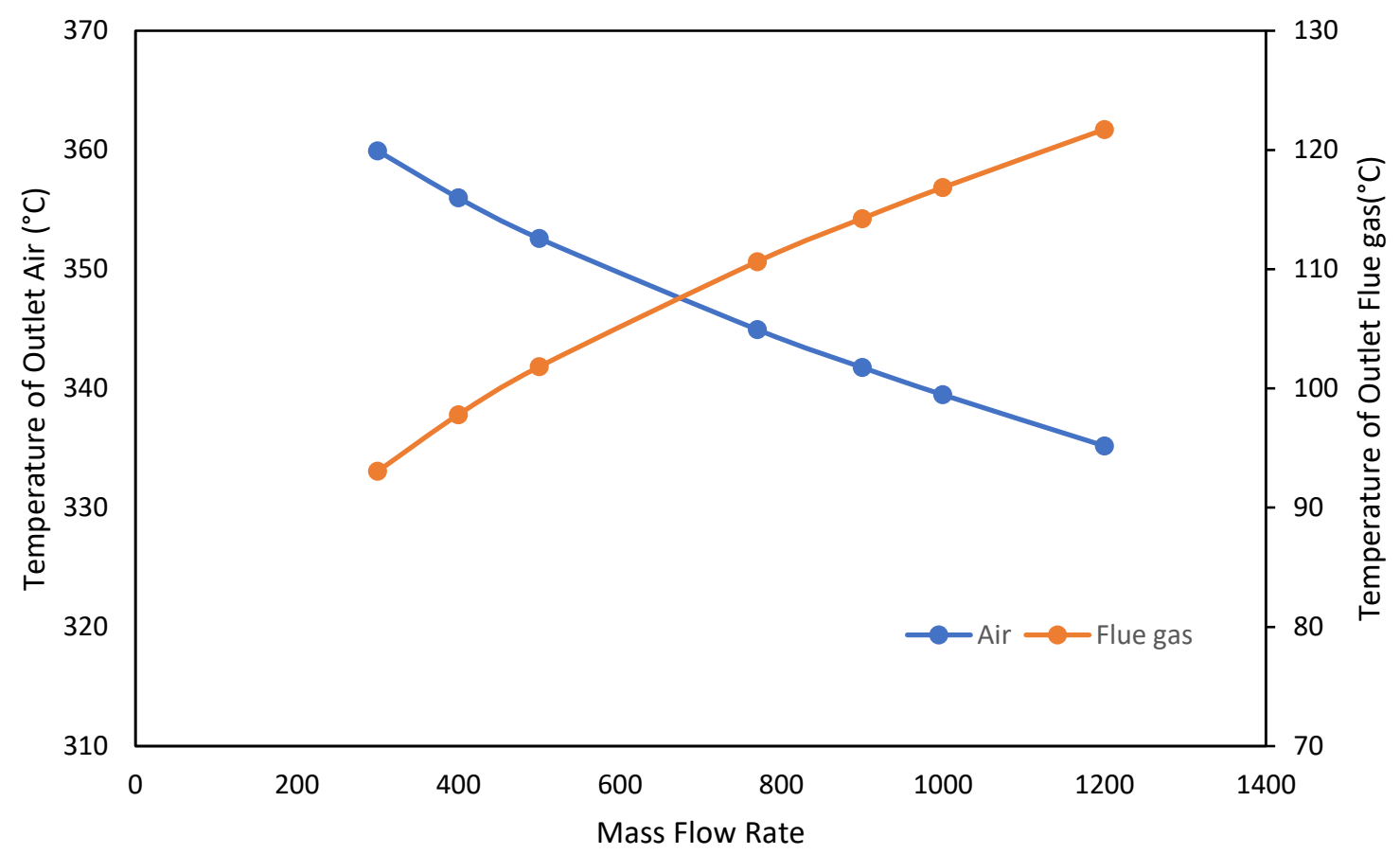

Figure 17: Effect of flow rate increase on the outlet temperatures

\section{Impact of carryover leakage}

In rotary APHs, leakages/carryover losses are inevitable and occur due to pressure differences between the high-pressure air and low-pressure flue gas (which occurs at seals or through the pores of the matrix) and also as a result of carryover (due to rotation of the matrix). Several works have been done in literature to investigate the influence of leakages on preheater heat transfer performance, a comprehensive approach was investigated for predicting the influences of leakages on the thermal efficiency of the APH (Shah \& Skiepko, 1999). Because accounting for leakages is highly dependent on the knowledge of geometry and size of seals and orifices present in the APH, a factor is usually used to correct the extra air leakage effect. For simplification, this factor is usually regarded as a percentage of the inlet mass flow rate of air. This approximation method is most appropriate for simple designs with single or double seals with a small gap size. The design leakage for regenerative APHs ranges from $5 \%$ to $15 \%$ but increases with time (assuming no maintenance) as the sealing system worsens (Maharaj et al., 2015). While some approximate methodologies have been developed in the literature for estimating leakage flowrates under simplifying assumptions, it is considerably difficult to estimate the leakage accurately. A simple equation has been proposed in the literature to estimate the carryover losses (Bu et al., 2018): 


$$
m_{\text {leak }}=V_{m} \omega \rho_{f}
$$

, where $V_{m}$ is the volume of the matrix, $\rho_{f}$ is the density of the fluid and $\omega$ is the rotational speed of the APH.

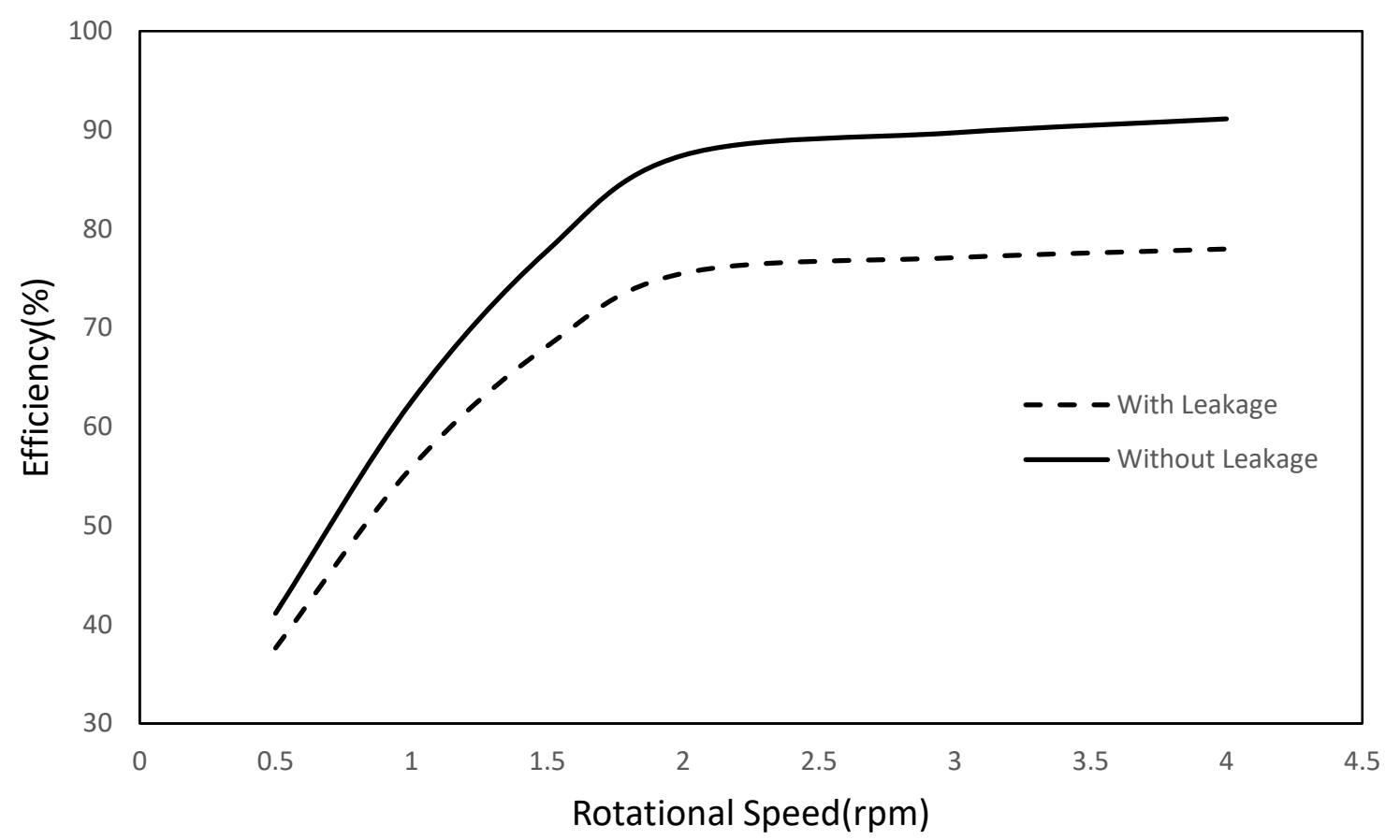

Figure 18: Effect of carryover losses on thermal efficiency of APH

As can be seen from the figure above, when the carryover leakage is accounted for, there is a significant decrease in the thermal efficiency of the APH, especially at higher rotational speeds.

\subsection{RPB for Reactive Systems}

Error! Reference source not found. shows the schematic of the RPB for $\mathrm{CO}_{2}$ capture. The regeneration and adsorption sections are in a counter-current flow arrangement with respect to their streams. 


\section{Flue Gas Inlet \\ Regeneration Steam Outlet}

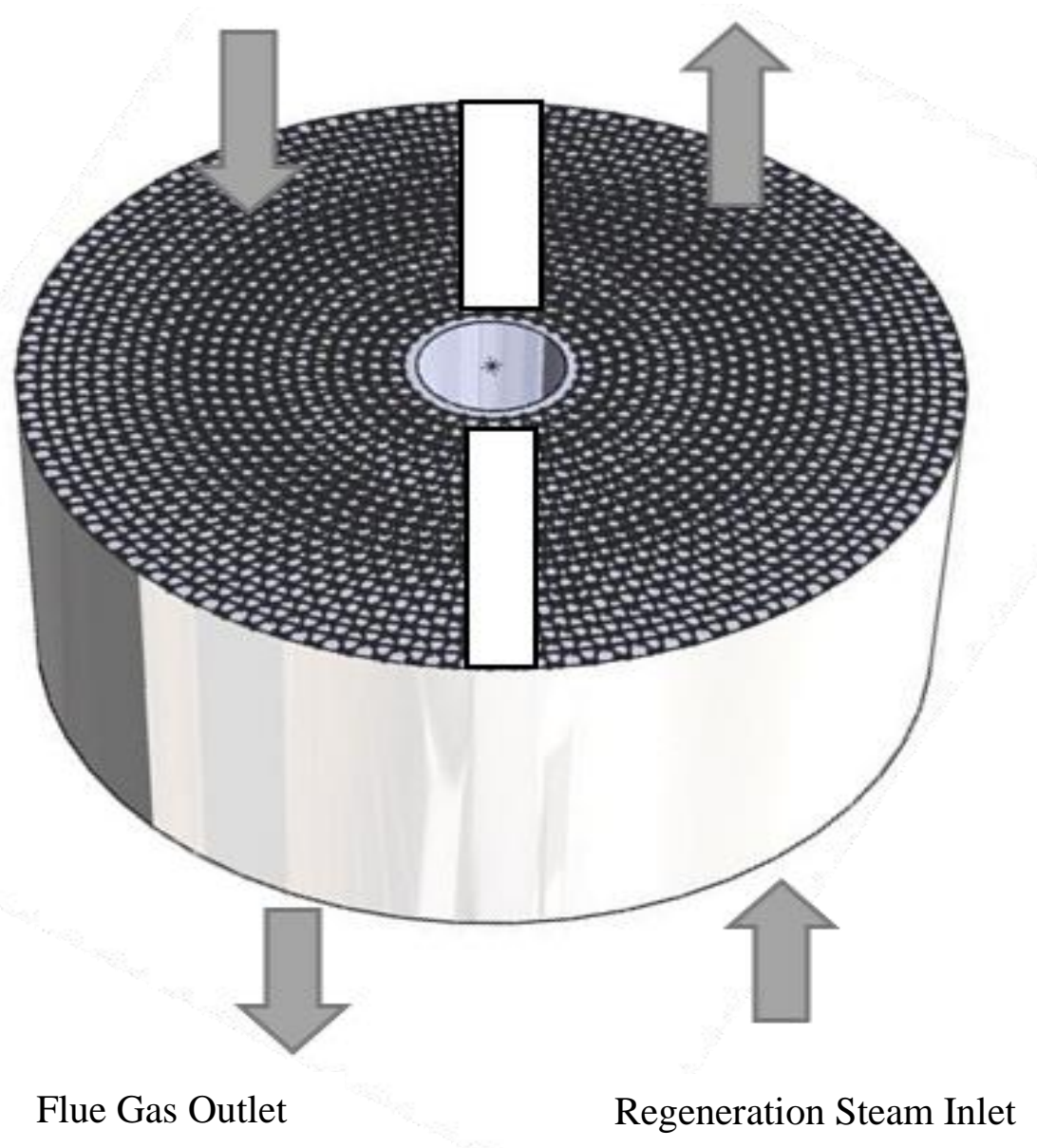

Figure 19: Schematic of the RPB for CO2 capture (without showing the embeeded cooling/heating sections)

During capture, the heat of sorption is released. The heat generated can significantly reduce the loading capacity of the MOF. Therefore, cooling water is used in the capture side. The cooler is static being located in between layers of rotating MOF with cooling water flow direction in the direction of the rotation of the solid. In the regeneration section, steam is being used for heating in a static heater that is laid out similarly as the cooler in the capture section. In addition, direct steam is injected to the desorption section. A full RPB process model was developed in Aspen Custom Modeler V.9 and the steady-state behavior is analyzed and shown in the results section below. The system of equations 
was solved using Aspen Custom Modeler, steady-state profiles for various process variables are shown in this section. Physical properties of the fluid are obtained through 'procedure' calls. Design parameters and operating conditions are presented in the table below. Base case design parameters are the same as those considered for economic analysis.

Table 8: Base case process variables and results

\begin{tabular}{lccc}
\hline Process Condition & Value & Units \\
\hline & Adsorber & & \\
\hline $\begin{array}{l}\text { Lean Solids Temperature } \\
\text { Lean Solids Flow }\end{array}$ & 25 & ${ }^{\circ} \mathrm{C}$ \\
Flue Gas Composition (mole fraction) & 1 & $(\mathrm{rpm})$ \\
$\quad \mathrm{CO}_{2}$ & & 0.147 & \\
$\quad \mathrm{H}_{2} \mathrm{O}$ & & 0.026 & {$[-]$} \\
$\quad \mathrm{N}_{2}$ & Desorber & 0.827 & {$[-]$} \\
Flue Gas Flow & & 1669 & {$[-]$} \\
Cooling Water Temperature & & 20 & ${ }^{\circ} \mathrm{C}$ \\
& & 110 & \\
\hline Rich Solids Temperature & & 1 & $([\mathrm{rpm})$ \\
Rich Solids Flow & & 110 & ${ }^{\circ} \mathrm{C}$ \\
Direct Steam Temperature & & 139 & ${ }^{\circ} \mathrm{C}$ \\
Indirect Steam Temperature & Design Conditions & \\
\hline & & $90 \%$ & {$[-]$} \\
\hline $\mathrm{CO}_{2}$ Capture & & 0.3 & {$[\mathrm{~mol} / \mathrm{kg}]$} \\
Lean Solids Loading & & 73 & $m^{2} / \mathrm{m}^{3}$ \\
Heat Exchanger Specific Surface Area & & & \\
\hline
\end{tabular}

\section{Capture Section:}

It can be seen in Figure 19 that the temperature of the solid phase increases gradually from the inlet to the exit along the direction of rotation. Due to the heat of reaction being released in the solid and convective heat exchange between the solid and the gas, the gas gets heated up. As the extent of reaction gets reduced due to the increase in the temperature, a lesser amount of heat gets released down the direction of rotation thus all temperatures move close to each other. 


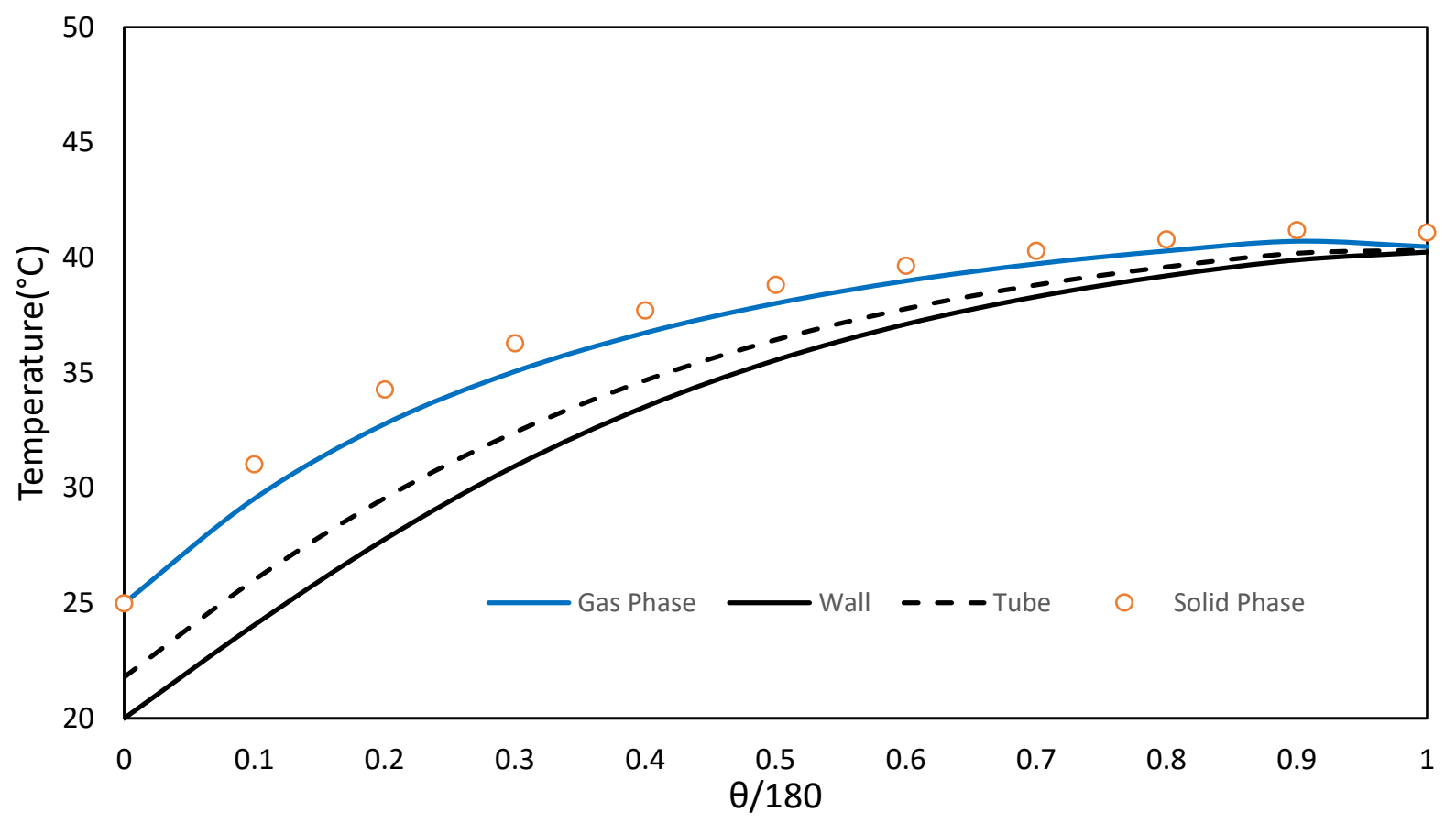

Figure 19: Temperature profile along the circumferential direction (axial location: gas exit from the capture section)

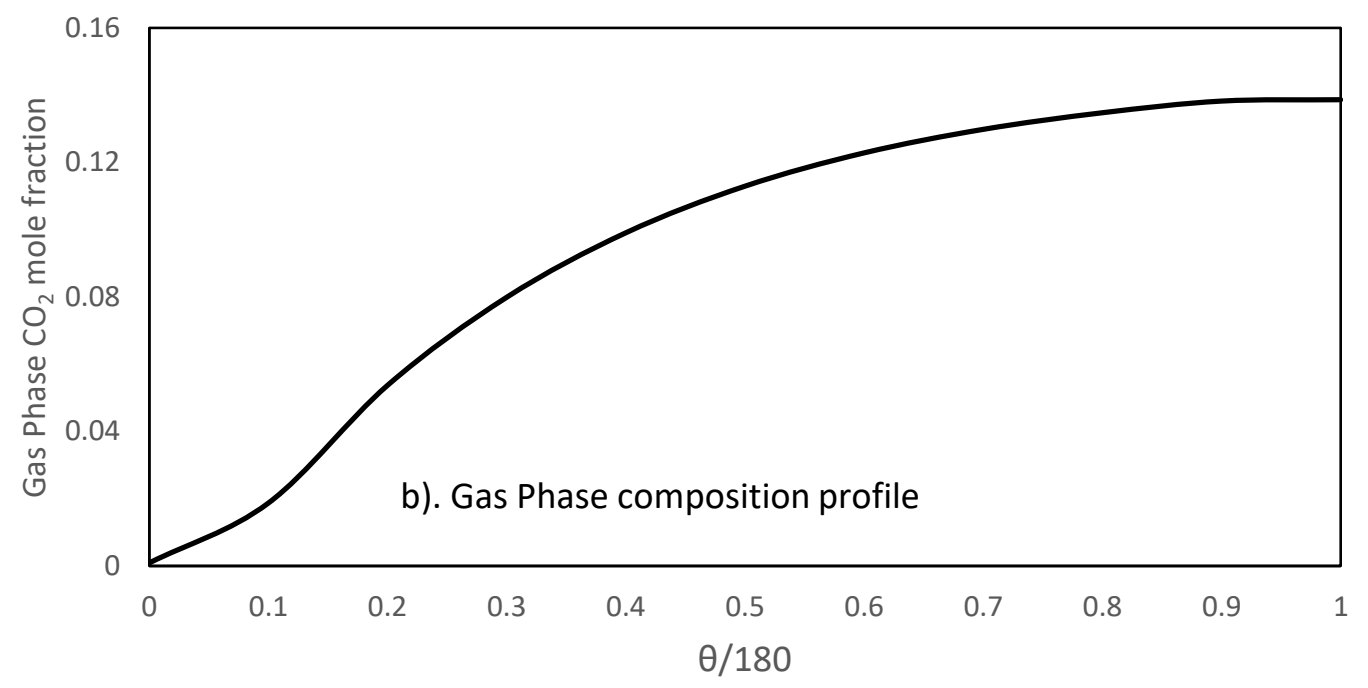

Figure 20: Gas-phase composition profile along circumferential direction (axial location: gas exit from the capture section) 


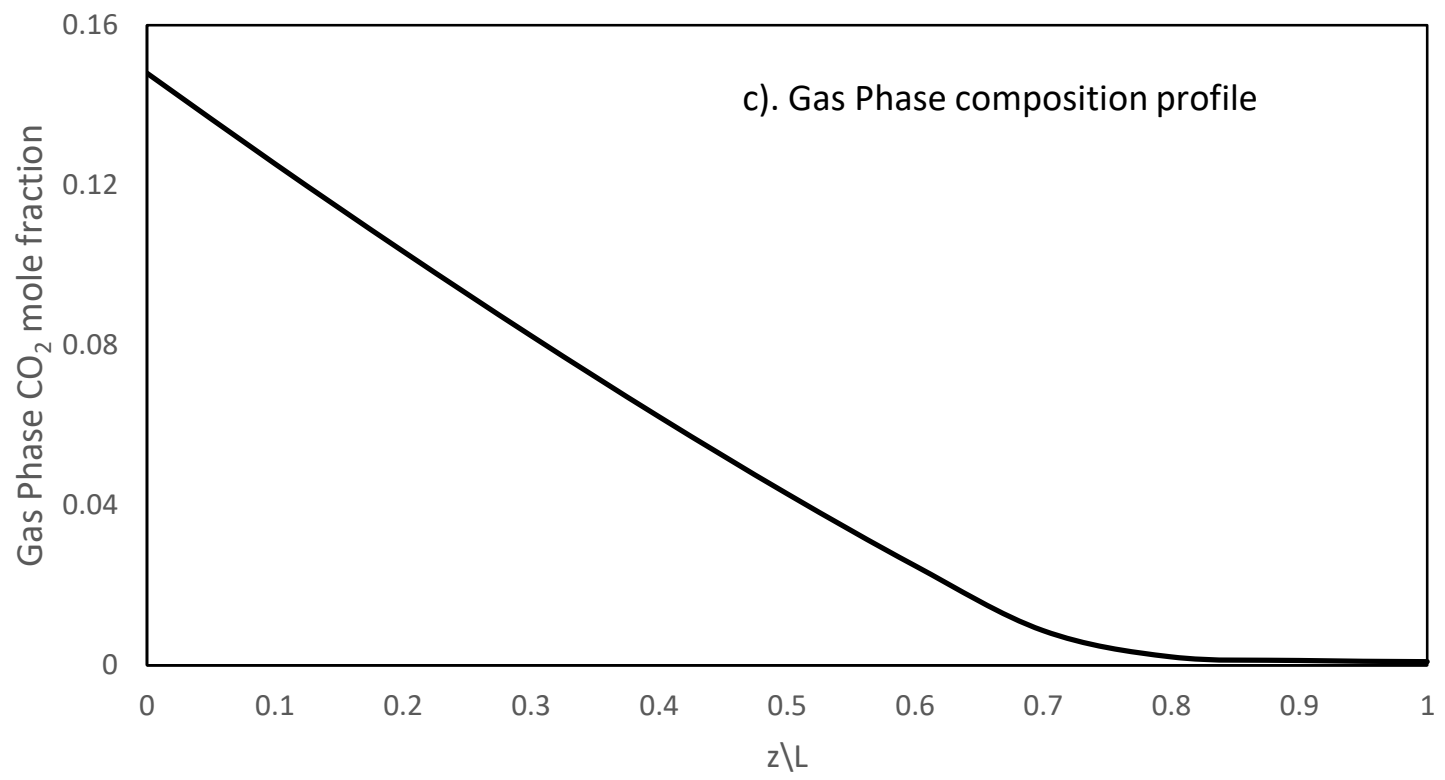

Figure 21: Gas phase composition profile along the axial direction (circumferential location: solid entrance to the capture section)

Figure 20 shows the gas phase composition profile along the direction of rotation where the axial location corresponds to the gas exit from the bed. It is seen that $\mathrm{CO}_{2}$ capture gets drastically reduced along the circumferential direction, which indicates that it is important to capture the variability in that direction. Obviously, such variability is a strong function of the rotational speed. Figure 21 shows the $\mathrm{CO}_{2}$ composition profile along the axial direction where the circumferential location corresponds to the solid entrance into the capture section. At this location, practically all of $\mathrm{CO}_{2}$ gets captured. 


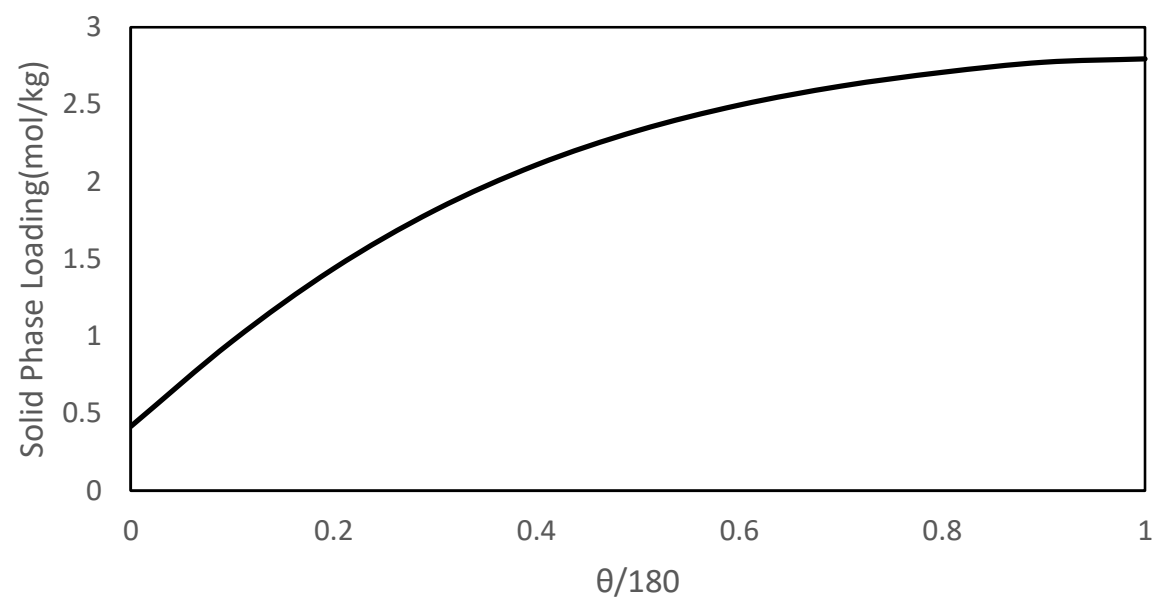

Figure 22: Solid phase total $\mathrm{CO}_{2}$ loading along circumferential direction (axial location: gas exit from the capture section)

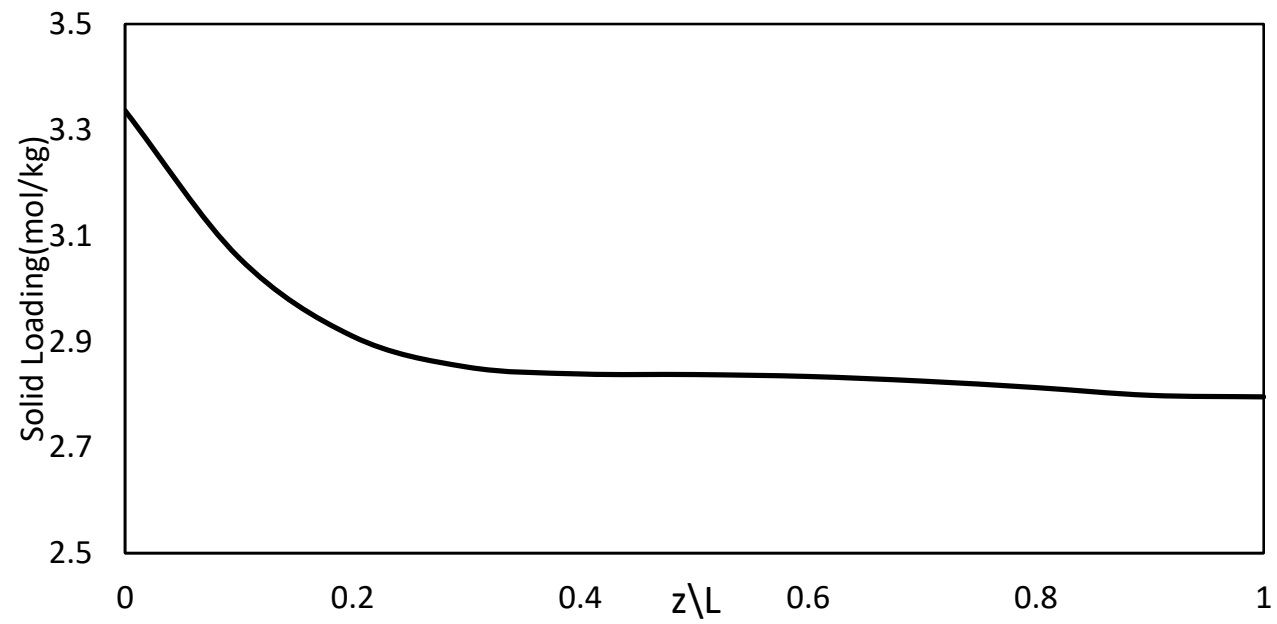

Figure 23: Solid phase $\mathrm{CO}_{2}$ loading along the axial direction (circumferential location: solid entrance to the capture section

Figure 22 shows the $\mathrm{CO}_{2}$ loading profiles along the direction of rotation at the bottom of the bed where the gas exits. As expected, it can be seen that the loading increases as the solids move along the circumferential direction as adsorption occurs. Figure 23 shows the solid loading profile along the direction of gas flow(axial) at the solid entrance of the bed.. It is seen that the loading decreases down the bed as $\mathrm{CO}_{2}$ mole fraction in the gas reduces due to capture at the top part of the bed where the gas enters. 


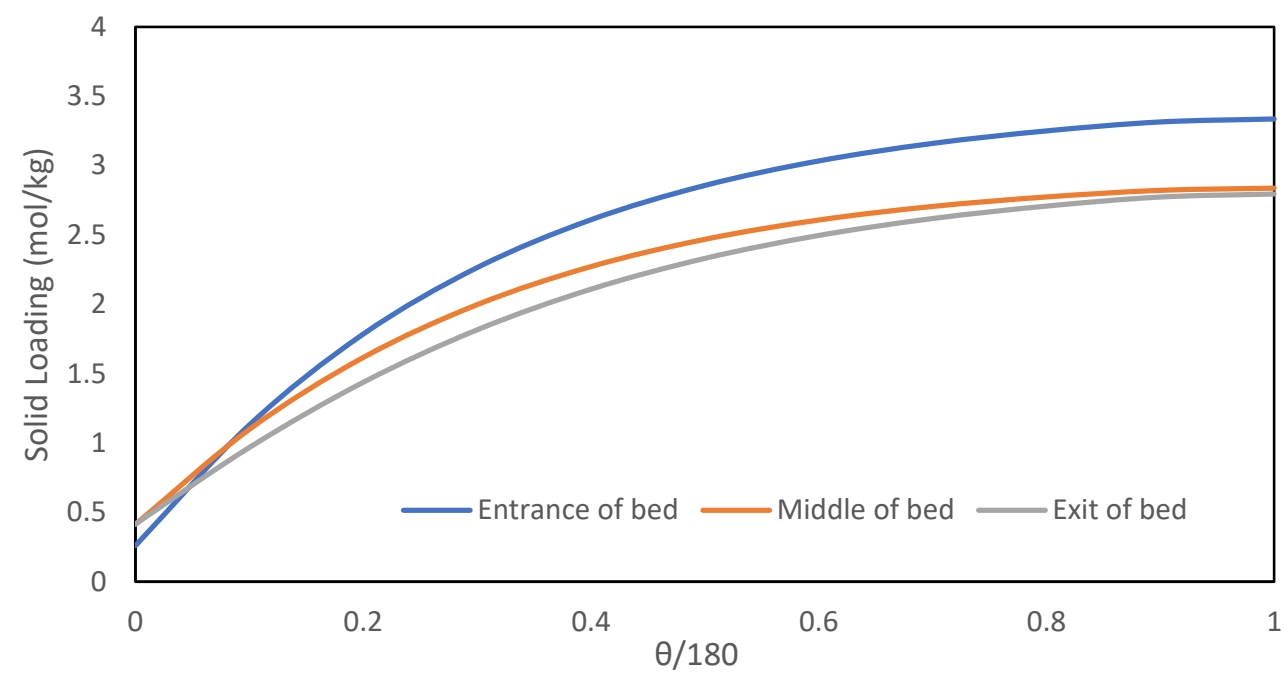

Figure 24: Solids loading profile along circumferential direction at various axial locations

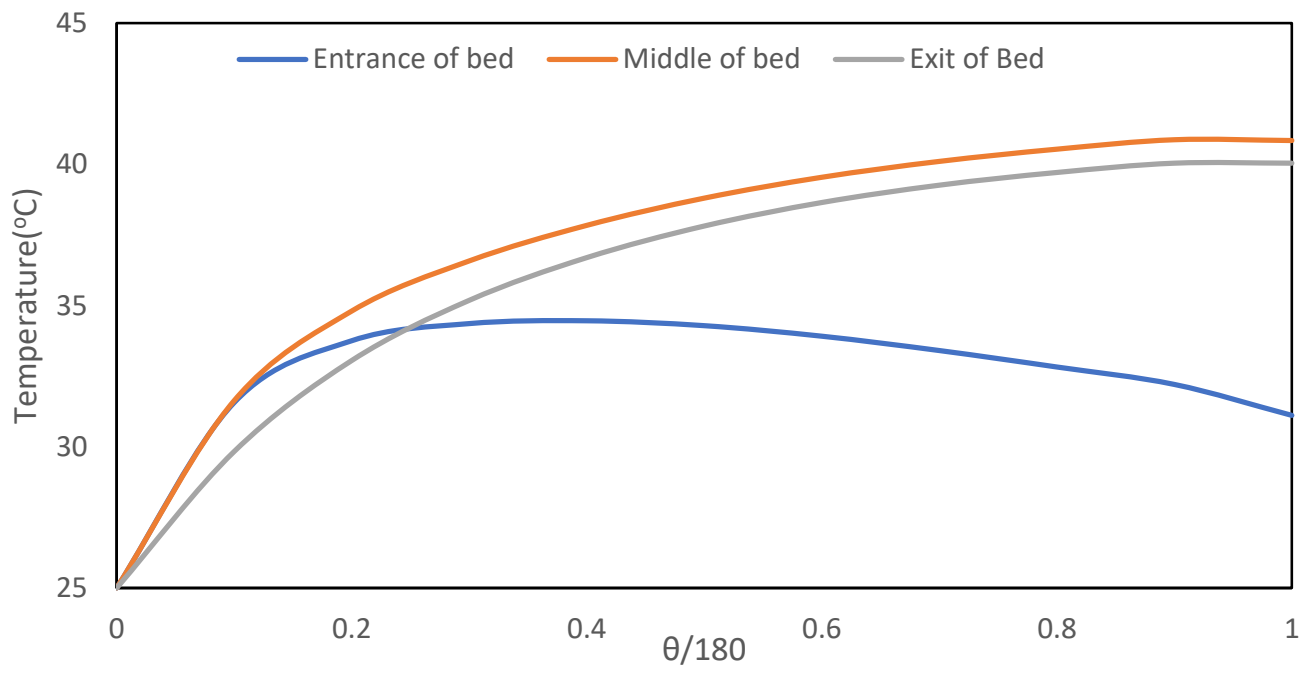

Figure 25: Temperature profile along circumferential direction at various axial positions

Figure 24 shows the solids loading at various axial locations along the circumferential direction. It is observed that the middle and exit of the bed reaches very close to the maximum loading that can be achieved under ambient conditions (i.e. similar to the entrance of the bed). Figure 25 shows the corresponding temperature profiles for various axial sections in the bed. It is interesting to note that at the (gas) entrance of the bed, the temperature goes up and then drops due to cooling since the $\mathrm{CO}_{2}$ capture rate drops as it leads to the maximum $\mathrm{CO}_{2}$ loading there. 


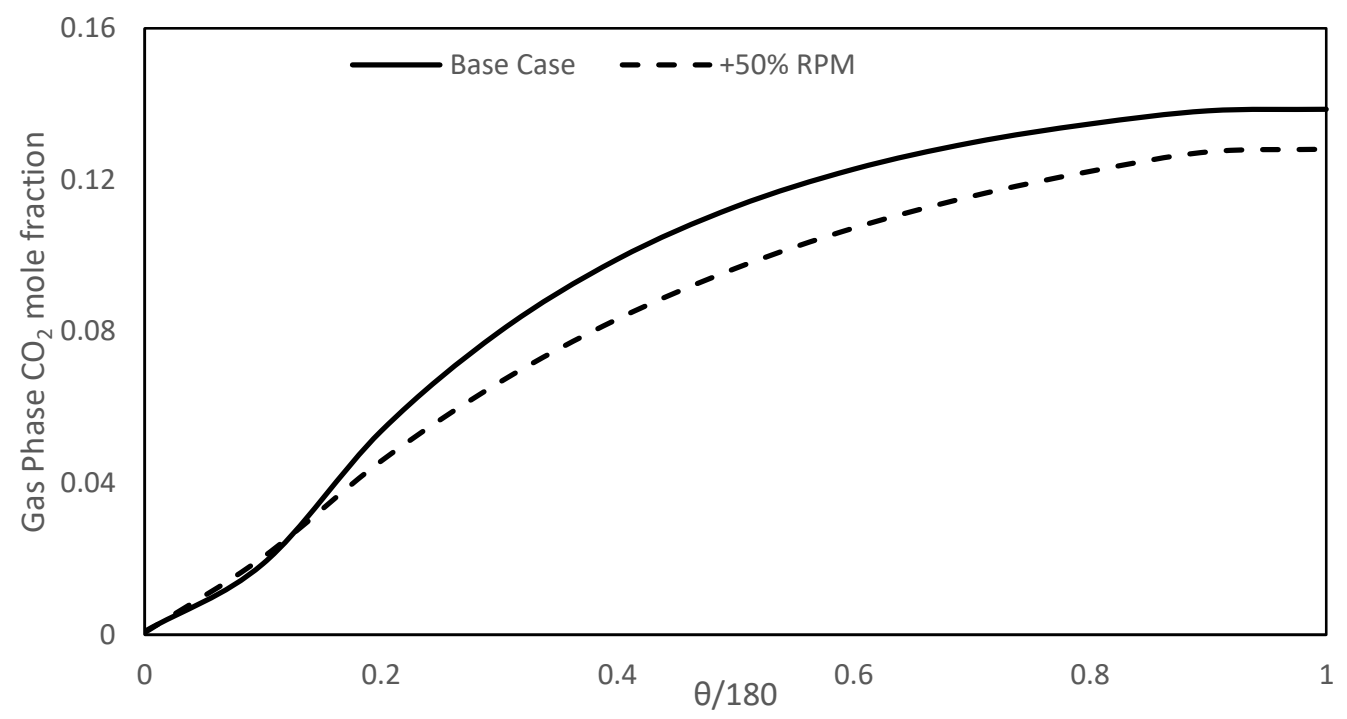

Figure 26 : Gas phase composition profile in the circumferential location for changes in rpm (Axial location: gas exit from the capture section)

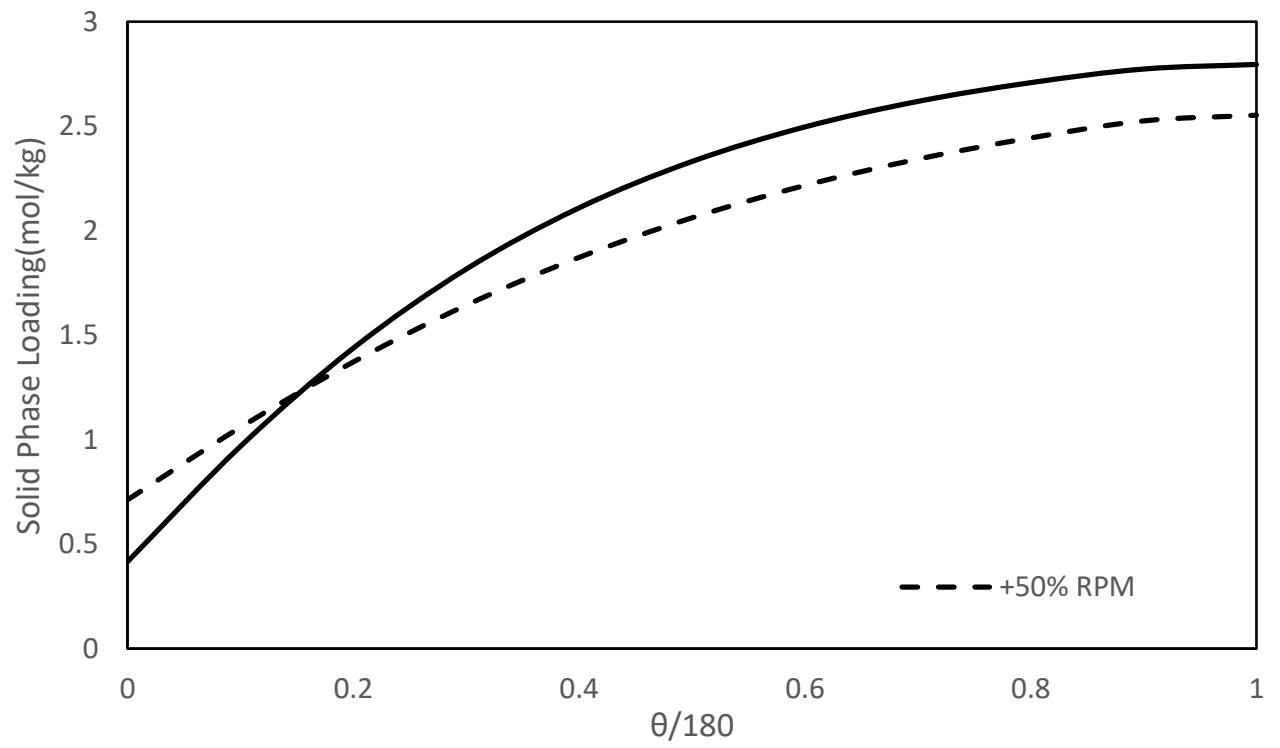

Figure 27: Solid loading profile in the circumferential location for changes in rpm (Axial location: gas exit from the capture section))

The rotary bed, powered by the driving motor, rotates at a constant speed, For the base case, $\mathrm{CO}_{2}$ capture was $90 \%$. Figure 26 shows that as the rotation speed is increased by $50 \%$ (i.e. specified to be $1.5 \mathrm{rpm}), \mathrm{CO}_{2}$ capture increases to $91.8 \%$. This is also reflected in Figure 27 where it is observed that 
the solid phase loading is lower as the bed exits the capture section. In Figure 27, it should be noted that when rpm is higher, the lean solid loading at the inlet (i.e. at $\theta=0$ ) is higher. This is because of lower residence time in the desorption section as will be explained in later sections. It should be noted that an increase in the rpm leads to higher parasitic desorption energy requirement and higher power consumption for rotation. Thus it is essential to take into consideration the impact of these variables in the desorber section.

\section{Desorber:}

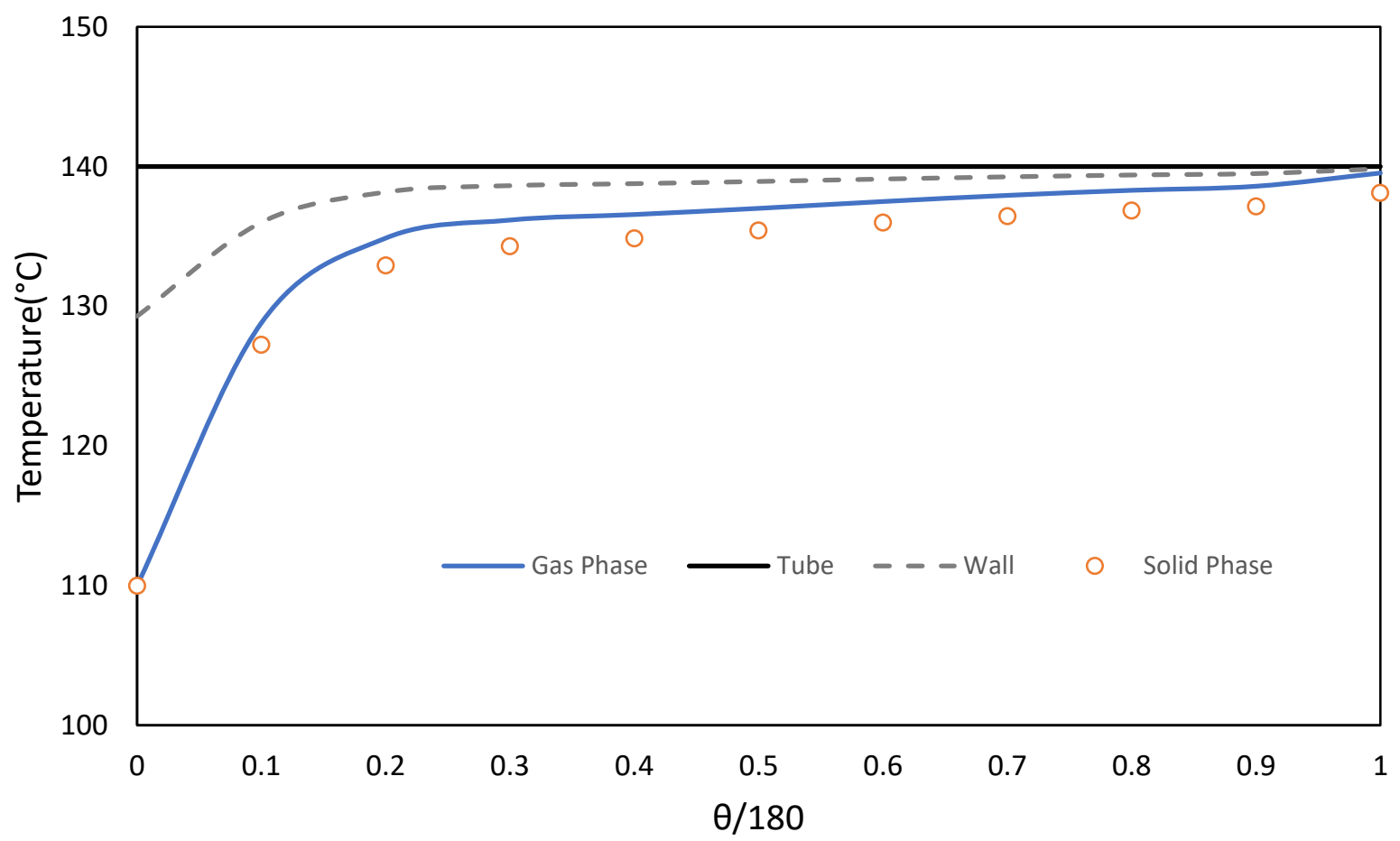

Figure 28: Temperature profile along circumferential direction (axial location: exit of bed) 


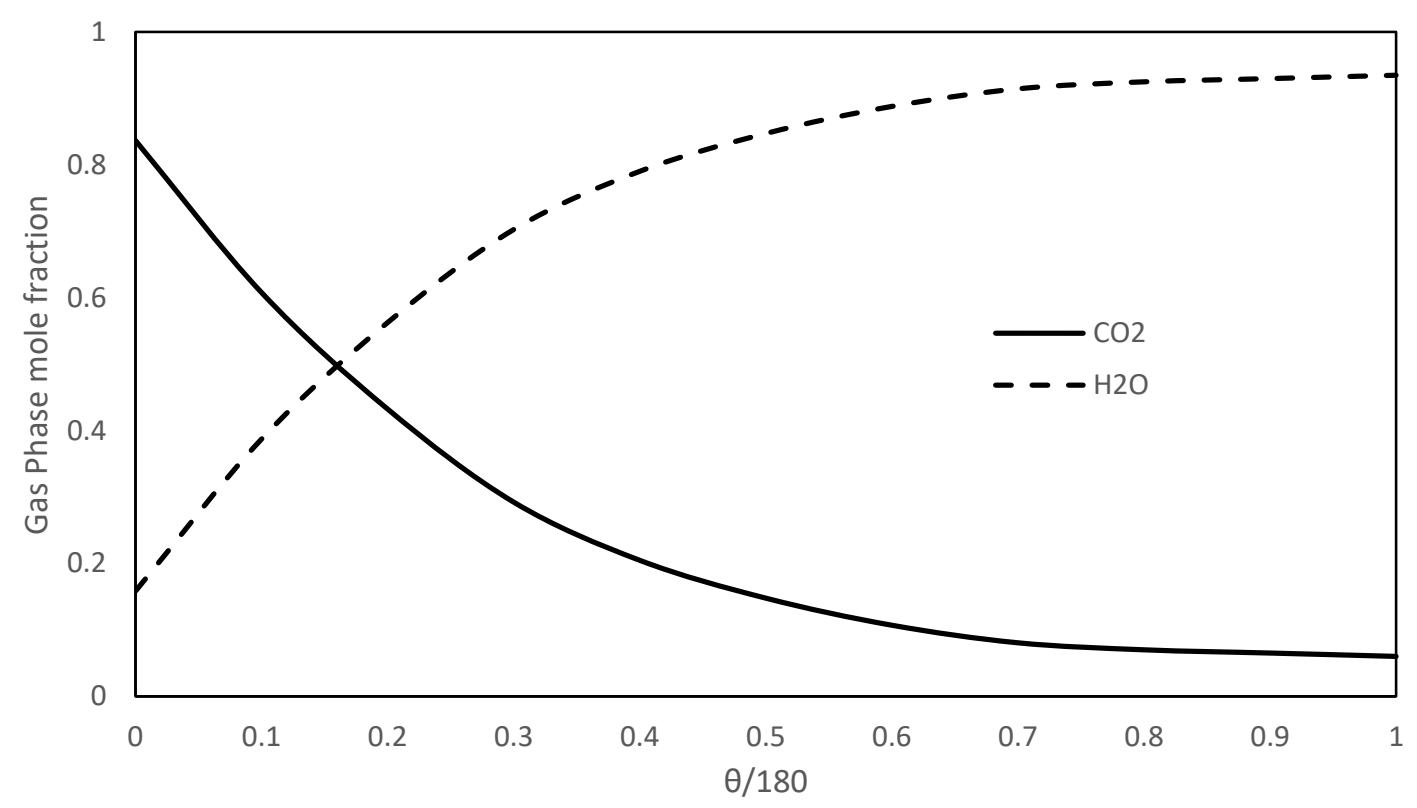

Figure 29: Gas phase composition profile along circumferential direction (axial location:exit of bed)

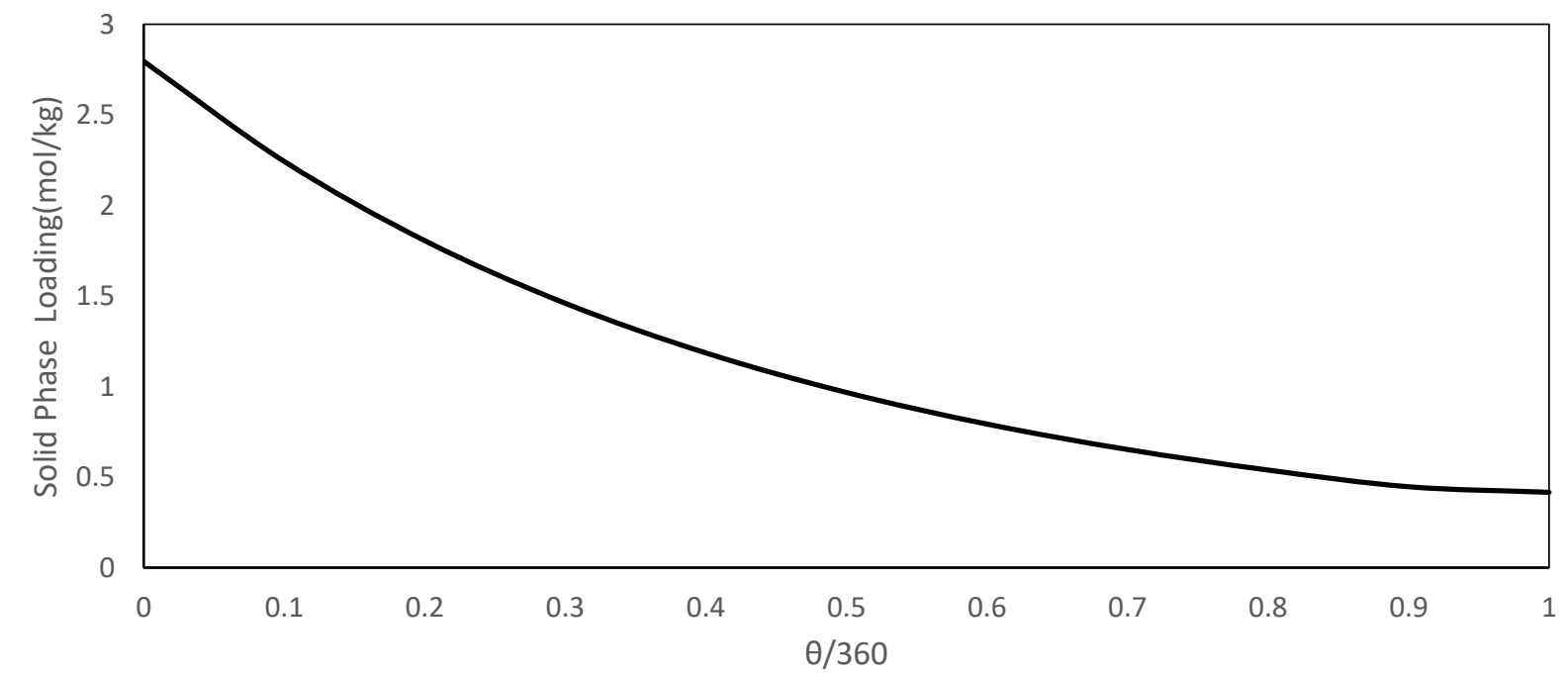

Figure 30: Solid phase total $\mathrm{CO}_{2}$ loading along circumferential direction (axial location: $\mathrm{CO}_{2}-$ rich stream exit of bed)

Figure 28 presents the temperature profiles of the desorbing section along the circumferential distance at the bottom of the bed where the $\mathrm{CO}_{2}$-rich stream exits. Figure 29 shows the corresponding gasphase composition profile while Figure 30 shows the corresponding solid phase loading 
corresponding to the axial location where the $\mathrm{CO}_{2}$-rich stream exists the bed. It is observed that reasonably low loading could be achieved at the bed outlet as the bed leaves the regeneration section.

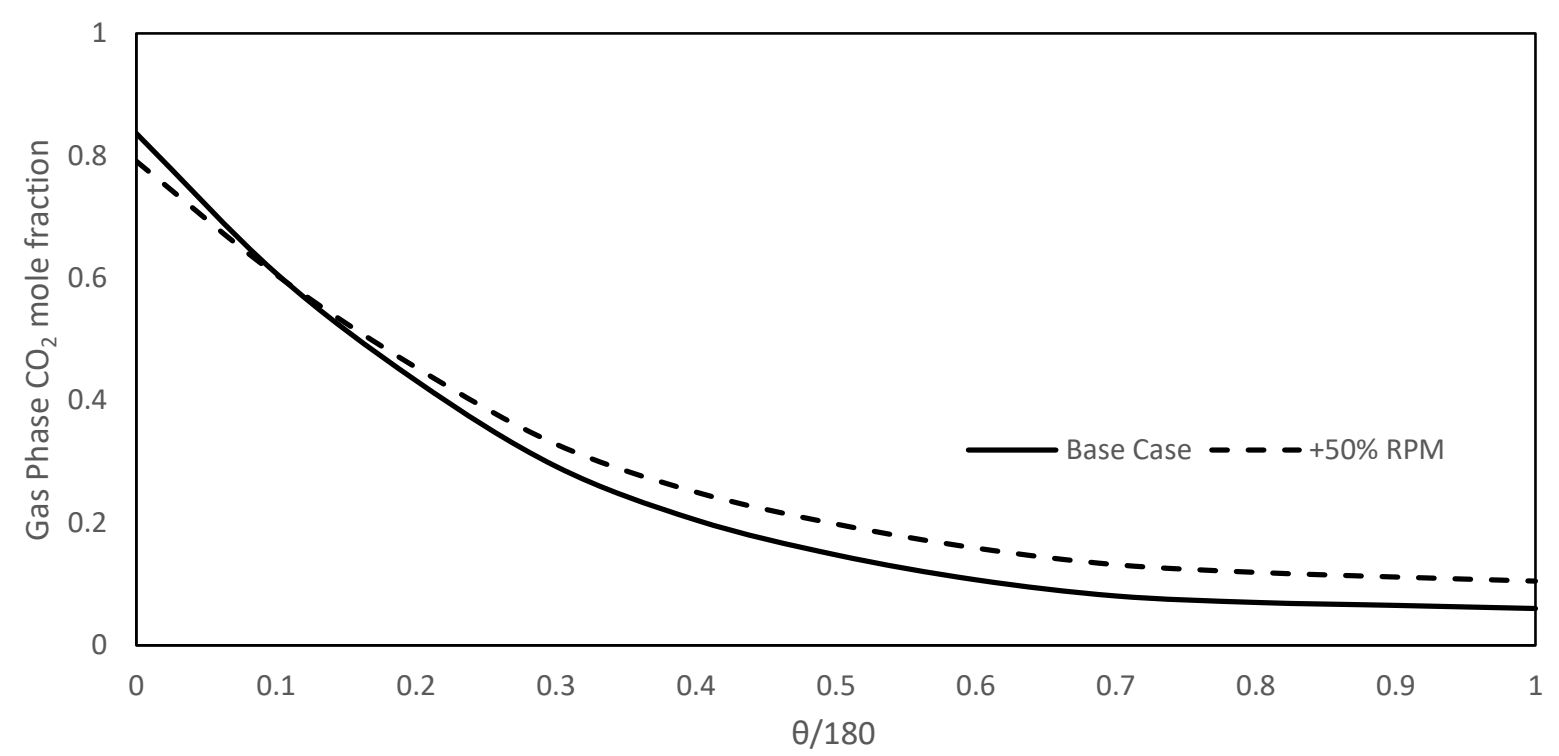

Figure 31: Gas-phase composition profile (bottom of bed) for changes in solids flow

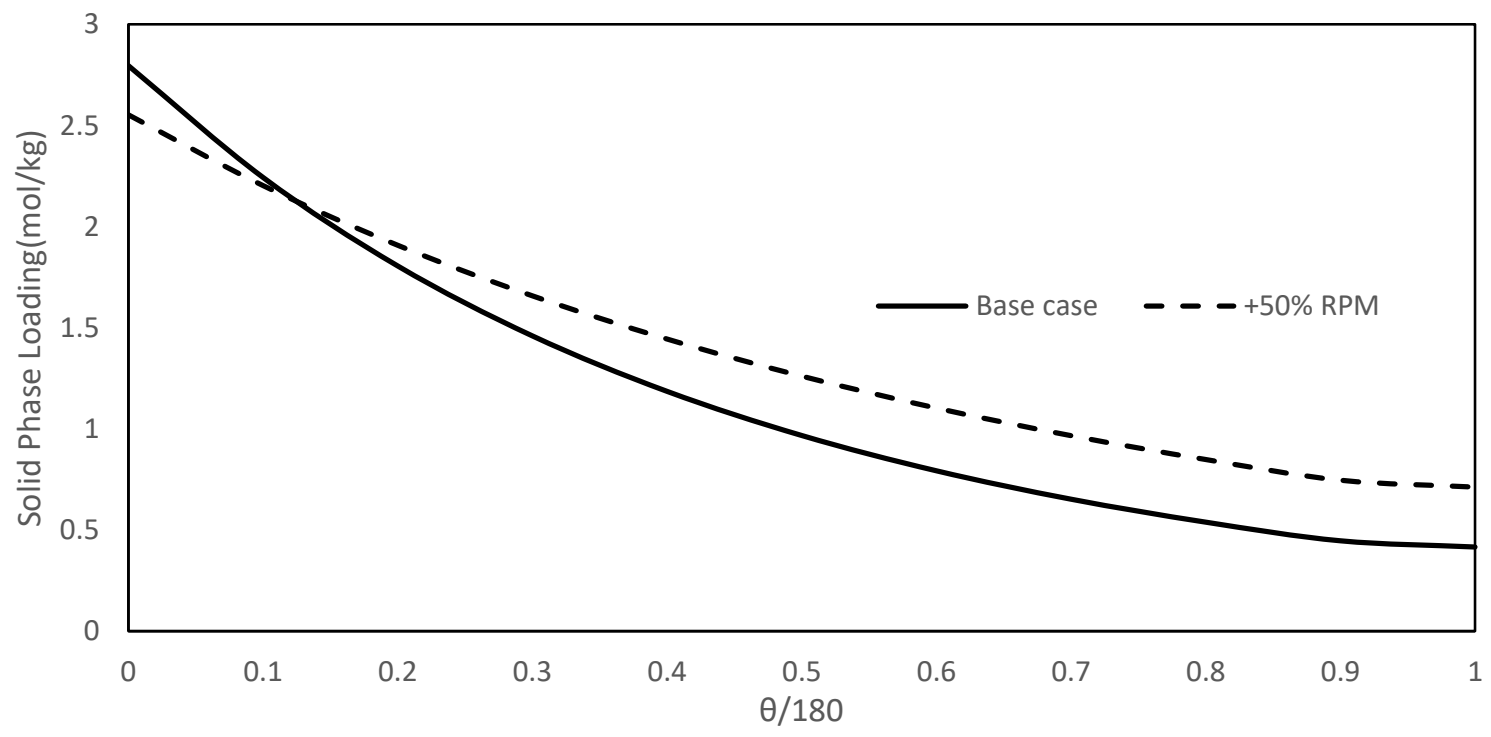

Figure 32: Solid loading profile (Bottom of bed) for changes in solid flow 
Figure 31 and 33 show the effect of increasing the rpm. It can be noted that the lower rich loading as the bed enters the regeneration section can be attributed to the lower residence time in the capture section as shown earlier under the capture section results. Figure 32 shows that even though the bed enters at a lower loading than the base case, it still leaves the regeneration section with higher loading than the base case thus adversely affecting the capture section. Figure 32 shows that the lean loading increases with the increase in the rpm and thereby affects the performance of the capture section.

\subsubsection{Cost Model}

The techno-economic analysis presented here is conducted by considering the following capital costs (Reactor with embedded heat exchanger, compressor and motor costs). The total capital cost for the RPB is made by an estimation of the components listed above in Aspen Process Economic Analyzer using Icarus database, stream information, such as temperature, pressure and flow rate, as well as the equipment type are specified in APEA, the RPB is rotated by means of an electrical motor, the capital costs for the motor is obtained using the range of rotational speed suitable, the RPB has an embedded heat exchanger which is represented in APEA as a shell and tube heat exchanger, for simplicity. The heat transfer area for the heat exchanger considered in this process is larger than the maximum heat transfer area for the heat exchanger available in APEA. Therefore, to determine the estimated cost for the RPB heat exchanger, the following equation is used:

$$
\text { Esimated cost }=\text { Base cost }\left(\frac{\text { required area }}{\text { base area }}\right)^{0.6}
$$

The total capital costs are then amortized over the projected plant life to obtain the annualized capital costs. The discount rate is assumed to be $10 \%$ and the lifespan of the reactor, compressors and motor is considered to be 10 years. The yearly operating cost (YOC) is calculated using utility prices which includes the costs for steam, cooling water, and electricity obtained from (Turton et al., 2018). The equivalent annual operating cost is calculated using Equation (34). 
$E A O C=$ Capital cost $\frac{\text { Discount rate }}{\left(1-(1+\text { Discount rate })^{- \text {Number of years })}\right.}+Y O C$

For a fair comparison, EAOC of a conventional solvent post-combustion capture system using MEA is used to compare the potential of the MOF system. Capital costs and operating costs are obtained from case 11B in the National Energy Technology Laboratory (NETL) baseline study (Fout et al., 2015).

The impact of two important operating conditions, rotational speed and bed temperature at the beginning of the capture were investigated by analyzing the sensitivity of the EAOC to changes in these variables. The study considered for this process is a subcritical pulverized coal power plant with a gross power of $644 \mathrm{MWe}$, flue gas conditions used for these studies correspond to the results presented in Case 11B in the NETL baseline study (Fout et al., 2015).

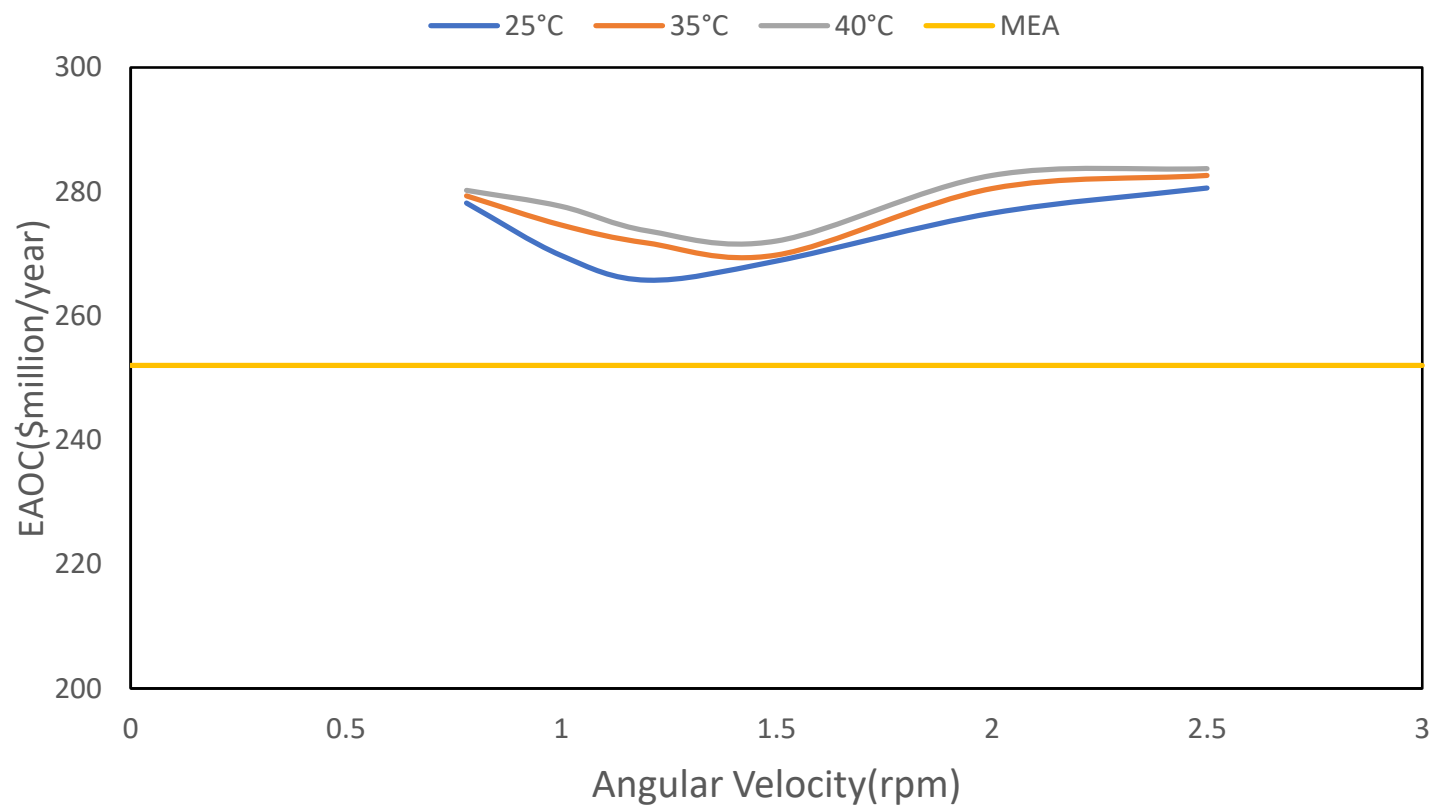

Figure 33: RPB EAOC (\$Million/year) versus rotational speed for no heat recovery 


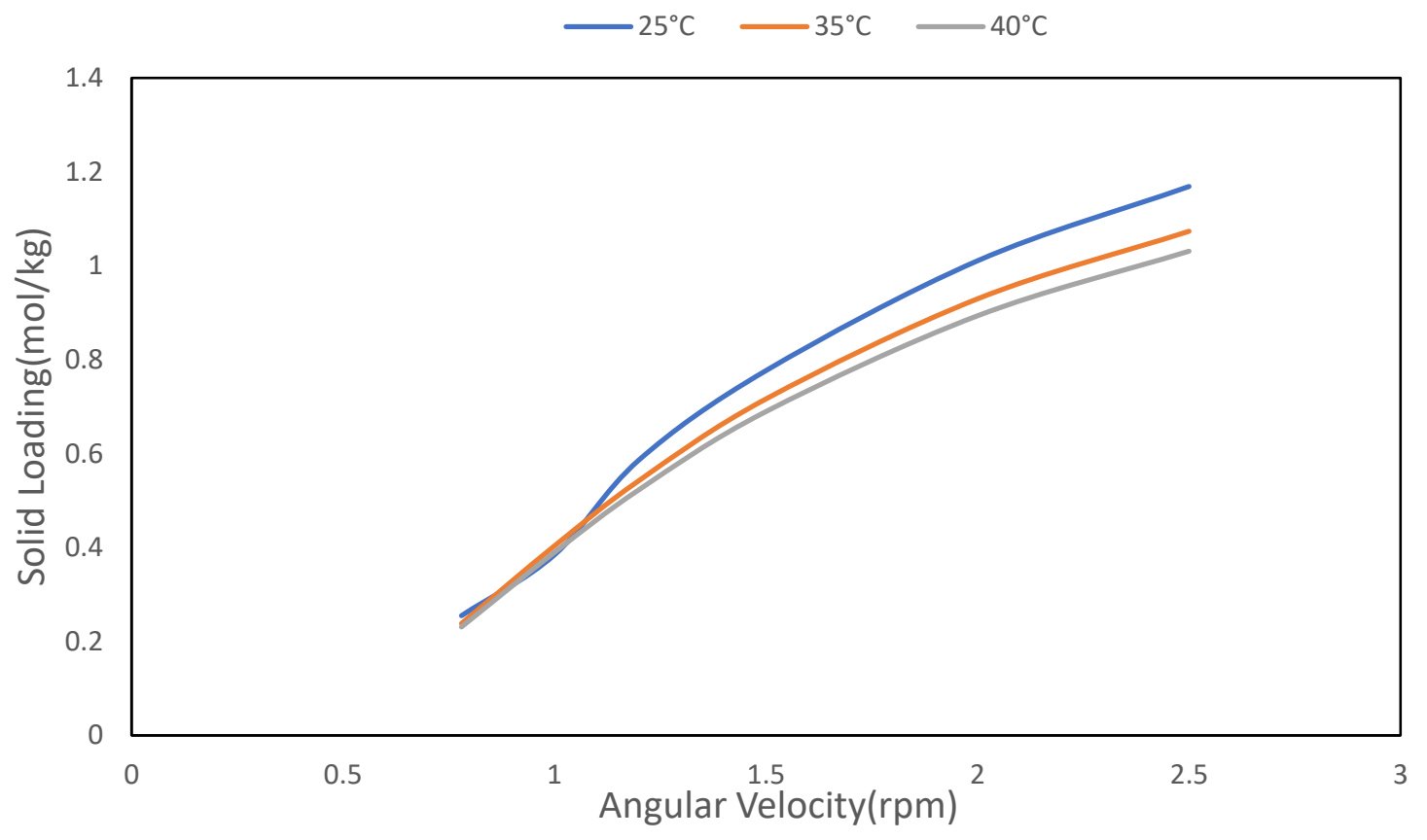

Figure 34: Lean Loading versus rotational speed for no heat recovery

Figure 33 shows the EAOC as a function of the rpm for different inlet temperatures of the solid to the capture section. No heat recovery is considered here, i.e. heat from the hot lean solids leaving the regeneration section is not utilized in heating the solids entering the desorption section. The optimum with respect to the rpm is observed for all cases. It can be seen that the EAOC in absence of any heat recovery is inferior to the MEA. As expected, Figure 35 shows that with lower rpm, the lean solids loading keeps decreasing. As the solids loading from the capture section is higher when the inlet temperature of the solid to the capture section is lower, it is observed that the lean loading from the desorption section for the corresponding case is higher when the rpm is higher.

\section{Impact of heat recovery:}

For a typical MEA system, about $85 \%$ of the sensible heat from the hot lean solvent can be recovered by incorporating heat integration. Figure 35 shows the results using $85 \%$ heat recovery if a similar extent of heat recovery as the MEA systems can be achieved. It shows that the EAOC can reduce considerably compared to the MEA system when heat recovery is considered. However, in reality, a heat integration scheme is difficult because of the rotating nature of these beds. 


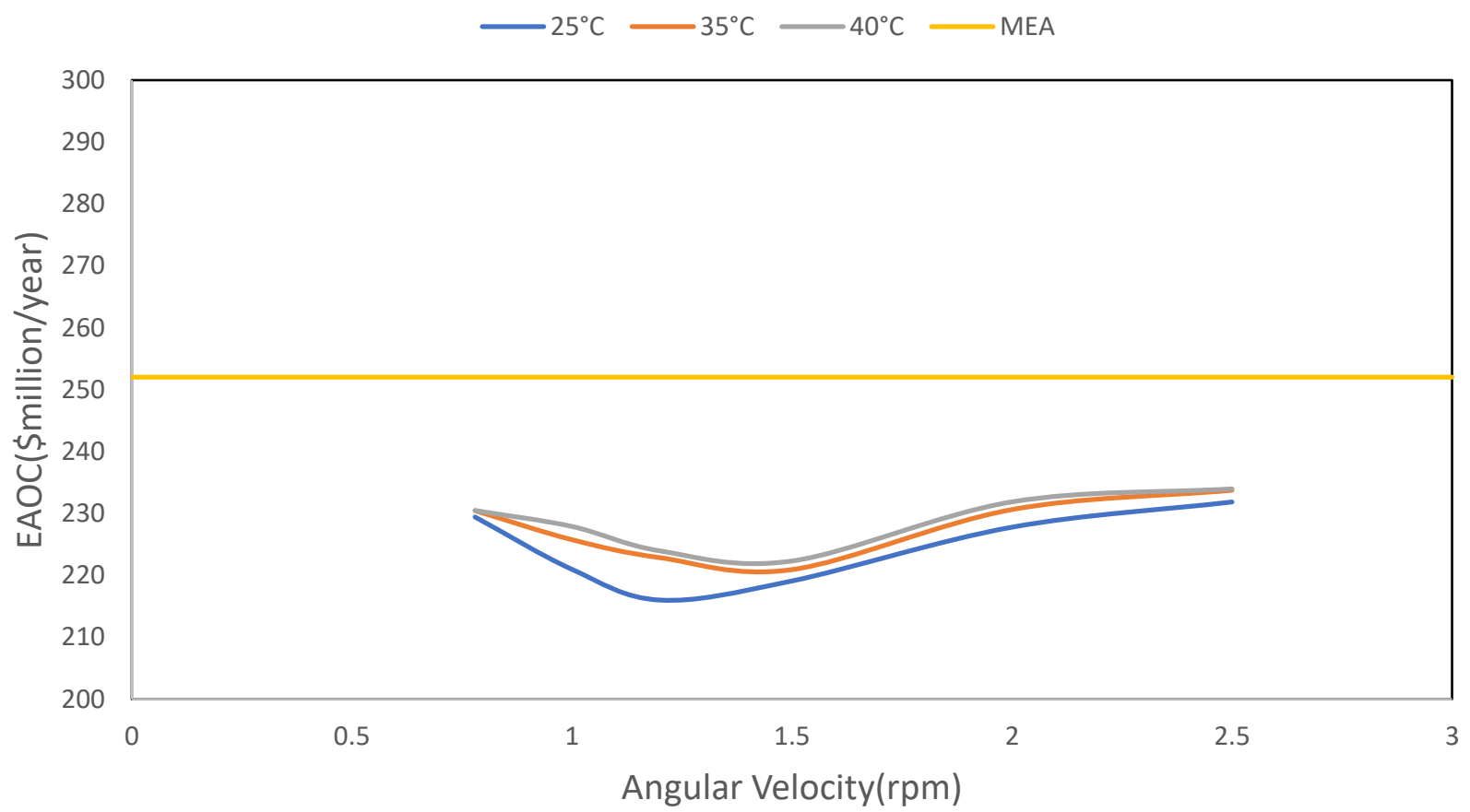

Figure 35: RPB EAOC (\$Million/year) versus rotational speed for $85 \%$ heat recovery

Table 9 shows the individual EAOC breakdown between the MEA baseline and the optimal RPB system $\left(25^{\circ} \mathrm{C}\right)$ with no heat recovery and $85 \%$ heat recovery.

Table 9: Optimal EAOC (\$Million/year) case with different heat recoveries

\begin{tabular}{|c|c|c|c|}
\hline & MEA & No Heat Recovery & $85 \%$ Heat Recovery \\
\hline Amortized Capital & 60.9 & 71.7 & 71.7 \\
\hline Reactor & - & 50.5 & 50.5 \\
\hline Compressor & - & 11.9 & 11.9 \\
\hline Motor & - & 9.3 & 9.3 \\
\hline YOC & 191.2 & 194.01 & 144.31 \\
\hline Steam & 191.2 & 173.1 & 123.4 \\
\hline Electricity & - & 18.4 & 18.4 \\
\hline Cooling Water & - & 2.51 & 2.51 \\
\hline $\begin{array}{c}\text { Total EAOC } \\
\text { (\$Million/year) }\end{array}$ & 252.0 & 265.71 & 216.01 \\
\hline
\end{tabular}


The results show that the optimal capture costs for the RPB without heat recovery is $\$ 13$ million/year higher than the capture cost of the conventional MEA absorption system. This is due to the higher capital costs and regeneration duty required. For $85 \%$ heat recovery cases, the EAOC decreases by about $\$ 49$ million/year when compared to the base process, and \$36 million/year when compared to the MEA system. These results demonstrate the effect of heat recovery in lowering the EAOC than that for the MEA system.

\section{MOF Particle cost:}

The cost of the MOF adsorbents is an important factor to be considered when costing of the rotary packed bed is made. Although little information is known on the present cost of the MOF being developed by LBNL, an estimate was made from literature using similar adsorbents like zeolite and Bare MOF's (Liu et al., 2012; Su \& Lu, 2012). In this work, a 2 year lifespan for the for MOF particles is used (full replacement every 2 years) and the total capital cost is then annuitized using Eqn 34. From the figure below, It can be seen that below about $\$ 15 / \mathrm{kg}$ cost, the total EAOC of the RPB is lower than the MEA using the same extent of heat recovery as MEA systems (i.e. 85\%).

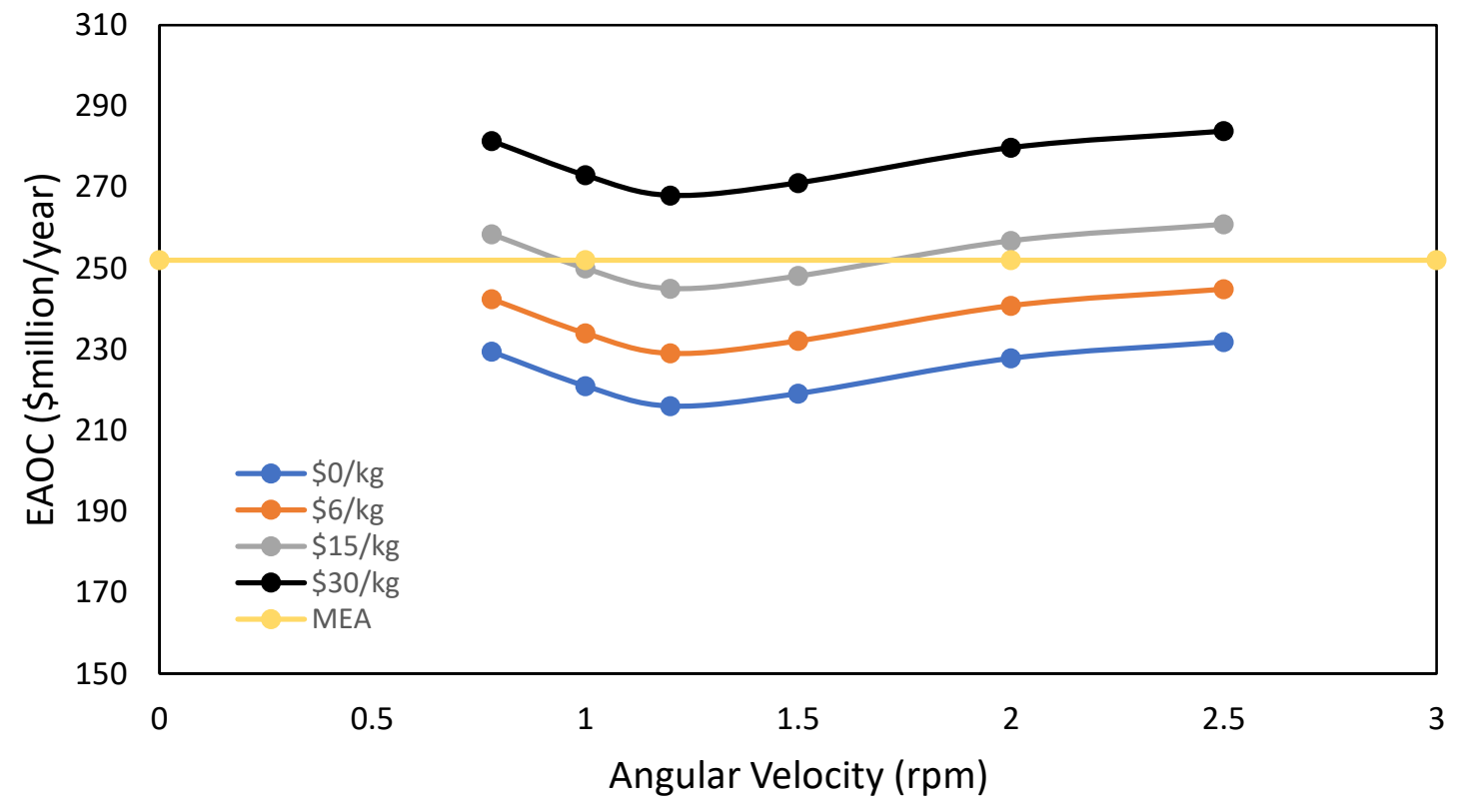

Figure 36: RPB EAOC (\$Million/year) for various MOF cost estimates 


\section{Capital Cost Uncertainty:}

For novel systems like RPB, there is a lack of information in the current literature. Because of this, high uncertainty can exist when computing capital costs. Figure 37 shows the effect of the variation in uncertainty on EAOC. The operating costs are kept constant and the impact of a +/-50\% variation in the capital cost was evaluated. For simplicity, the cost of the MOF is assumed to be zero. As seen in Figure 37, +50\% uncertainty in the capital cost brings the EAOC for the RPB at $\$ 49$ million/year above the EAOC of the MEA system. A $-50 \%$ uncertainty in the capital cost can result in an EAOC that is $\$ 48$ million/year lower than the MEA-based capture. The analysis shows that with a $-50 \%$ uncertainty, the RPB can be economically viable.

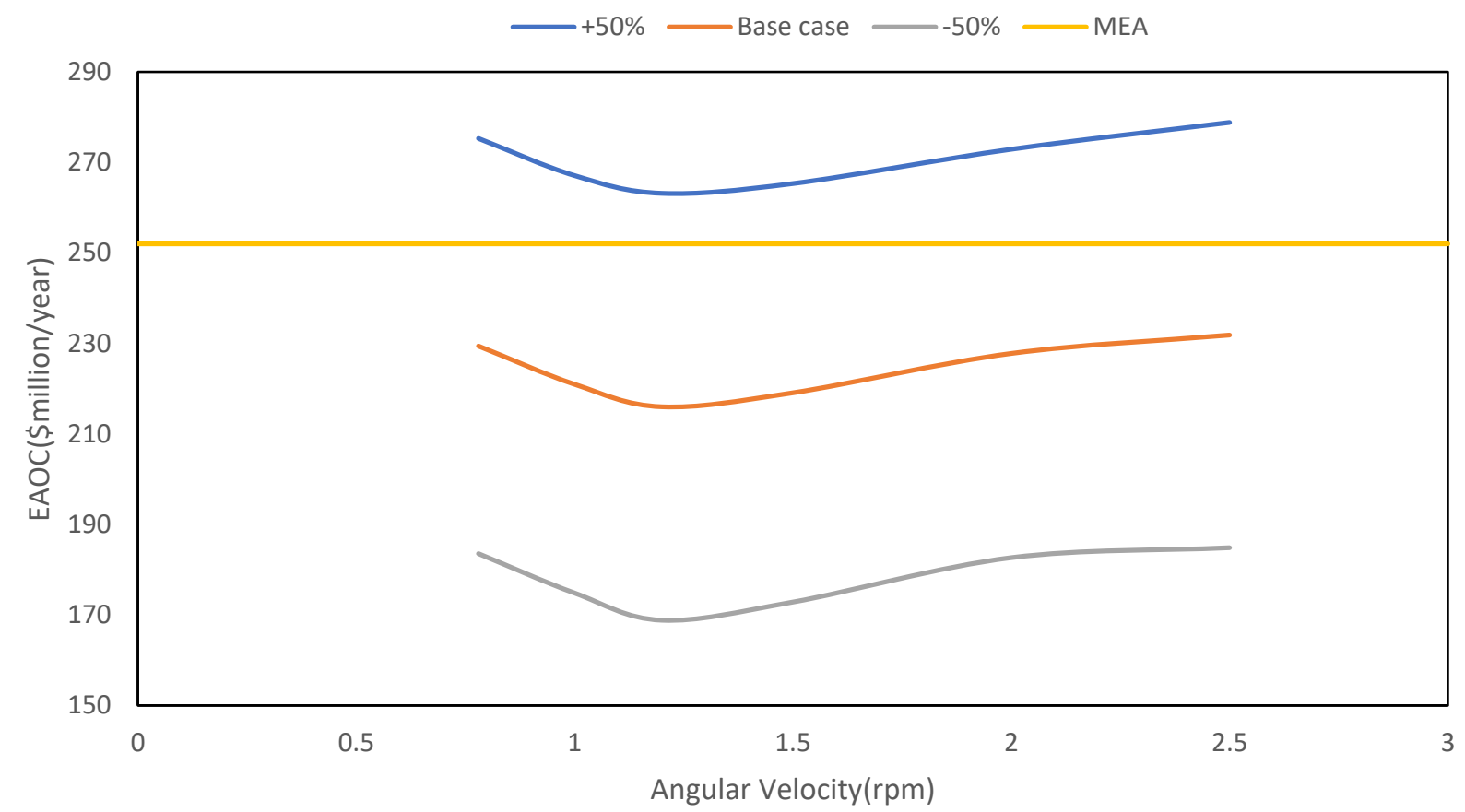

Figure 37: Capital cost uncertainty effect on RPB EAOC(\$Million/year) 


\section{Conclusions}

Two RPB models have been developed- a model of the APH and a model of the reactive RPB for $\mathrm{CO}_{2}$ capture using a functionalized MOF. A numerical model that simulates the transient heat transfer problem in an APH has been developed and validated. The model is 2-D and resolves the axial (flow) direction and the circumferential direction. A sensitivity analysis is carried out to evaluate the sensitivity to key operating conditions like rotational speed, inlet flow rate, inlet temperatures, etc. on the thermal performance of the APH. The study can be useful for analysis of APH (and therefore power plant) performance under design and off-design conditions.

The 2-d non-isothermal, steady-state model of the reactive RPB resolves the axial (gas flow) direction and the circumferential (solid flow) direction. The effect of key process variables like the rotational speed is studied and the results are compared with the base case study. A techno-economic analysis is performed for different initial bed temperatures using a costing model and the results are compared is to a conventional MEA system. The results show that the lowest EAOC for the RPB is approximately $5 \%$ higher than the EAOC for a traditional MEA system when no heat recovery is considered. When a similar amount of heat recovery $(85 \%)$ as in the conventional MEA system is considered, the EAOC of RPB becomes approximately $14 \%$ lower than the MEA system. This shows that heat recovery is important in reducing the energy penalty of the RPB. Also, the impact of $+/-50 \%$ uncertainty in the capital cost for the $85 \%$ heat recovery is considered. The $+50 \%$ uncertainty in capital cost results in 4\% higher EAOC than the MEA system. However, for a $-50 \%$ uncertainty, the EAOC is $33 \%$ lower compared to the MEA system. In summary, the RPB for $\mathrm{CO}_{2}$ capture using a $\mathrm{RPB}$ is a promising prospect for the functionalized MOF if heat recovery can be achieved and with some reduction in the capital cost. 


\section{Future Recommendations}

In the course of this study, the primary focus was limited to developing two numerical models to predict the distributions of temperature and composition in rotary packed beds. A lot of factors were considered in this research; however, there are still some other issues that need to be investigated. The following are recommended for future works.

- The developed APH model should be integrated in a plant-wide dynamic model of a coalfired power plant for realistic studies. It is also desired that the model be validated with more experiemental data under load-following condition of the power plnat.

- Thermal expansions and contractions in large air preheters can lead to changes in gap sizes causing variability in leakages. To estimate the leakage flow more accurately than what was done in this research, more information on the geometry and size of orifices/seals of the APH along with the representative models for describing their expansion/contraction is required. While an accurate estimation of the leakage flow can still be challenging, that model can be used in conjunction with the plant-wide model for investigating the impact of load-following operation and startup/shut-down on the APH performance.

- Since a detailed temperature distribution of the APH can be obtained by using the model developed in this work, impacts of various operating conditions on the overall efficiency of the APH can be evalauted including the numerical analysis of ammonium bisulfate deposition and corrosion of the APH that can reduce the operation and maintenance cost of the Ljungstrom-type APH.

- For the RPB model developed for $\mathrm{CO}_{2}$ capture, the current model should be upgraded to a dynamic model. When additional details about the mass transfer and heat transfer resistances of the MOF are available, the current model can be updated by incorporating those. 


\section{Notation}

\subsection{RPB for Non-Reactive Systems(Ljungstrom APH)}

\begin{tabular}{|c|c|}
\hline$A_{c r}$ & Cross sectional area perpendicular to rotation axis \\
\hline$A_{s p}$ & Specific surface area \\
\hline$A_{k}$ & Total area for longitudinal conduction \\
\hline$A$ & Heat transfer Area \\
\hline$c_{p}$ & Specific heat capacity \\
\hline$d_{h}$ & Hydraulic diameter \\
\hline$f$ & Frictional Factor \\
\hline$h$ & Heat transfer coefficient \\
\hline$k$ & Thermal conductivity \\
\hline$L$ & Matrix length for gas flow \\
\hline$M$ & Matrix mass \\
\hline$m$ & Mass flow Rate \\
\hline $\mathrm{Nu}$ & Nusselt Number \\
\hline $\operatorname{Pr}$ & Prandtl Number \\
\hline$p$ & Pressure \\
\hline $\operatorname{Re}$ & Reynold Number \\
\hline$s p$ & Flow split of Matrix sector \\
\hline $\bar{T}$ & Temperature \\
\hline$T$ & Dimensionless Temperature \\
\hline$T_{\text {hin }}$ & Inlet Temperature of flue gas \\
\hline$T_{\text {cin }}$ & Inlet Temperature of air \\
\hline$V$ & Total Volume of matrix \\
\hline$v_{z}$ & Interstitial Velocity of Fluid \\
\hline $\bar{z}$ & Axial co-ordinate \\
\hline$z$ & Dimensionless Axial co-ordinate \\
\hline
\end{tabular}




$\begin{array}{ll}\text { Greek Variables } \\ \bar{\theta} & \text { Circumferential position } \\ \theta & \text { Dimensionless Circumferential position } \\ \omega & \text { angular velocity } \\ \varepsilon & \text { porosity } \\ \mu & \text { viscosity } \\ \rho & \text { Density }\end{array}$

$\begin{array}{ll}\text { Subscripts } & \\ \mathrm{h} & \text { hot side } \\ \mathrm{m} & \text { Matrix } \\ \mathrm{c} & \text { cold side } \\ c_{1} & \text { Primary Air Sector } \\ c_{2} & \text { Secondary Air Sector } \\ \mathrm{f} & \text { fluid } \\ m c & \text { Air sector of matrix } \\ m h & \text { Flue gas sector of matrix }\end{array}$

\subsection{RPB for Reactive Systems}

$\begin{array}{ll}a & \text { external surface area per unit volume, } \mathrm{m}^{2} / \mathrm{m}^{3} \\ C & \text { mole concentration, } \mathrm{mol} / \mathrm{m} 3 \\ c_{p} & \text { Heat capacity } \\ D_{k, i} & \text { Knudsen diffusivity }\left(\mathrm{m}^{2} / \mathrm{s}\right) \\ D_{m, i} & \text { Molecular diffusivity }\left(\mathrm{m}^{2} / \mathrm{s}\right) \\ d_{p} & \text { Diameter of particle } \\ D_{z} & \text { Axial dispersion coefficient }\left(\mathrm{m}^{2} / \mathrm{s}\right) \\ h_{g s} & \text { Film heat transfer coefficient between the gas and the adsorbent } \\ \Delta H_{r x n} & \text { heat of adsorption of species i }(\mathrm{kJ} / \text { mol }) \\ k_{o c} & \text { Overall mass transfer coefficient }(\text { chemisorption })(\mathrm{m} / \mathrm{s})\end{array}$




$\begin{array}{ll}k_{o p} & \text { Overall mass transfer coefficient(physisorption })(\mathrm{m} / \mathrm{s}) \\ k_{f} & \text { fluid film mass transfer coefficient }(\mathrm{m} / \mathrm{s}), \\ \mathrm{L} & \text { Reactor height, } \mathrm{m} \\ M_{i} & \text { molecular weight of component } \mathrm{i}(\mathrm{kg} / \mathrm{kmol}) \\ P & \text { Pressure } \\ q_{i} & \text { Amount of Adsorbent Transferred in } \mathrm{mol} / \mathrm{kg} \\ r_{\text {pore }} & \text { Particle macropore radius, } \mathrm{m} \\ \mathrm{Re} & \text { Reynolds number } \\ \mathrm{Sh} & \text { Sherwood number } \\ \mathrm{Sc} & \text { Schmidt number } \\ T & \text { Temperature } \\ t & \text { Time } \\ v_{g} & \text { superficial velocity, } \mathrm{m} / \mathrm{s} \\ C_{S, i} & \text { Particle loading of species } \mathrm{i},\left(\mathrm{kmol} / \mathrm{m}^{3}\right) \\ C_{s, i}{ }^{*} & \text { Equilibrium loading of species i }\left(\mathrm{kmol} / \mathrm{m}^{3}\right), \\ \theta & \text { Angular co-ordinate } \\ z & \text { Axial co-ordinate } \\ \omega & \text { Angular velocity } \\ \rho & \text { Density } \\ \mu & \text { Dynamic viscosity } \\ \varepsilon & \text { Porosity } \\ \tau & \text { particle tortuosity }\end{array}$

\section{Subscripts}

$\begin{array}{ll}g & \text { gas } \\ b & \text { bed } \\ p & \text { particle } \\ \mathrm{t} & \text { tube } \\ r & \text { Radial position } \\ i & \text { Specific components }\end{array}$


$S$

in

$\mathrm{X}$

chem

phys solid

inlet

Heat exchanger

chemisorption

physisorption 


\section{Appendix}

\subsection{Appendix A}

Model Equations for Non - Reactive Systems

Taking a balance across the control volume as shown in Figure 4, the energy equation for the fluid can be written as

The energy equation for the fluid can be written as

$$
\begin{aligned}
& \rho_{c} c_{p, c} \varepsilon \frac{\partial \bar{T}_{c}}{d t}+\rho_{c} c_{p, c} \varepsilon v_{z} \frac{\partial \bar{T}_{c}}{d \bar{z}}=h A_{s p}\left(\bar{T}_{c}-\bar{T}_{m c}\right) \\
& \rho_{c} c_{p, c} \varepsilon \frac{\partial \bar{T}_{c}}{d t}+\rho_{h} c_{p, h} \varepsilon v_{z} \frac{\partial \bar{T}_{h}}{d \bar{z}}=h A_{s p}\left(\bar{T}_{m h}-\bar{T}_{h}\right) \\
& (1-\varepsilon) \rho_{m} c_{p, m} \frac{\partial \bar{T}_{m}}{\partial t}+(1-\varepsilon) \rho_{m} c_{p, m} \omega \frac{\partial \bar{T}_{m}}{\partial \bar{\theta}}=h A_{s p}\left(\bar{T}_{f}-\bar{T}_{m}\right)+k_{m} \frac{\partial^{2} \bar{T}_{m}}{\partial z^{2}}
\end{aligned}
$$

Introducing the following dimensionless independent variables

$$
\begin{aligned}
& z=\frac{\bar{Z}}{L} \\
& \theta=\frac{\bar{\theta}}{2 \pi} \\
& T=\frac{\bar{T}-T_{c i n}}{T_{\text {hin }}-T_{\text {cin }}}
\end{aligned}
$$

With these dimensionless variables, Eqs. (1), (2) and (3) are as follows:

$$
\rho_{c} c_{p, c} \varepsilon \frac{\partial \bar{T}_{c}}{d t}+\frac{\rho_{c} c_{p, c} \varepsilon v_{z}}{L} \frac{\partial T_{c}}{d z}=h A_{s p}\left(T_{c}-T_{m c}\right)
$$




$$
\begin{aligned}
& \rho_{c} c_{p, c} \varepsilon \frac{\partial \bar{T}_{c}}{d t}+\frac{\rho_{h} c_{p, h} \varepsilon v_{z}}{L} \frac{\partial T_{h}}{d \bar{z}}=h A_{s p}\left(T_{m h}-T_{h}\right) \\
& (1-\varepsilon) \rho_{m} c_{p, m} \frac{\partial \bar{T}_{m}}{\partial \bar{t}}+(1-\varepsilon) \frac{\rho_{m} c_{p, m} \omega}{2 \pi} \frac{\partial T_{m}}{\partial \theta}=h A_{s p}\left(T_{f}-T_{m}\right)+\frac{k_{m}}{L^{2}} \frac{\partial^{2} T_{m}}{\partial z^{2}}
\end{aligned}
$$

\section{Area Correlations for APH}

The specific surface area $A_{s p}$ is defined as the ratio of the surface area to the bed volume, the specific surface area available for heat transfer is:

$$
A_{s p}=\frac{A}{V}
$$

The total heat transfer surface area A of the APH is represented as:

$$
A=A_{h}+A_{c}
$$

Also, the hot side and cold side heat transfer area of the exchanger is correlated with each other by a dimensionless term defined as split given by 'sp' below:

$$
s p=\frac{A_{h}}{A_{c}}
$$

The total volume of the matrix bed $V$ is:

$$
V=A_{c r} * L
$$

where $A_{c r}$ is the free flow cross-section area of the matrix bed and $\mathrm{L}$ is the length of the bed in the flow direction.

Substituting these terms appropriately, we obtain

$$
\begin{aligned}
& \rho_{c} c_{p, c} \varepsilon A_{c r} L \frac{\partial \bar{T}_{c}}{d t}+\frac{\rho_{c} c_{p, c} \varepsilon A_{c r} L v_{z}}{L} \frac{\partial T_{c}}{d z}=h A\left(T_{c}-T_{m c}\right) \\
& \rho_{c} c_{p, c} \varepsilon A_{c r} L \frac{\partial \bar{T}_{c}}{d t}+\frac{\rho_{h} c_{p, h} \varepsilon A_{c r} L v_{z}}{L} \frac{\partial T_{h}}{d \bar{z}}=h A\left(T_{m h}-T_{h}\right) \\
& (1-\varepsilon) \rho_{m} c_{p, m} A_{c r} L \frac{\partial \bar{T}_{m}}{\partial \bar{t}}+(1-\varepsilon) \frac{\rho_{m} c_{p, m} A_{c r} L \omega}{2 \pi} \frac{\partial T_{m}}{\partial \theta}=h A\left(T_{f}-T_{m}\right)+\frac{k_{m} A_{k} L}{L^{2}} \frac{\partial^{2} T_{m}}{\partial z^{2}}
\end{aligned}
$$


The mass flow rate of the fluids and the matrix mass is defined as

$m_{f}=\rho_{f} \varepsilon v_{z} A_{c r}$

$M_{m}=\rho_{m} A_{c r} L(1-\varepsilon)$

Substituting these terms in eq's (11) - (13), we obtain

$$
\begin{aligned}
& m_{c} c_{p, c} \frac{L}{v_{x}} \frac{\partial T_{c}}{d t}+m_{c} c_{p, c} \frac{\partial T_{c}}{d z}=h A\left(T_{c}-T_{m c}\right) \\
& m_{h} c_{p, h} \frac{L}{v_{x}} \frac{\partial T_{h}}{d t}+m_{h} c_{p, h} \frac{\partial T_{h}}{d z}=h A\left(T_{m h}-T_{h}\right) \\
& M_{m} c_{p, m} \frac{\partial T_{m}}{\partial t}+\frac{M_{m} c_{p, m} \omega}{2 \pi} \frac{\partial T_{m}}{\partial \theta}=h A\left(T_{f}-T_{m}\right)+\frac{k_{m} A_{k}}{L} \frac{\partial^{2} T_{m}}{\partial z^{2}}
\end{aligned}
$$

Conversion from rpm to $\mathrm{rad} / \mathrm{s}$

$1 \mathrm{rad} / \mathrm{s}=2 \pi / 60 \mathrm{rpm}$

$$
M_{m} c_{p, m} \frac{\partial T_{m}}{\partial t}+\frac{M_{m} c_{p, m} \omega}{60} \frac{\partial T_{m}}{\partial \theta}=h A\left(T_{f}-T_{m}\right)+\frac{k_{m} A_{k}}{L} \frac{\partial^{2} T_{m}}{\partial z^{2}}
$$

Where

$A_{k}=A_{c r}(1-\varepsilon)$

The average outlet temperature of the fluid is given by:

$$
T_{f, a v g}=\int_{\theta_{0}}^{\theta_{n}} \frac{\dot{\mathrm{m}} c_{p, f} T_{f} \partial \theta}{\dot{\mathrm{m}} c_{p, f}}
$$

The geometry-dependent flow properties are evaluated using Eqs. (18-22). The heat transfer coefficients of the hot and cold sides are computed using Eq. (18). Heat transfer and friction factor data for the matrix surfaces in rotary APHs are presented as experimental correlations in terms of Reynolds number. There are various correlations in literature for different bed configurations using the experimental data. The Nusselt number is calculated for computing the heat transfer coefficient

$$
N u=A R e^{0.69} \operatorname{Pr}^{0.4}
$$




$$
N u=\frac{h d_{h}}{k_{f}}
$$

The Reynold number and Prandtl number are calculated as follows:

$$
\begin{gathered}
R e=\frac{m_{f} d_{h}}{A_{c r} \mu_{f}} \\
\operatorname{Pr}=\frac{c_{p, f} \mu_{f}}{k_{f}}
\end{gathered}
$$

The pressure loss of the fluid as it passes through the matrix is mainly caused by the flow acceleration and core friction. It is calculated from the equaion below:

$$
\Delta p=\frac{\rho_{f} f L \varepsilon^{2} v_{z}{ }^{2}}{2 d_{h}}
$$

$f$ is the fanning friction factor associated with the matrix, which is a function of Reynold's number. For laminar flow, the following correlation was used.

$$
f=B R e^{-C}
$$

The model results are compared with the experimental data reported in ( Wang et al., 2019) where a tri-sector APH commonly used in coal-fired power plants was examined.

\section{PARAMETER ESTIMATION}

To validate the model, parameter A corresponds to the convective heat transfer coefficient (Eq. 52) and the parameters $\mathrm{B}$ and $\mathrm{C}$ corresponding to the frictional factor correlation are estimated. Design parameters and operating conditions of the industrial APH are presented in Table 4. Estimated parameters are presented in the table below. Aspen Custom Modeler is used to estimate the parameters by using the inbuilt 'Estimation' option.

Table 10: Estimated Parameters

\begin{tabular}{|c|c|c|}
\hline Parameter & Value & Estimate \\
\hline$A$ & 0.083 & 0.042 \\
\hline$B$ & 2.64 & 2.96 \\
\hline $\mathrm{C}$ & 0.376 & 0.3 \\
\hline
\end{tabular}




\subsection{Appendix B}

Model Equations for Reactive Systems

In adsorption processes, the adsorbent is in contact with a fluid in a packed bed. The equation for the RPB was adapted from the conventional fixed adsorption bed model(Ruthven, 1984).

\section{Bulk Gas Phase Material Balance:}

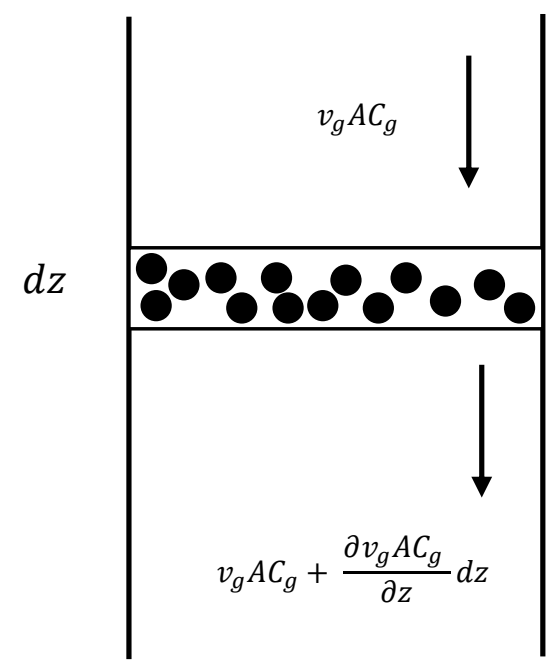

Figure 38: Conservation of adsorbate flowing through an increment $\mathrm{dz}$ of a rotary packed bed

A mass balance of adsorbate in the fluid flowing through an increment $d z$ of bed as shown in Figure 1 below may be represented below:

$$
\begin{gathered}
\text { Input - Output }- \text { Amount } \frac{\text { reacted }}{\text { Adsorbed }}=0 \\
\left.C_{g, i} v_{g} \Delta r r \Delta \theta\right|_{z}-\left.C_{g, i} v_{g} \Delta r r \Delta \theta\right|_{z+\Delta z}+\left.\varepsilon_{b} \Delta r r \Delta \theta J_{i}\right|_{z+\Delta z}-\left.\varepsilon_{b} \Delta r r \Delta \theta J_{i}\right|_{z+\Delta z} \\
-\left(1-\varepsilon_{b}\right) N_{i} \Delta r r \Delta \theta \Delta z=0
\end{gathered}
$$

Dividing by control Volume $\Delta r r \Delta \theta \Delta z$ and taking limits

$$
\frac{\left.C_{g, i} v_{g}\right|_{z}-\left.C_{g, i} v_{g}\right|_{z+\Delta z}}{\Delta z}+\varepsilon_{b} \frac{\left.D_{z} \frac{\partial C_{g, i}}{\partial z}\right|_{z+\Delta z}-\left.D_{z} \frac{\partial C_{g, i}}{\partial z}\right|_{z}}{\Delta z}-\left(1-\varepsilon_{b}\right) N_{i}=0
$$

The equations may be rearranged to give 


$$
\varepsilon_{b} \frac{\partial}{\partial z}\left(D_{z} \frac{\partial C_{g, i}}{\partial z}\right)-\frac{\partial v_{g} C_{g, i}}{\partial z}-\left(1-\varepsilon_{b}\right) \rho_{s} \frac{d q_{i}}{d t}=0
$$

The following boundary conditions are used:

$$
\begin{aligned}
& \left.\frac{d C_{g, i}}{d z}\right|_{z=L}=0 \\
& v_{g} C_{g, i(z=0)}-\left.\varepsilon_{b} D_{z} \frac{d C_{g, i}}{d z}\right|_{z=0}=v_{g} C_{g, i n} \\
& C_{g, i(z=0, \theta)}=C_{g, i n}
\end{aligned}
$$

The mass transfer rate is approximated using a linear driving force approach:

$$
\rho_{s} \frac{d q_{i}}{d t}=k_{f} a_{s}\left(C_{g, i}-C_{s, i(r=R)}\right)
$$

The external film mass transfer coefficient, $k_{f}$, around the particles can be estimated from the following correlation [Wakao et al., 1979]:

$$
\begin{aligned}
& S h=2.0+1.1 R e^{0.6} S c^{1 / 3}=\frac{K_{f} d_{p}}{D_{m, i}} \\
& R e=\frac{v_{g} d_{p} \rho_{g}}{\mu} \\
& S c=\frac{\mu_{g}}{\rho_{g} D_{m, i}}
\end{aligned}
$$

The effective axial dispersion coefficient is estimated using the following correlation [Ruthven, 1984]

$$
\frac{\varepsilon_{b} D_{z}}{D_{m i}}=20+0.5 S c R e
$$

Solid Phase Species Balance: 
Transport occurs within the fluid-filled pores inside the particle packed in the bed, in this situation, a differential mass balance equation for species $i$ over a spherical adsorbent particle moving through an annular element of thickness $d \theta$ with an angular velocity of $\omega$ may be written as follows;

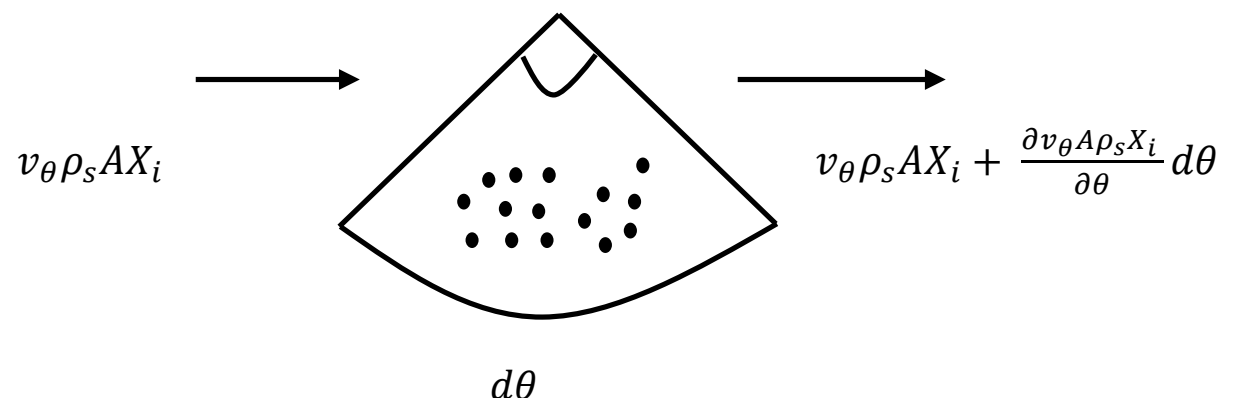

Figure 39: Conservation of adsorbent across an increment of a rotary packed bed

In a volume element of the spherical particle. the mass balance for each species at the solid phase can be written as:

Input - Output - Amount Adsorbed $/$ Reacted $=0$

$$
\left.x_{i} v_{\theta} \Delta r \Delta z\right|_{\theta}-\left.x_{i} v_{\theta} \Delta r \Delta z\right|_{\theta+\Delta \theta}-\left(1-\varepsilon_{b}\right) \Delta r r \Delta \theta \Delta z N_{i}=0
$$

Dividing by control Volume $\Delta r r \Delta \theta \Delta z$

$$
\begin{gathered}
\frac{\left.x_{i} v_{\theta}\right|_{\theta}-\left.x_{i} v_{\theta}\right|_{\theta+\Delta \theta}}{r \Delta \theta}-\left(1-\varepsilon_{b}\right) N_{i}=0 \\
N_{i}=\frac{\partial q_{i}}{\partial t}, \omega=\frac{v_{\theta}}{r} \\
-\omega \frac{\partial x_{i}}{\partial \theta}-\left(1-\varepsilon_{b}\right) \rho_{s} \frac{d q_{i}}{d t}=0
\end{gathered}
$$

The boundary conditions are the following

$$
x_{i(\theta=0, z)}=x_{i, i n}
$$

\section{Bulk Gas Phase Energy Balance:}


Adsorption is an exothermic process, and temperature changes may affect the adsorption equilibrium and adsorption rates. For the non-isothermal system, the differential energy balance for the fluid phase can be written as follows:

$$
\begin{gathered}
\text { Input }- \text { output }+ \text { Energy of Reaction from solid }=0 \\
\left.\Delta r r \Delta \theta \rho_{g} C_{p, g} v_{g} T_{g}\right|_{z}-\left.\Delta r r \Delta \theta \rho_{g} C_{p, g} v_{g} T_{g}\right|_{z+\Delta z}+\Delta r r \Delta \theta \Delta z h_{g s} a_{s}\left(T_{s}-T_{g}\right)=0
\end{gathered}
$$

Dividing by control Volume $\Delta r r \Delta \theta \Delta z$

$$
\begin{gathered}
\frac{\left.\rho_{g} C_{p, g} v_{g} T_{g}\right|_{z}-\left.\rho_{g} C_{p, g} v_{g} T_{g}\right|_{z+\Delta z}}{\Delta z}+h_{g s} a_{s}\left(T_{s}-T_{g}\right)=0 \\
-\rho_{g} C_{p, g} v_{g} \frac{\partial T_{g}}{\partial z}+\left(1-\varepsilon_{b}\right) h_{g s} a_{s}\left(T_{s}-T_{g}\right)=0
\end{gathered}
$$

The convective heat transfer coefficient between the gas and adsorbent, $h_{g s}$ can be estimated through the following correlation

$$
N u=\frac{h_{g s} d_{p}}{k_{g}}=2+1.1 \operatorname{Pr}^{1 / 3} R e^{0.6}
$$

The boundary conditions applied are as follows:

$$
T_{g}(t, z=0)=T_{o}
$$

\section{Bulk Solid phase energy balance}

For the solid phase, an energy balance equation can be written that considers the accumulation term, energy transfer by convection through the bed by the bulk movement of the solid due to the rotation of the bed, the heat transfer between the solid and the gas, and the heat generated by the adsorption: 


$$
\begin{gathered}
\left.\Delta r \Delta z \rho_{s} C_{p, s} \omega T_{s}\right|_{z}-\left.\Delta r \Delta z \rho_{s} C_{p, s} \omega T_{s}\right|_{z+\Delta z}-\Delta r r \Delta \theta \Delta z h_{g s} a_{s}\left(T_{s}-T_{g}\right) \\
+\Delta r r \Delta \theta \Delta z\left(E R_{x}\right)=0
\end{gathered}
$$

Dividing by control Volume $\Delta r r \Delta \theta \Delta z$

$$
\begin{gathered}
\frac{\left.\rho_{s} C_{p, s} \omega T_{s}\right|_{\theta}-\left.\rho_{s} C_{p, s} \omega T_{s}\right|_{\theta+\Delta \theta}}{\Delta \theta}-h_{g s} a_{s}\left(T_{s}-T_{g}\right)+\left(E R_{x}\right)=0 \\
-\rho_{s} C_{p, s} \omega \frac{\partial T_{s}}{\partial \theta}-\left(1-\varepsilon_{b}\right) h_{g s} a_{s}\left(T_{s}-T_{g}\right)+\rho_{s}\left(\Delta H_{r x n}\right) \frac{d q_{i}}{d t}=0
\end{gathered}
$$

The boundary conditions applied are as follows:

$$
T_{s}(t, \theta=0)=T_{s, i n}
$$

\section{Reaction model:}

A model describing the physisorption and chemisorption rates of $\mathrm{CO}_{2}$ species is given below

$$
\begin{aligned}
& \rho_{s} \frac{d q_{i}}{d t}=\frac{d x_{c h e m, i}}{d t}+\frac{d x_{p h y s, i}}{d t} \\
& \frac{d x_{c h e m}}{d t}=k_{O C}\left[x_{c h e m}^{*}\left(P_{C O 2}, T\right)-x_{c h e m}\right] \\
& \frac{d x_{p h y s}}{d t}=k_{O P}\left[x_{p h y s}^{*}\left(P_{C O 2}, T\right)-x_{p h y s}\right] \\
& \frac{\partial x_{c o 2}}{\partial t}=k_{O C}\left[x_{c h e m}^{*}\left(P_{C O 2}, T\right)-x_{c h e m}\right]+k_{O P}\left[x_{p h y s}^{*}\left(P_{C O 2}, T\right)-x_{p h y s}\right]
\end{aligned}
$$

The overall mass transfer coefficients $k_{o c}$ and $k_{o p}$ are used to lump both the intraparticle and external mass transfer resistances and are defined by

$$
\frac{1}{k_{O C}}=\frac{r_{p}^{2}}{15 \varepsilon_{p} K_{p, i}}+\frac{1}{k_{C, 0} \exp \left(E_{C} /_{R T}\right)}
$$


$\frac{1}{k_{O C}}=\frac{r_{p}^{2}}{15 \varepsilon_{p} K_{p, i}}+\frac{1}{k_{C, 0} \exp \left(E_{C} / R T\right)}$

$K_{p, i}$ which is the diffusion coefficient in the macropores is calculated from

$$
\begin{aligned}
\frac{1}{K_{p, i}} & =\tau\left(\frac{1}{D_{K, i}}+\frac{1}{D_{m, i}}\right) \\
D_{K, i} & =97 r_{\text {pore }}\left(\frac{T}{M_{i}}\right)^{0.5}
\end{aligned}
$$

A dual site Sips isotherm is used to describe the adsorption equilibrium:

$$
\begin{aligned}
& x_{c o 2}^{*}=x_{c h e m}^{*}+x_{\text {phys }}^{*}=n_{\max , c}\left[\frac{\left(b_{a} P\right)^{1 / n_{a}}}{1+\left(b_{a} P\right)^{1 / n_{a}}}\right]+n_{\max , p}\left[\frac{\left(b_{b} P\right)^{1 / n_{b}}}{1+\left(b_{b} P\right)^{1 / n_{b}}}\right] \\
& n_{\max , c}=\frac{n_{\max } K_{e q}}{1+K_{e q}} ; n_{\max }=3.82 \mathrm{mmol} / \mathrm{g} \\
& \ln \left(K_{e q}\right)=K_{a}+\frac{K_{b}}{T} \\
& b=b_{0} \exp \left[\frac{Q_{s t}}{R T_{0}}\left(\frac{T_{0}}{T}-1\right)\right] ; T_{0}=318 \mathrm{~K} \\
& n_{a}=n_{a, 1} \exp \left[\frac{E_{n a}}{R T_{0}}\left(\frac{T_{0}}{T}-1\right)\right] \\
& n_{\text {max }, p}=n_{\max , p, 1}\left[\frac{\exp \left(K_{c}+\frac{K_{d}}{T}\right)}{1+\exp \left(K_{c}+\frac{K_{d}}{T}\right)}\right]
\end{aligned}
$$




\section{Pressure drop}

As the bulk fluid flows through the void spaces between adsorbent particles, it experiences a pressure drop due to viscous energy losses and a drop in kinetic energy. The momentum balance considers the terms of pressure drop and velocity changes across the packed bed and relates them by the Ergun equation.

$$
-\frac{\partial P}{\partial z}=\frac{150 \mu\left(1-\varepsilon_{b}\right)^{2}}{\varepsilon_{b}^{3} d_{p}^{2}} v_{g}-\frac{1.75\left(1-\varepsilon_{b}\right) \rho_{g}}{\varepsilon_{b}^{3} d_{p}^{2}} v_{g}{ }^{2}
$$

\section{References}

Agarwal, Lava, Pavani, V, Rao, DP, \& Kaistha, N. (2010). Process intensification in HiGee absorption and distillation: design procedure and applications. Industrial \& Engineering Chemistry Research, 49(20), 10046-10058.

Bu, Yufan, Wang, Limin, Chen, Xun, Wei, Xiaoyang, Deng, Lei, \& Che, Defu. (2018). Numerical analysis of ABS deposition and corrosion on a rotary air preheater. Applied Thermal Engineering, 131, 669-677.

Büyükalaca, Orhan, \& Y1lmaz, T. (2002). Influence of rotational speed on effectiveness of rotarytype heat exchanger. Heat and mass transfer, 38(4-5), 441-447.

Chen, Yu-Shao, Lin, Fang-Yi, Lin, Chia-Chang, Tai, Clifford Yi-Der, \& Liu, Hwai-Shen. (2006). Packing characteristics for mass transfer in a rotating packed bed. Industrial \& engineering chemistry research, 45(20), 6846-6853.

D'Alessandro, Deanna M, Smit, Berend, \& Long, Jeffrey R. (2010). Carbon dioxide capture: prospects for new materials. Angewandte Chemie International Edition, 49(35), 6058-6082. 
Dantas, Tirzha LP, Amorim, Suelen M, Luna, Francisco Murilo T, Silva Jr, Ivanildo J, de Azevedo, Diana CS, Rodrigues, Alírio E, \& Moreira, Regina FPM. (2009). Adsorption of carbon dioxide onto activated carbon and nitrogen-enriched activated carbon: surface changes, equilibrium, and modeling of fixed-bed adsorption. Separation Science and Technology, 45(1), 73-84.

Dantas, TL, Luna, FM T, Silva Jr, IJ, Torres, AE, De Azevedo, DCS, Rodrigues, AE, \& Moreira, RFPM. (2011). Modeling of the fixed-bed adsorption of carbon dioxide and a carbon dioxide-nitrogen mixture on zeolite 13X. Brazilian Journal of Chemical Engineering, 28(3), 533-544.

De Antonellis, Stefano, Joppolo, Cesare Maria, \& Molinaroli, Luca. (2010). Simulation, performance analysis and optimization of desiccant wheels. Energy and Buildings, 42(9), 1386-1393.

Ghodsipour, N, \& Sadrameli, M. (2003). Experimental and sensitivity analysis of a rotary air preheater for the flue gas heat recovery. Applied Thermal Engineering, 23(5), 571-580.

Heidari-Kaydan, Armin, \& Hajidavalloo, Ebrahim. (2014). Three-dimensional simulation of rotary air preheater in steam power plant. Applied Thermal Engineering, 73(1), 399-407.

Jung, Wonho, Park, Junhyung, Won, Wangyun, \& Lee, Kwang Soon. (2018). Simulated moving bed adsorption process based on a polyethylenimine-silica sorbent for $\mathrm{CO} 2$ capture with sensible heat recovery. Energy, 150, 950-964.

Kanaś, Paulina, Jedlikowski, Andrzej, Anisimov, Sergey, \& Vager, Borys. (2019). The influence of airflow on the effectiveness of rotary heat exchangers operating under high-speed rotor conditions. Paper presented at the E3S Web of Conferences.

Kim, Kiwoong, Kim, Daewook, Park, Yong-Ki, \& Lee, Kwang Soon. (2014). A solid sorbent-based multi-stage fluidized bed process with inter-stage heat integration as an energy efficient carbon capture process. International Journal of Greenhouse Gas Control, 26, 135-146.

Kim, Kiwoong, Son, Yongho, Lee, Won Bo, \& Lee, Kwang Soon. (2013). Moving bed adsorption process with internal heat integration for carbon dioxide capture. International Journal of Greenhouse Gas Control, 17, 13-24.

Li, Chung-Hsiung. (1983). A numerical finite difference method for performance evaluation of a periodic-flow heat exchanger.

Li, Jian-Rong, Ma, Yuguang, McCarthy, M Colin, Sculley, Julian, Yu, Jiamei, Jeong, Hae-Kwon, . . . Zhou, Hong-Cai. (2011). Carbon dioxide capture-related gas adsorption and separation in metal-organic frameworks. Coordination Chemistry Reviews, 255(15-16), 1791-1823.

Liang, Zhiwu, Fu, Kaiyun, Idem, Raphael, \& Tontiwachwuthikul, Paitoon. (2016). Review on current advances, future challenges and consideration issues for post-combustion $\mathrm{CO} 2$ capture using amine-based absorbents. Chinese Journal of Chemical Engineering, 24(2), 278-288.

Lin, Chia-Chang, Chen, Yu-Shao, \& Liu, Hwai-Shen. (2004). Adsorption of dodecane from water in a rotating packed bed. Journal-Chinese institute of chemical engineers, 35(5), 531-538.

Lin, Chia-Chang, \& Liu, Hwai-Shen. (2000). Adsorption in a centrifugal field: basic dye adsorption by activated carbon. Industrial \& engineering chemistry research, 39(1), 161-167.

Liu, Jian, Thallapally, Praveen K, McGrail, B Peter, Brown, Daryl R, \& Liu, Jun. (2012). Progress in adsorption-based CO 2 capture by metal-organic frameworks. Chemical Society Reviews, 41(6), 2308-2322. 
Lutze, Philip, Gani, Rafiqul, \& Woodley, John M. (2010). Process intensification: a perspective on process synthesis. Chemical Engineering and Processing: Process Intensification, 49(6), 547-558.

Maharaj, Avinash, Schmitz, Walter, Naidoo, Reshendren, Jestin, Louis, Fuls, Wim, \& Pronobis, Marek. (2015). A numerical study of air preheater leakage. Energy, 92, 87-99.

McDonald, Thomas M, Mason, Jarad A, Kong, Xueqian, Bloch, Eric D, Gygi, David, Dani, Alessandro, . . . Drisdell, Walter S. (2015). Cooperative insertion of CO 2 in diamineappended metal-organic frameworks. Nature, 519(7543), 303-308.

Milner, Phillip J, Siegelman, Rebecca L, Forse, Alexander C, Gonzalez, Miguel I, Runčevski, Tomče, Martell, Jeffrey D, . . Long, Jeffrey R. (2017). A diaminopropane-appended metalorganic framework enabling efficient $\mathrm{CO} 2$ capture from coal flue gas via a mixed adsorption mechanism. Journal of the American Chemical Society, 139(38), 13541-13553.

Mioralli, PC, \& Ganzarolli, MM. (2013). Thermal analysis of a rotary regenerator with fixed pressure drop or fixed pumping power. Applied Thermal Engineering, 52(1), 187-197.

Modekurti, Srinivasarao, Bhattacharyya, Debangsu, \& Zitney, Stephen E. (2013). Dynamic modeling and control studies of a two-stage bubbling fluidized bed adsorber-reactor for solid-sorbent co2 capture. Industrial \& Engineering Chemistry Research, 52(30), 1025010260.

Nielsen, Kaspar Kirstein, Nellis, GF, \& Klein, SA. (2013). Numerical modeling of the impact of regenerator housing on the determination of Nusselt numbers. International Journal of Heat and Mass Transfer, 65, 552-560.

Ruthven, Douglas M. (1984). Principles of adsorption and adsorption processes: John Wiley \& Sons.

Sanaye, Sepehr, \& Hajabdollahi, Hassan. (2009). Multi-objective optimization of rotary regenerator using genetic algorithm. International Journal of Thermal Sciences, 48(10), 1967-1977.

Shah, RK, \& Skiepko, T. (1999). Influence of leakage distribution on the thermal performance of a rotary regenerator. Applied Thermal Engineering, 19(7), 685-705.

Siegelman, Rebecca L, McDonald, Thomas M, Gonzalez, Miguel I, Martell, Jeffrey D, Milner, Phillip J, Mason, Jarad A, . . Long, Jeffrey R. (2017). Controlling cooperative CO2 adsorption in diamine-appended $\mathrm{Mg} 2$ (dobpdc) metal-organic frameworks. Journal of the American Chemical Society, 139(30), 10526-10538.

Skiepko, Teodor, \& Shah, Ramesh K. (2004). A comparison of rotary regenerator theory and experimental results for an air preheater for a thermal power plant. Experimental Thermal and Fluid Science, 28(2-3), 257-264.

Son, Yongho, Kim, Kiwoong, \& Lee, Kwang Soon. (2014). Feasibility study of a moving-bed adsorption process with heat integration for $\mathrm{CO} 2$ capture through energy evaluation and optimization. Energy \& fuels, 28(12), 7599-7608.

Su, Fengsheng, \& Lu, Chungsying. (2012). CO 2 capture from gas stream by zeolite 13X using a dual-column temperature/vacuum swing adsorption. Energy \& Environmental Science, 5(10), 9021-9027.

Sudhoff, D, Leimbrink, M, Schleinitz, M, Górak, A, \& Lutze, P. (2015). Modelling, design and flexibility analysis of rotating packed beds for distillation. Chemical Engineering Research and Design, 94, 72-89.

Sumida, Kenji, Rogow, David L, Mason, Jarad A, McDonald, Thomas M, Bloch, Eric D, Herm, Zoey R, . . Long, Jeffrey R. (2012). Carbon dioxide capture in metal-organic frameworks. Chemical reviews, 112(2), 724-781. 
Thiels, Matt, Wong, David SH, Yu, Cheng-Hsiu, Kang, Jia-Lin, Jang, Shi Shang, \& Tan, ChungSan. (2016). Modelling and design of carbon dioxide absorption in rotating packed bed and packed column. IFAC-PapersOnLine, 49(7), 895-900.

Turton, Richard, Shaeiwitz, Joseph, Bhattacharyya Debangsu, Whiting, Wallace (2018). Analysis, synthesis and design of chemical processes: $5^{\text {th }}$ Ed., Prentice Hall, NJ.

Wang, HY, Bi, XL, Zhao, LL, Zhou, QT, Kim, HT, \& Xu, ZG. (2009). A study on thermal stress deformation using analytical methods based on the temperature distribution of storage material in a rotary air-preheater. Applied thermal engineering, 29(11-12), 2350-2357.

Wang, Limin, Bu, Yufan, Li, Dechao, Tang, Chunli, \& Che, Defu. (2019). Single and multiobjective optimizations of rotary regenerative air preheater for coal-fired power plant considering the ammonium bisulfate deposition. International Journal of Thermal Sciences, $136,52-59$.

Wang, Meihong, Lawal, Adekola, Stephenson, Peter, Sidders, J, \& Ramshaw, C. (2011). Postcombustion $\mathrm{CO}_{2}$ capture with chemical absorption: a state-of-the-art review. Chemical engineering research and design, 89(9), 1609-1624.

Wang, Zhenqiang, \& Cohen, Seth M. (2009). Postsynthetic modification of metal-organic frameworks. Chemical Society Reviews, 38(5), 1315-1329.

Wu, Xiao, Wang, Meihong, Liao, Peizhi, Shen, Jiong, \& Li, Yiguo. (2020). Solvent-based postcombustion $\mathrm{CO} 2$ capture for power plants: A critical review and perspective on dynamic modelling, system identification, process control and flexible operation. Applied Energy, 257, 113941.

Zhao, Zhenlong, Chen, Tianjiao, \& Ghoniem, Ahmed F. (2013). Rotary bed reactor for chemicallooping combustion with carbon capture. Part 1: reactor design and model development. Energy \& fuels, 27(1), 327-343.

Zhao, Zhonglin, Cui, Xingyu, Ma, Jinghong, \& Li, Ruifeng. (2007). Adsorption of carbon dioxide on alkali-modified zeolite 13X adsorbents. International Journal of Greenhouse Gas Control, 1(3), 355-359. 